\title{
Sport Psychology "App"lication: NCAA Coaches' Preferences for a Mental Training Mobile App
}

\author{
Raymond F. Prior
}

Follow this and additional works at: https://researchrepository.wvu.edu/etd

\section{Recommended Citation}

Prior, Raymond F., "Sport Psychology "App"lication: NCAA Coaches' Preferences for a Mental Training Mobile App" (2014). Graduate Theses, Dissertations, and Problem Reports. 6453.

https://researchrepository.wvu.edu/etd/6453

This Dissertation is protected by copyright and/or related rights. It has been brought to you by the The Research Repository @ WVU with permission from the rights-holder(s). You are free to use this Dissertation in any way that is permitted by the copyright and related rights legislation that applies to your use. For other uses you must obtain permission from the rights-holder(s) directly, unless additional rights are indicated by a Creative Commons license in the record and/ or on the work itself. This Dissertation has been accepted for inclusion in WVU Graduate Theses, Dissertations, and Problem Reports collection by an authorized administrator of The Research Repository @ WVU.

For more information, please contact researchrepository@mail.wvu.edu. 


\title{
Sport Psychology “App”lication: NCAA Coaches' Preferences \\ for a Mental Training Mobile App
}

\author{
Raymond F. Prior
}

Dissertation submitted to the College of Physical Activity and Sport Sciences at West Virginia University

in partial fulfillment of the requirements for the degree of Doctor of Philosophy in

Kinesiology with an emphasis in Sport and Exercise Psychology

\author{
Jack Watson, Ph.D., Chair \\ Damien Clement, Ph.D. \\ William Fremouw, Ph.D. \\ Christine Schimmel, Ed.D \\ Sam Zizzi, Ed.D.
}

Department of Sport and Exercise Psychology

Morgantown, West Virginia

2014

Keywords: mental training, mobile applications, conjoint analysis 


\author{
Abstract \\ Sport Psychology “App”lication: NCAA Coaches' Preferences \\ for a Mental Training Mobile App \\ Raymond F. Prior
}

This study utilized a consumer marketing approach to investigate National Collegiate Athletic Association (NCAA) head coaches' preferences for a mental training mobile application (mobile map) using a conjoint market analysis. Head coaches' preferences for a mental training mobile app were compared based on price, ability to track athlete use of the app, recommendation sources, the inclusion of daily functions, coaches' awareness of the app being used by other teams, and the credibility of the mobile app content creators. Price and tracking athlete use were the two most important characteristics to coaches. Considering all characteristics, coaches preferred mobile apps that cost less than $\$ 200$, provided comprehensive tracking of athlete use, came with an internal recommendation, included daily functions, were used by other teams, and were created by content creators who work with other successful programs. Based on market simulations, more than two-thirds of coaches would purchase a mental training mobile app with the characteristics presented in this study if given the chance. The present findings are evidence that the use of mental training at the NCAA level may rely more on the delivery method and cost of services than previously thought. 


\section{Table of Contents}

\section{Part}

Page

Introduction. 1

NCAA Coaches' Perceptions of Sport Psychology Services.........................1

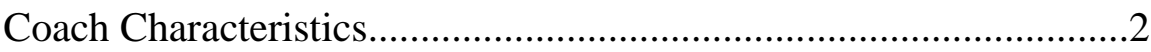

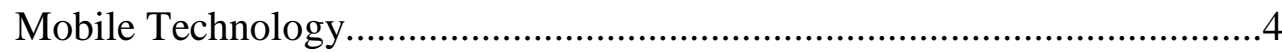

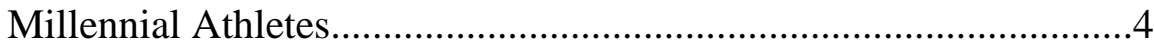

The Mobile Market...............................................................................

Mobile Technology and the Millennial Generation.............................5

Sport Psychology in the NCAA........................................................6

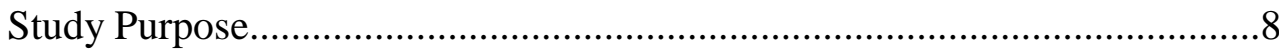

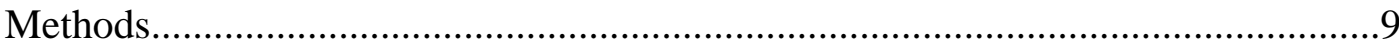

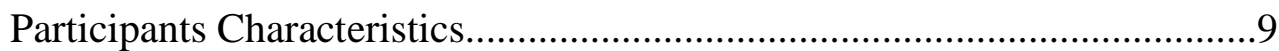

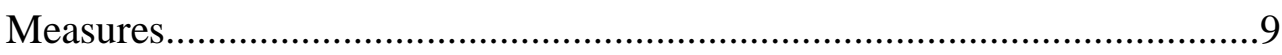

Characteristics of a Mental Training Mobile App............................9

Contact and Sampling Procedures...............................................12

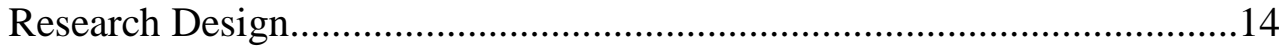

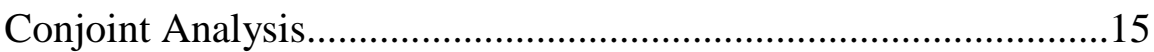

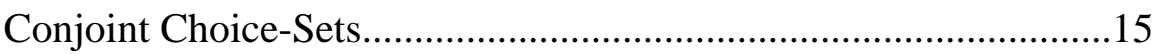

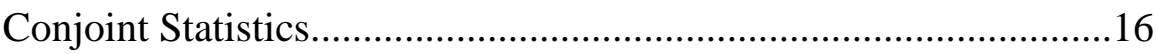

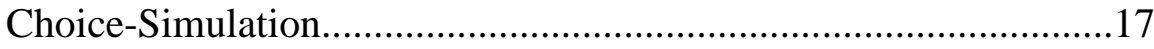

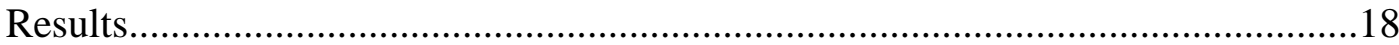

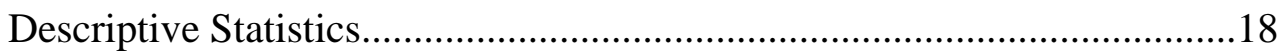

Coaches' Preferred Mobile App...............................................................19

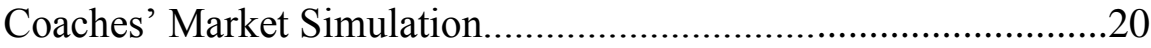


Coaches' Choice-Simulation Preferences......................................20

Male and Female Coaches................................................................21

Revenue and Non-Revenue Sport Coaches............................................22

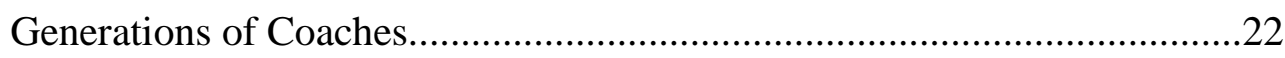

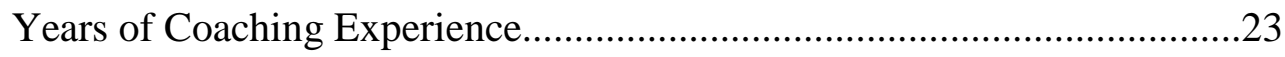

"Yes" and "No" App Value Coaches..........................................................24

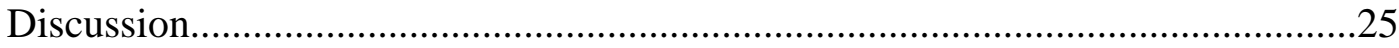

Interest in Mental Training versus Access to Mental Training...................28

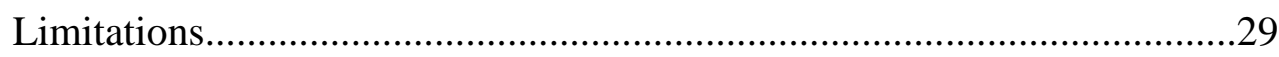

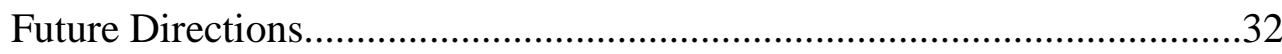

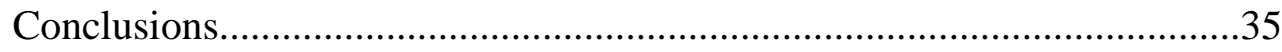

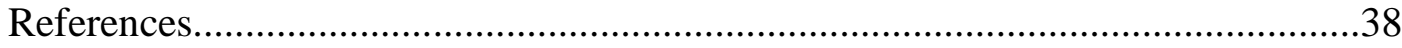

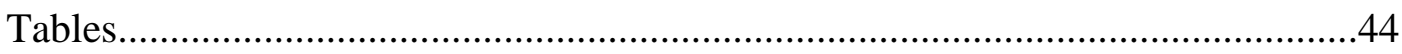

Appendices

Appendix A: Internet-based Survey Part 1: CBC Introduction...................57

Appendix B: Survey Review Step One....................................................59

Appendix C: Recruitment Email 1: Pre-Notice Email.................................65

Appendix D: Recruitment Email 2: Email Invitation to Participate............66

Appendix E: Recruitment Email 3: Email Reminder...............................67

Appendix F: Recruitment Email 4: Final Email Contact..........................68

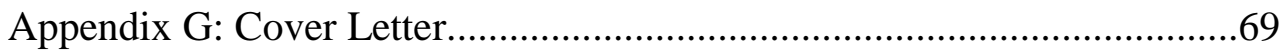

Appendix H: Internet-based Survey Part 2: CBC Sample Choice Set..........70

Appendix I: Internet-based Survey Part 3: Demographics Questionnaire...71

Appendix J: Internet-based Survey Part 4: Separate Follow-Up Page..........74

Appendix K: Expanded Review of Literature..........................................75 


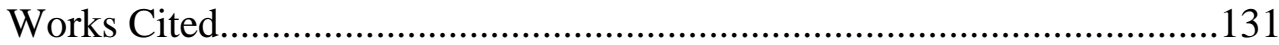




\section{List of Tables}

\section{Table}

Page

Table 1: Conjoint Analysis Profiles Characteristics and Options..... .44

Table 2: Participant Demographic and Descriptive Statistics. .45

Table 3: Results of a CBC-HB Analysis for NCAA Division I Head Coaches.......46

Table 4: Results of a CBC-HB Analysis for Male and Female Division I Head Coaches. .47

Table 5: Results of a CBC-HB Analysis for Revenue and Non-Revenue sport Division I Head Coaches. .48

Table 6: Results of a CBC-HB Analysis for Generations of Division I Head Coaches .49

Table 7: Results of a CBC-HB Analysis for Years of Collegiate Coaching Experience for Division I Head Coaches .50

Table 8: Results of a CBC-HB Analysis) for Division I Coaches who report "Yes" and "No" to value in a mental training mobile app. .51

Table 9: List of Preferred Profiles and Results of Market Simulations. .52

Table 10: Coaches' Choice-Simulation Selections. .56 
Sport Psychology “App”lication: NCAA Coaches’ Preferences for a Mental Training Mobile App

Athletes are the ultimate beneficiaries of mental training, however, coaches are often the final decision makers related to making mental training available to their teams and athletes (Voight \& Callaghan, 2001). Coaches hold a uniquely powerful role within sport, especially within intercollegiate athletics, because of their relationship to student-athletes. Research exploring relationships between coaches and athletes highlights that the coachathlete relationship is one of the most significant within sport and has a strong influence on an athlete's development (Jowett \& Cockerill, 2003). By the nature of their position, coaches have tremendous influence and even control over the performances of their athletes and teams, as well as skill development, attitudes, values, beliefs, and structure of daily life. To that degree, athletes' attitudes and perceptions of sport psychology are often influenced by their coaches' attitudes (Dieffenbach, Gould, \& Moffett, 2002). Coaches' feelings toward sport psychology becomes especially important at the collegiate level because coaches are the gatekeepers to their teams and individual athletes, and often control who is allowed to provide resources and services to their teams. As such, if coaches have knowledge of a service and find it valuable, the coach is more likely to make it available to their athletes (Voight \& Callaghan, 2001).

\section{NCAA Coaches' Perceptions of Sport Psychology Services}

Overall, researchers examining mental training suggest that college coaches believe that mental skills are important to the success of their respective teams and have an interest in sport psychology services being available to their teams (Zakrajsek, Steinfeldt, Bodey, Martin, \& Zizzi, 2013). Despite the indicated importance of mental skills and the value of having sport psychology services available, usage rates of sport psychology services across all three NCAA divisions hover between $20 \%$ and 30\% (Wrisberg, Loberg, Simpson, 
Withycombe, \& Reed, 2010). The discrepancy between college coaches' reported interest and what they actually provide to their teams in the form of sport psychology services and mental skills, highlights the need for more specific information about coaches' preferences for delivery methods of sport psychology services. A better understanding of a delivery method that NCAA coaches prefer may improve the availability of mental training for athletes and increase coaches' decisions to make sport psychology services available to their teams. Research related to coaches' perceptions of sport psychology services appears to be growing, but is still limited. The examination of this relationship remains an integral area of research as it could provide valuable information for better understanding the barriers to providing sport psychology services to athletes as well as increasing the effectiveness of the services offered (Zakrajsek, et al., 2013).

Research regarding coaches' attitudes toward sport psychology services highlights specific factors about their interest and usage of such services. Specifically, factors that influence coaches' attitudes toward sport psychology services and their decisions to use sport psychology services include stigma tolerance (belief that peers will view coaches or athletes as damaged or having mental problems if they utilize sport psychology services), confidence in the effectiveness of sport psychology consulting services, personal openness (willingness to explore the option of using sport psychology consulting services), and cultural preference (the preference to work with a sport psychology professional with similar experiences) (Zakrajsek, Martin, \& Zizzi, 2011; Zakrajsek \& Zizzi, 2007; 2008). Of these identified attitudes, confidence in the effectiveness of sport psychology consulting services is the most consistent predictor of a coach's decision to utilize sport psychology services (Zakrajsek et al., 2011; Zakrajsek \& Zizzi, 2007).

Coach Characteristics. Research examining the factors that influence coaches' decisions to utilize sport psychology services also have examined the personal characteristics 
of coaches. In general, compared to coaches with no experience with sport psychology services, coaches with previous experiences and exposure to sport psychology services are more open to utilizing these services, less likely to stigmatize sport psychology services, more likely to encourage their athletes to utilize sport psychology services, and have expectations that are more accurate with regard to the results of sport psychology services (Wrisberg et al., 2010; Zakrajsek \& Zizzi, 2007).

Level of education and years of coaching experience have also been shown to influence coaches' attitudes and perceptions toward sport psychology services. Specifically, coaches holding doctoral or master's degrees report more confidence in sport psychology services compared to coaches whose highest level of education is a bachelor's degree or high school diploma (Zakrajsek et al., 2011). Older coaches (e.g., age 50 and older) and coaches with more years of experience (i.e., more than 15 years of coaching experience) are generally more open to utilizing sport psychology services and associate less of a negative stigma with sport psychology services compared to younger (i.e., age 20-29) and less experienced coaches (i.e., less than 7 years of coaching experience; Zakrajsek et al., 2011). Finally, female coaches have reported more personal openness to utilizing sport psychology services, associate less of a negative stigma related to sport psychology services, and have more confidence in sport psychology services than male coaches (Wrisberg et al., 2010; Zakrajsek \& Zizzi, 2007).

Identifying the personal characteristics and factors that influence coaches' attitudes and perceptions of sport psychology services and influence their decisions to utilize these services is important and provides valuable insight for sport psychology professionals. To date, coaches' attitudes and perceptions toward newer and more technologically oriented delivery methods of sport psychology remain unexamined. 


\section{Mobile Technology}

Mobile technology has become widespread thanks to increased usability and functioning, and the vast array of services offered to users. Mobile technology is technology that connects people to tools, services, information, or other people via a digital device such as a smartphone or tablet that connects to the Internet through a wireless network to allow users to utilize server-based programs (Neilson, 2012). In 2009, the United States had an estimated 285 million wireless subscribers using mobile devices (Lee et al., 2012). The insurgence of mobile technology has revolutionized nearly every facet of daily life, from communicating with friends and family, connecting to the Internet and social media, and managing personal finances (Venkatesh, Thong, \& Xu, 2012).

Among mobile devices, smartphones and tablets are particularly notable because thirdparties are able to create mobile applications. Mobile applications (mobile apps) are Internet programs that run on mobile devices. Rather than connecting through an Internet browser, mobile apps connect users to Internet-based services by cutting through the clutter of domainname servers and non-calibrated information services, taking the user straight to the content he or she values (Johnson, 2012). Through the innovation of mobile apps, service providers are now able to offer a variety of "traditional services" (e.g., banking) at the tap of a touchscreen from remote and mobile locations (Fjeldsoe, Marshall, \& Miller, 2009). While mobile technology is used by individuals of all ages, it is used mostly by individuals between the ages of 18 and 25 (Baile, 2012).

Millennial Athletes. The Millennial generation is classified as the segment of the world's population born between 1980 and 2000 (Kaifi, Nafei, Khanfar, \& Kaifi, 2012). This generation is unique in terms of mobile technology use because this is the first generation to grow up with digital technology fully integrated into their lives (Bailie, 2012). The Millennial generation also consists of a significant number of athletes competing at a wide range of 
competitive levels, including intercollegiate athletics. Intercollegiate athletics is one of the most competitive levels of sport and is comprised of approximately 430,000 Millennial student-athletes that filter into college teams from an array of youth sports (NCAA, 2012). Examining newer methods of delivering sport psychology services to intercollegiate Millennial student-athletes may provide valuable information for reaching the massive market of 26 million Millennial athletes within the vast and diverse population of youth sport (see Kelley \& Carchina, 2013).

\section{The Mobile Market}

With the ease of access to services that mobile technology provides, the mobile market is unlike any financial market previously seen. To date, the mobile technology market is the largest and most cost effective market in history (Subramanya \& Farahani, 2012). Globally, the mobile app market consists of 4.6 billion wireless subscribers (Lee et al., 2012). The US mobile market is expected to be worth more than $\$ 25$ billion by 2015 , and is growing by nearly $30 \%$ each year (Astarita et al., 2014). As such, the mobile market is booming with mobile app developers and advertisers in a wide range of services taking advantage of users' download rates and volume, low costs for development, marketing, distribution, maintenance, and low financial requirements for breaking into the mobile app market (Kourouthanassis \& Giaglis, 2012).

Mobile Technology and the Millennial Generation. Of the diverse population of mobile technology users, the Millennial generation stands out as the most frequent users of mobile technology (Nikirk, 2009). A poll conducted by Pew (2013) showed that Millennials were significantly more likely to own a smartphone than those surveyed over the age of 50 . Specifically, 66\% of participants age 18-29 reported owning a smartphone (Taylor, Voelker, \& Pentina, 2011). Millennial users also dominate rates for both the number of mobile apps downloaded per mobile device and the amount of time spent using mobile apps (Nielson, 
2011). Mobile users between the ages of 18 and 25 have an average of 41 mobile apps downloaded to their smartphones and spend an average of 58 minutes per day using mobile apps (Garg \& Telang, 2013).

Overall, there is significant evidence that Millennials are not only the most technologically savvy generation to date (Taylor, Voelker \& Pentina, 2011), but they also prefer digital communication to other forms of communication (Goodwin-Jones, 2005). Specifically, research examining the communication preferences of the Millennial generation indicate that when given the option, the majority of Millennials (67\%) prefer communicating through a digital device, such as a laptop, compared to face-to-face communication in the form of a meeting or casual conversation (McMahon \& Pospisil, 2005). Moreover, research examining communication between clients and sport psychology service providers indicates that many athletes prefer communicating with sport psychology professionals through technology (Zizzi \& Perna, 2002). Given the frequency and proficiency by which Millennials use mobile technology and their preference for digital communication, the use of mobile technology to provide sport psychology services could result in an increase in the use of sport psychology services by the Millennial generation of athletes.

Sport Psychology in the NCAA. To date, sport psychology services remain less than fully integrated into intercollegiate athletics. The NCAA is the primary governing body for intercollegiate athletics and aims to serve its student-athletes that compete within the 1,066 active member institutions (Coakley, 2008; NCAA, 2012b). Sport psychology services aim to provide student-athletes with assistance, building skills that improve their performance under pressure, motivation, self-control, communication, leadership, decision making, appropriate focus, and self-awareness (Danish, Petitpas, \& Hale, 1992). Despite these potential benefits to utilizing sport psychology services, only $24 \%$ (Wilson, Gilbert, Gilbert, \& Sailor, 2009) to 53\% (Wrisberg, Withycombe, Simpson, Loberg, \& Reed, 2012a) of NCAA Division I athletic 
departments report using sport psychology services. Moreover, only $11 \%$ of Division II and III athletic departments reported having sport psychology services available to their athletes (Kornspan \& Duve, 2006).

Given the demanding and competitive nature of intercollegiate athletics, as well as the business model by which it is run, the underutilization of sport psychology services in intercollegiate athletics is noteworthy. Results from surveys of NCAA institutions highlight the underutilization of sport psychology services within NCAA athletics, specifically within institutions with limited financial resources (Kornspan \& Duve, 2006; Voight \& Callaghan, 2001). These seminal surveys of intercollegiate athletics related to the utilization of sport psychology were among the first to provide a picture of sport psychology services in the NCAA (Bemiller \& Wrisberg, 2011). Although these results are valuable and helped guide future research examining sport psychology in intercollegiate athletics, the use of sport psychology services has evolved significantly since these studies were completed. These studies also highlight an empirical emphasis on traditional sport psychology positions within intercollegiate athletics (e.g., employed by athletic department, private contractor) and sport psychology services delivered in person. The usage rates of sport psychology within the NCAA may be due in part to a lack of access and funds. However, many coaches may also have a negative perception of sport psychology and choose not to make services available to their respective teams and athletes. The lack of access and coaches' negative perceptions of sport psychology services in intercollegiate athletics may be better addressed by presenting and evaluating new forms of delivering sport psychology services. Newer forms of sport psychology services may serve to improve coaches' perceptions of these services and better meet the needs of the athletes that compete in the NCAA. 


\section{Study Purpose}

Sport psychology services remain underutilized within intercollegiate athletics.

Coaches, who are the gatekeepers to a tech-savvy generation of college student-athletes, value mental training but often do not utilize sport psychology services delivered traditionally in a face-to-face manner. In recent years, digital technology has allowed for sport psychology services to be delivered in new forms that may better reach Millennial athletes (Schwartz \& Lamphere, 2012). Given the underutilization of sport psychology services within the NCAA, the role of coaches in deciding to utilize sport psychology, and the technological skills and preferences within the population of Millennial student-athletes, evaluating newer forms of delivery may prove beneficial for expanding the provision of sport psychology services rendered within the NCAA.

The current study sought to extend previous literature related to the provision of sport psychology services within intercollegiate athletics by taking a consumer marketing approach targeted toward head coaches. This approach provided a series of choices to college coaches to help determine their preferred characteristics to be included in a possible mental training mobile app. Evaluation of coaches' preferences for characteristics of a mental training mobile app is a realistic demonstration of choices and trade-offs that coaches will make as more evolved forms of sport psychology services become available. Specifically, through the use of a conjoint analysis, this study focused on determining the relative importance of each potential characteristic of a mental training mobile app. The weight of college coaches' actual preferences for the following six characteristics of a mental training mobile app were also examined: 1) Price, 2) Tracking Athlete Use, 3) Recommendation Source, 4) Daily Functions 5) Teams Using the App, and 6) Content Creators. Each mobile app characteristic contains two to three options that are completely defined in Appendix A. 


\section{Methods}

\section{Participant Characteristics}

Participants for this study were male $(n=221)$ and female $(n=147)$ head coaches $(N$ $=375 ; 7$ undisclosed gender) from NCAA Division I institutions. Coaches were contacted via publically available email addresses. Emails sent used the subject line "NCAA Coaches' Survey." Of the 6,731 emails collected, 6,481 were received by an active email account. Approximately 30,000 emails were sent in total over the 4 rounds of survey recruitment with 773 surveys started by coaches. Although the sample size of the opened emails was $5.7 \%$ of the total number of emails received by active email accounts, those who completed the survey represent a sample of potential consumers of a mental training mobile app. As such, using a conjoint analysis, the results of the study reflect NCAA Division I head coaches who are the most likely consumers of a mental training mobile app, making them a very important group to complete this survey.

Data were collected via a short internet-based survey. Internet-based research is beneficial for researchers and participants because it provides access to a large number of participants in a short period of time, eliminates the need to schedule participants, allows free access to a survey, limits the intrusion from researchers, and offers greater anonymity to participants (Dillman, 2001).

\section{Measures}

Characteristics of a mental training mobile app. An initial bank of 21 possible characteristics of a mental training mobile app was derived from a review of the literature related to providing sport psychology services within intercollegiate athletics (Kornspan \& Duve, 2006; Lubker et al., 2012; Voight \& Callaghan, 2001; Wilson et al., 2009; Wrisberg et al., 2012), a review of mobile app literature (Bellman, Potter, Treleaven-Hassard, Robinson, \& Varan, 2011; Cameron, Gregory, \& Batagglia, 2012; Chappuis, Gaffey, \& Parvizi, 2011; 
Kaplan, 2012; Sexton, 2012), and practical consideration for characteristics of a mental training mobile app. Through deliberation between the primary researcher and a tenured sport psychology faculty member, the initial bank of characteristics was narrowed and consolidated into ten characteristics that included; Price, Tracking Athlete Use, Daily Functions, Recommendation Source, Teams Already Using the Mental Training Mobile App, Content Creators, Interactivity, Personalization, and Social Networking. These ten characteristics were presented as part of a three step pilot test based on the survey development techniques outlined by Lubker and colleagues (2012).

In the first step of the pilot survey, an examination of potential conjoint characteristics and options was conducted using the set of ten potential characteristics of a mental training mobile app. Each of the ten characteristics contained two to three options. Once selected, these characteristics and respective options were presented to graduate students in sport psychology $(n=6)$ and athletic coaching education $(n=9)$, as well as, NCAA Division I coaches $(n=10)$ from different institutions. These graduate students and coaches were asked to select their preferred option for each potential characteristic presented, rank the characteristics presented in order of importance, and provide any feedback related to the mobile app characteristics, or any other information that may improve the content of the survey and characteristics presented.

General feedback from the first step of the pilot study included: 1) improving the operational definitions of the characteristics, 2) combining and consolidating similar characteristics, and 3) altering the wording of characteristics and options. Mean rankings of each characteristic presented were calculated for sport psychology graduate students, athletic coaching education graduate students, coaches, and the combination of these groups. A copy of the ten characteristics and options presented during the first step of the survey review, the mean rankings, and a record of characteristic option selections are presented in Appendix B. 
After making revisions based on the feedback from graduate students and coaches and the review of characteristic rankings and option selections, the final six characteristics were selected, as presented in Table 1. Given the target sample of the study, more emphasis was given to the results and feedback from college coaches who took part in the pilot test. Based on the feedback from reviewers, the Coach Recommendation and Athletic Director Recommendation characteristics were combined to create a consolidated characteristic Recommendation Source that includes options for both coach and athletic director recommendations. Additionally, coaches ranked characteristics related to popular mobile app features (interactivity, personalization, and social networking) the lowest of all characteristics that were presented. Based on coaches' low mean rankings of these characteristics and considering that these characteristics are vital to creating a viable mobile app, and thus would most likely be included in any mobile app design, they were eliminated from the final survey. Moreover, these characteristics were perceived to be less important because they are adjustable through effective mobile app design and construction allowing for user customization of these characteristics.

The characteristics that remained after step one of the survey review process were 1) Price, 2) Tracking Athlete Use, 3) Recommendation Source, 4) Daily Functions, 5) Teams Using the App, and 6) Content Creators. Price had three options: less than $\$ 200$ per athlete, between $\$ 200$ - $\$ 400$ per athlete, and more than $\$ 400$ per athlete. These options for price were developed from price points based on design costs, marketing options, and operating costs of an actual mental training mobile app. Tracking Athlete Use had three options: does not track athletes' use of the app, tracks athletes' use of the app by giving coaches restricted access to athletes' use including time spent on the app and mental skills accessed, or tracks athletes' use of the app by giving coaches unrestricted access to athletes use. Recommendation Source also had three options: no recommendation, recommendation from an athletic director or coach 
from another institution, or recommendation from an athletic director or coach from your institution. Daily Functions, which addresses planning and communication features of the app, had two options: does not include daily functions or includes daily functions. Teams Using the App had two options: unaware of any other teams using the app or aware of other teams using the app. Lastly, Content Creators had two options: creators who do not work with any other successful teams or creators who work with other successful teams. Some of the factors such as Content Creators, were included in the final set of characteristics to allow for comparison of relative importance to other characteristics such as Recommendation Source and thus lead to results that can be directly applied to designing and marketing a mental training mobile app. Randomized choice-sets were created from the various characteristic options using Sawtooth Software's CBC survey design (Sawtooth, 2014).

The second step in the pilot test process included an online survey review that was conducted with sport psychology graduate students and faculty who had worked within intercollegiate athletics. Sport psychology graduate students and faculty were asked to complete the online survey and provide any feedback to improve the readability of the survey and identify any inconsistencies, errors, or issues with completing the survey.

The third and final step of the pilot test process was completed with another small sample of college coaches who were not included in the final population sampled. In this step, NCAA Division I coaches were also asked to complete the online survey and provide any feedback to improve the readability of the survey and identify any inconsistencies, errors, or issues with completing the survey.

Contact and sampling procedures. After gaining Institutional Review Board approval, head coaches were contacted via their publically-available university email address following Dillman's (2001) guidelines for survey research. The initial contact was a personalized invitation (Appendix C) notifying participants that within one week he/she 
would receive an email about participating in the study. Participants were informed that their total participation time should be less than 10 minutes. This initial contact included a link to the survey, should the participant choose to complete it immediately. Participants who chose to complete the survey immediately were then removed from the email list. The second email contact (Appendix D) to potential participants was the actual invitation to take part in the research study and the two remaining contacts (Appendices E \& F) were made over the course of four weeks from the second email to remind participants about the opportunity to complete the survey. Head coaches who chose to participate in this study, clicked the link to the survey and were directed to a cover letter that outlined the study and participant rights. The cover letter (Appendix G) included statements about the voluntary nature of participation, the estimated time commitment for participation, the right to discontinue participation at any time, and the confidentiality of responses. A brief description of the study's purpose, potential risks of participation, potential benefits of participation, and information regarding IRB approval were also specified in the cover letter and all email contacts. After agreeing to participate in this internet-based survey, participants were presented with a short list of instructions, which explained how to complete the survey (Appendix A). Participants were not able to skip survey questions, thus participants were excluded from data analysis for any surveys that were not completed in their entirety.

When starting the survey, participants were asked to choose the characteristics of a mental training mobile app he or she would prefer from a series of potential mental training mobile apps (Appendix H). Each choice-set followed the same final purchase option, which asked participants if they would purchase a mobile app for their respective teams based on the different characteristics of that app. After completing the choice sets, participants completed a short demographic questionnaire (Appendix I) and were thanked for their participation (Appendix J). 
A short demographic questionnaire was developed for the current study based on previous research investigating college coaches' perceptions of sport psychology services (Wrisberg et al., 2012; Zakrajsek, Martin, \& Zizzi, 2011; Zakrajsek \& Zizzi, 2007). Demographic questions included participants' gender, age, years of coaching experience, the gender of the athletes currently coaching, the sport(s) currently coaching, the financial classification of the sport(s) coached, availability of mental training services at their institution, previous experience with mental training services, satisfaction with previous mental training experiences, use of mobile technology, and use of mobile apps. Demographic information was collected after the completion of the choice-based conjoint tasks in order to reduce awareness of the potential demand characteristics of the survey (Orne, 1962). In order to protect participant confidentiality, this study did not collect names or university affiliations.

\section{Research Design}

The primary purpose of this study was to explore NCAA head coaches' preferences related to the characteristics of a mental training mobile app through the use of a conjoint market analysis. The present study was descriptive in nature and utilized a quantitative research design. Specifically, a choice-based conjoint (CBC) analysis was used for this exploratory survey study. This type of analysis is regarded as the most commonly used form of conjoint analysis (Orme, 2006). Choice-based conjoint analysis is also the most appropriate methodology for this study because it identifies potential interactions between consumer decisions and product characteristics, examines data from the perspective of "real life" application, and measures the predictive utility of consumers' behaviors based on their reported preferences (Orme, 2006).

Specifically, the current study used a conjoint analysis to assess college coaches' preferences for various characteristics of a mental training mobile app to be utilized by the athletes they coach. Sawtooth Software's CBC/HB Software with SSI Web V8 (Sawtooth, 
2014) was used for all data analyses. Choice-simulations were conducted with Sawtooth Software's Academic Analysis Online Market Simulator for Conjoint Analysis. In accordance with $\mathrm{CBC}$ conjoint analysis, $\mathrm{CBC}-\mathrm{HB}$ individual and group utility scores were calculated and entered into the Sawtooth market simulator. This market simulation process was repeated with several selected subgroups.

Conjoint Analysis. Conjoint analysis is a widely accepted analysis used by a variety of industries to address consumer decision making (Green, Krieger, \& Wind, 2001) and has traditionally been used as an analysis technique in market and business strategy research (Orme, 2006). On a fundamental level, conjoint analysis measures the value consumers place on various characteristics of a product or service by projecting combinations of the options for a given product or service and forcing consumers to make trade-offs between these characteristics. With each trade-off, consumers indicate what they value more. Overall, this process simulates how a market is likely to react to the introduction of novel products or services with the characteristics and options presented (Orme, 2006).

Compared to simple rankings and comparisons on Likert-scales, conjoint analysis offers three major benefits: 1) it presents real world examples of consumer choices without isolating ratings on a single variable, thus allowing for immediate application in a market (Green, Krieger, \& Wind, 2001); 2) it allows for relationships to be drawn between product or service characteristics to be examined; and 3) it allows for the creation of predictive simulations to determine how potential products or services may fare when introduced to a sample market (Orme, 2006).

Conjoint choice-sets. Instead of a fixed-design where the order and combination of profiles are predetermined and the same for every participant, this study presented participants with randomly derived variations of options for each of the six characteristics of a mental training mobile app using a randomized design approach. The random assignment of 
characteristics and options within those characteristics ensures that participants had equal exposure to each option and that each participant saw a uniquely derived combination of options within each choice set. The advantages of a randomized design include: eliminating order effects, allowing interactions to appear, and minimizing the influence of psychological context in the form of recognition, memory, comparisons, compromise effects, and previous experience (Orme, 2006). Market research has also shown that examining random subsets of products can allow for more information to be obtained more efficiently than from an investigation of all potential products independently (Zeithammer \& Lenk, 2009).

Conjoint Statistics. Utility is a term of measurement often used in economics and marketing as a way of measuring satisfaction and how it relates to the decisions consumers make (Furber, Segal, Leach, \& Cocks, 2014). Utility measures the benefits or drawbacks from consuming a good or service. Although utility is not directly measurable, it can be inferred from the decisions that people make by calculating relative importance scores and utility scores, which are projections of utility based on choices consumers make (Furber et al., 2014). Relative importance scores are a projections of a characteristic's importance compared to other characteristics, while utility scores are a projects of the preference for each option within a given characteristic. In short, a relative importance scores and utility scores are used to quantifiably represent each aspect of a product or service in a consumer's overall preference ratings.

Although some characteristic options have positive utility scores and others have negative utility scores, the positive or negative nature of the utility score does not necessarily indicate that some are good and others are bad or that participants hold positive or negative opinions about either (Orme, 2006). The sign and magnitude of each value simply represents its relative attractiveness. For example, Jack really loves cookies and eats one every day. Jack also likes brownies and eats three each week. Yet, if Jack is given the choice between two 
dinners and one of the options he has is which dessert he would like with it, he will consistently choose the dinner with a cookie because he likes it more. If this were part of a conjoint analysis, Jack's results would indicate a positive utility score for cookies and a negative utility score for brownies. It would be incorrect to conclude that Jack dislikes brownies, but it would be correct to say that Jack prefers cookies to brownies.

Both relative importance scores and utility scores are interval scaled and used to highlight the importance of characteristics and the preferences for options within characteristics relative to other characteristics and options. In short, they provide a ranking and degree of characteristics and options in order of importance, but not exact measures of importance. To gain a more precise measure of importance, utility scores can be used to calculate attribute importance. Attribute importance is calculated based on the total utility range of a product and the utility scores within each characteristic and is a projection of how much difference each characteristic could make in the total utility of a product. Attribute importance is ratio scaled out of $100 \%$ and allows for direct comparisons of importance between characteristics (Sawtooth, 2014) and a more thorough consideration of the ratios (Ligon \& Prior, 2003).

Choice-simulation. One limitation of relying solely on utility scores is the ability of these static averages to miss the strength of preferences within subgroups of the populations. A unique feature of conjoint analysis is the ability to build a data set of preferences that allows predictive analyses or simulations to be run for particular "profiles," or in this study, specific characteristics of a mental training mobile app. Thus, a choice-simulation was created using the online survey features to incorporate the individual utility ratings for each participant, allow participants to select the option within each characteristic they prefer most, as well as provide an indication as to whether they would find a mental training mobile app valuable for his/her respective team. 


\section{Results}

\section{Descriptive Statistics}

Of the 375 coaches that completed the online survey, 205 (54.6\%) reported they were currently coaching female athletes, 106 (28.3\%) reported currently coaching male athletes, 56 (14.9\%) reported currently coaching both a men's and women's team, and eight $(2.2 \%)$ reported currently coaching a coed team. The majority of coaches $(n=309,82.4 \%)$ reported coaching a non-revenue sport, while $57(15.2 \%)$ reported coaching a revenue sport. Nine coaches $(2.4 \%)$ reported being unsure of the financial classification of sport they were coaching. The current sample consisted of more female coaches and revenue sport coaches when compared to the actual demographics of coaches within the NCAA. Currently, between $20 \%$ and $25 \%$ of NCAA coaches are female and between $8 \%$ and $10 \%$ are coaching revenue sports.

When asked about their use of digital devices, 281 coaches (74.9\%) reported using a digital device consistently throughout the day. Sixty coaches (16.0\%) reported using a device several times a day, 25 coaches $(6.7 \%)$ reported using a digital device a few times a day, five coaches $(1.3 \%)$ used a digital device once or twice a day, and four (1.1\%) did not use digital devices. To that degree, 143 coaches $(38.1 \%)$ reported accessing mobile apps consistently throughout the day, 89 coaches $(23.7 \%)$ accessed mobile apps several times a day, 76 coaches (20.3\%) accessed mobile apps a few times a day, 54 coaches (14.4\%) accessed mobile apps only once or twice a day, and 13 coaches (3.5\%) did not access mobile apps. Demographic and descriptive statistics are presented in Table 2.

In terms of access to mental training, 185 coaches (49.3\%) reported that their current institution had access to mental training services or a mental training professional, 167 coaches $(44.5 \%)$ reported that they did not have access to mental training or a mental training professional at their institution, and 23 coaches $(6.2 \%)$ were unsure of the availability of 
mental training at their institution. Although only half of the coaches reported having access to mental training at their institution, 247 coaches $(65.9 \%)$ reported having previously utilized the services of a mental training professional and 128 (34.1\%) reported never having utilizing the services of a mental training professional. Of the 247 coaches with previous experience with a mental training professional, $42(17.0 \%)$ coaches were extremely satisfied with their experience working with a mental training professional, 115 (46.6\%) were very satisfied, 83 (33.6\%) were slightly satisfied, and seven coaches $(2.8 \%)$ were not at all satisfied. Finally, 295 coaches (78.7\%) reported "Yes" and 80 coaches $(21.3 \%)$ reported "No" when asked if they believe a mental training mobile app would be valuable for their team and athletes.

\section{Coaches' Preferred Mobile App}

In order to address the research question, $\mathrm{CBC}-\mathrm{HB}$ analyses were run to determine relative importance scores for each mobile app characteristic and utility scores for options within each characteristic for NCAA Division I head coaches. Relative importance scores and utility scores also were calculated independently for each analyzed subgroup of coaches (e.g., gender, revenue classification, age, years of collegiate coaching experience, and reported value of a mental training mobile app). Relative importance scores and utility scores for analyzed subgroups are presented in Tables 3 through 8 . This section will address relative importance scores and utility scores as well as independent market simulations that predict the likelihood that NCAA Division I Coaches would purchase a mental training mobile app.

Of the characteristics presented Price was the most important characteristic $(38.42 \pm 4.81 \%)$ for coaches when choosing to purchase a mental training mobile app and accounted for $40.22 \%$ of the total utility. The second most important characteristic was

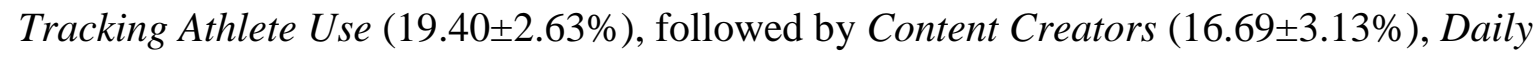

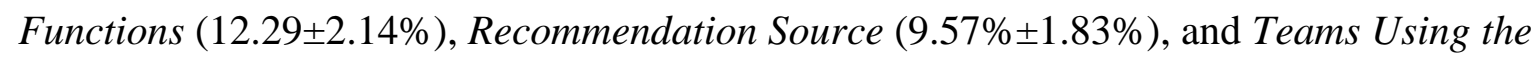


App (3.62 $\pm 1.19 \%)$. Preferred mobile apps for all subgroups of coaches are presented in Table 9.

Utility scores explain the attractiveness of each option within each characteristic. Therefore, higher utility scores represent greater coach preferences for profiles that include the given option for each characteristic. Utility scores for these mental training mobile app characteristics and coaches preferred profile are presented in Table 3. With a very large utility score of 100.46 , mental training mobile apps that cost less than $\$ 200$ were preferred most, providing additional support to Price being the most preferred characteristic by coaches. Furthermore, coaches preferred mental training mobile apps that provide comprehensive tracking of athlete use, come with an internal recommendation, and include daily functions. They also preferred mobile apps that they knew were used by other teams and were created by content creators who work with other successful programs.

Coaches' market simulation. The utility scores for the "None" option (the option to not purchase any of the presented mobile apps) for all coaches and each sub-group of coaches were all very large $(M=164.75, S D=86.48)$. Because Price was the most popular characteristic for all subgroups of coaches and "less than $\$ 200 "$ was the most popular option for any characteristic option presented, market simulations predicating the likelihood of coaches purchasing a mental training mobile app were also conducted. Market simulations tested coaches' preferred mental training mobile app against the option to not purchase a mental training mobile app. Results of market simulations for all subgroups of coaches are presented in Table 9. Although the "None" option utility score for all coaches who completed the survey was 136.23 , based on market simulations, $65.16 \pm 2.26 \%$ of coaches would choose to purchase the mental training mobile app if given the opportunity.

Coaches' choice-simulation preferences. A choice-simulation in the survey allowed coaches to build their own version of a mental training mobile app when given the 
opportunity to choose from all the options within each mobile app characteristic. The full results of the choice-simulation can be seen in Table 10. In the choice-simulation, for the characteristic of Price, the option of less than $\$ 200$ was the most popular and was selected by $344(91.7 \%)$ coaches. For Tracking Athlete Use, comprehensive tracking was the most popular option and was selected by $199(53.1 \%)$ coaches. An external recommendation was the most popular option for Recommendation Source selected by 154 (41.1\%) coaches. For Daily Functions, the option to include daily functions was selected by 321 (85.6\%) of coaches while being aware of other teams using the app was the more popular option for the Teams Using the App, as this characteristic was selected by 229 (61.1\%) coaches. Finally, 353 (94.1\%) coaches chose the option for creators that work with other successful programs for the Content Creators characteristic.

The choice-simulation allowed coaches to create a mental training mobile app without having to make tradeoffs between options for each characteristic and projects a picture of coaches' ideal mobile app based on the characteristics and options presented. Alternatively, the use of a conjoint analysis helps to compare the importance of characteristics and options in relation to each other when coaches are forced to make tradeoffs.

\section{Male and Female Coaches}

Comparisons of relative importance scores and utility scores for male $(n=221)$ and female $(n=147)$ coaches' preferences for a mental training mobile app showed minimal differences (see Table 4). Both male and female coaches' preferred mobile apps that cost less than $\$ 200$, and included options that comprehensively track athlete use, comes with an internal recommendation, includes daily functions, is created by content creators with other successful programs, and when they are aware of other teams using the app. Based on market simulations, if given the opportunity to purchase a mental training mobile app based upon 
their preferences, $72.42 \pm 3.26 \%$ of male coaches and $62.12 \pm 3.03 \%$ of female coaches would choose to purchase the mobile app.

\section{Revenue and Non-Revenue Sport Coaches}

Comparisons of relative importance scores and utility scores for revenue $(n=57)$ and non-revenue $(n=309)$ sport coaches' preferences for a mental training mobile app also show minimal differences between all characteristics and options with the exception of Price (see Table 5). As expected from coaches working with different budgets, non-revenue sport coaches placed higher importance on the cost of the mobile app with a relative importance score of $40.87 \pm 5.50 \%$, while revenue sport coaches had a relative importance score of $26.95 \pm 8.86 \%$ for the same characteristic.

Coaches that were unsure of their team's revenue classification were excluded from any analyses. Both revenue and non-revenue coaches' preferred a mobile app that provides limited tracking of athlete use, comes with an internal recommendation, includes daily functions, and is created by content creators that work with other successful programs. These coaches also preferred a mobile app that costs less than $\$ 200$ and that they knew of other teams using the same app. Based on market simulations, if given the opportunity to purchase a mental training mobile app based on their preferences, $62.64 \pm 5.86 \%$ of revenue coaches and $65.48 \pm 2.43 \%$ of non-revenue coaches would choose to purchase the mobile app.

\section{Generations of Coaches}

The mean age for coaches who completed the survey was 44.5 years $(\mathrm{SD}=10.4)$. Four generational classifications of coaches were compared to assess generational differences. Comparisons of relative importance scores and utility scores for Traditionalist $(n=7)$, Baby Boomer $(n=106)$, Generation X $(n=201)$, and Millennial $(n=61)$ aged coaches' preferences for a mental training mobile app show minimal differences. Ages for each generation of coaches are presented with relative importance scores and utilities scores for generations of 
coaches in Table 6. Because the number of Traditionalist and Millennial coaches are below 80, the results of any conjoint and market analyses for these coaches are not considered large enough to be generalizable (Furber et al., 2014).

Each generation of coaches preferred a mobile app that includes options for an app that costs less than $\$ 200$, comes with an internal recommendation, includes daily functions, is created by content creators with other successful programs, and if they are aware of other teams using the app. The only difference in a preferred mobile app was that Traditionalist, Generation X, and Millennial coaches preferred a mobile app that provided comprehensive tracking of athlete use, while Baby Boomer coaches preferred a mobile app that provided limited tracking of athlete use. Based on market simulations, if given the opportunity to purchase a mental training mobile app based on their preferences, $49.61 \pm 16.66 \%$ of Traditionalist coaches, $60.42 \pm 4.17 \%$ of Baby Boomer coaches, $68.38 \pm 3.10 \%$ of Generation X, and $69.35 \pm 5.42$ of Millennial coaches would choose to purchase the mobile app.

\section{Years of College Coaching Experience}

The mean number of years coaching at the collegiate level was 26.29 years $(\mathrm{SD}=$ 9.08). Four levels of the variable years of college coaching experience' were compared to assess any differences. Comparisons of relative importance scores and utility scores for coaches with less than $10(n=94), 10-19(n=149), 20-29(n=201)$, and more than $30(n$ $=41$ ) years of college coaching experience preferences for a mental training mobile app also showed minimal differences (see Table 7). Because the number of coaches with 30 or more years of experience was below 80, the results of any conjoint analyses and market simulations for these coaches was not considered large enough to be generalizable (Furber et al., 2014).

Each group of coaches with different durations of coaching experiences had the same preferred mobile app. They preferred an app that cost less than $\$ 200$, comprehensively tracks athlete use, comes with an internal recommendation, includes daily functions, is created by 
content creators with other successful programs, and that they are aware of other teams using the app. Based on market simulations, if given the opportunity to purchase a mental training mobile app based on their preferences, $70.38 \pm 4.21 \%$ of coaches with less than 10 years of experience, $62.11 \pm 3.75 \%$ of coaches with $10-19$ years of college coaching experience, $68.12 \pm 4.43 \%$ of coaches with $20-29$ years of experience, and $56.74 \pm 7.19$ of coaches with more than 30 years of experience would choose to purchase the mobile app.

\section{"Yes" and "No" App Value Coaches}

As part of the survey, coaches were asked to indicate "Yes" or "No" to whether they believed a mental training mobile app with their preferred options would be beneficial to their team and athletes. Comparisons of relative importance scores and utility scores for "Yes" $(n=$ $295)$ and "No" $(n=80)$ responses demonstrate the most noticeable differences for coaches preferences for a mental training mobile app. Coaches' preferences for a mental training mobile app showed the most noticeable differences (see Table 8). Both "Yes" coaches and "No" coaches' had a preferred mobile app that included options for a mobile app that costs less than $\$ 200$, comes with an internal recommendation, includes daily functions, is created by content creators that work with other successful programs, and that they are aware of other teams using the app. The only difference in preferred mobile apps was that "No" coaches preferred a mobile app that provides limited tracking of athlete use, while "Yes" coaches preferred a mobile app that provides comprehensive tracking of athlete use. Although relative and utility scores varied slightly more between these groups than any other groups compared (see tables 3-8), the most significant difference in these groups was the utility scores for the "None" option (the option to not purchase any of the presented mobile apps). As expected, "No" coaches, who reported a mental training mobile app would not be valuable to their team or athletes had a "None" utility score that was much higher than the "None" utility score of "Yes" coaches who reported a mental training mobile app would be beneficial for their team 
and athletes. Logically, consumers who do not find value in a product or service, would not choose to purchase that product or service. Similarly, coaches who did not value a mental training mobile app had the highest utility score for the "None" option of any subgroup of coaches at 422.41. In contrast, coaches who reported "Yes" to valuing a mental training mobile app had the lowest "None" option utility score for any subgroup at 72.21. Based on market simulations, if given the opportunity to purchase a mental training mobile app based on their preferences, only $20.03 \pm 4.24 \%$ of "No" coaches would choose to purchase the mobile app while $78.84 \pm 2.05 \%$ of "Yes" coaches would choose to purchase the mobile app.

\section{Discussion}

This study provides evidence that the majority of NCAA Division I head coaches are interested in a mental training mobile app and prefer a mobile app that costs less than $\$ 200$, tracks athlete use, is created by content creators who work with other successful teams, includes daily functions, comes with an internal recommendation, and is being used by other successful programs. When assessing NCAA Division I head coaches' preferences for a mental training mobile app there was little variability between any subgroup of coaches, except for coaches who reported that a mobile app would not benefit their team and athletes. These coaches were the only subgroup unlikely to purchase a mental training mobile app when given the option to do so.

Specific to the use of a mental training mobile app, the cost of the mobile app was consistently the most important characteristic chosen by coaches. These results are not surprising considering that many head coaches are working with limited budgets and are forced to prioritize resources and services offered to their teams (Chapman, Ridpath, \& Denhart, 2014). Currently, the only NCAA sports that are classified as revenue sports, meaning they bring in money to an athletic department, are football and men's basketball (NCAA, 2012a). As such, most coaches at the NCAA level have limited funds to provide 
resources to their teams. Considering these budgetary restrictions and the results of this study, it is logical that coaches would place a higher importance on the cost of services for their teams over the other characteristics of a mental training mobile app.

Tracking Athlete Use was the second most preferred characteristic of a mental training mobile app and Content Creators was the third most preferred characteristic of a mental training mobile app for all coaches except male coaches and coaches who reported that an app would not be valuable for their team and athletes. For these coaches, Tracking Athlete Use was the third most preferred characteristic and Content Creators was the second most preferred characteristic. Tracking Athlete Use and Content Creators being the second and third most preferred characteristics is likely evidence that if coaches are to invest funds from limited budgets in a mobile app, they would prefer a product they can be sure athletes are using and a product that comes from a reputable content creator. For coaches, these characteristics may be a reflection of wanting to ensure that the cost of a mental training mobile app will be a valuable investment. This trend can be seen in market research from a variety of products such as automobiles and clothing. Market researchers suggest consumers order characteristics in a common manner to ensure that a purchase is worth the cost (Dellaert \& Häubl, 2012). In short, the characteristics of Tracking Athlete Use and Content Creators likely reflects coaches' preferences for a quality product that they can ensure is being used to confirm they made a justifiable purchase.

Daily Functions and Recommendation Source were of lesser importance to coaches compared to Price, Tracking Athlete Use, and Content Creators. The results of this study could reflect that the usability of the mobile app may make it more appealing to coaches but these characteristics are not as important as the cost for a quality app that will be used by the athletes. Daily functions, such as calendars and messaging capabilities, are also standard 
functions available on most digital devices making the use of Daily Functions through a mental training mobile app a less important characteristic of the app.

If coaches' receive a recommendation to purchase the app, they would prefer a recommendation from a coach of athletic director within their institution. This Recommendation Source finding may reflect the relationships developed between coaches and administrators from the same institution working to improve the overall athletic success of their athletic department. Teams Using the App was the least preferred characteristic for all subgroups. Being the least preferred characteristic is evidence that the use of the mobile app by other successful programs was of little importance to coaches. Previous research has noted the strength of networking between coaches at different institutions and organizations, especially at the NCAA level (Voight \& Callaghan, 2001). There is established evidence that coaches at these different institutions form strong relationships and communicate frequently (Kornspan \& Duve, 2006). However, coaches' value of Recommendation Source and Teams Using the App may be a reflection of coaches' focus on their own teams and athletic departments and a lack of substantial influence from other programs and athletic departments influencing the purchasing of services for their own teams.

Overall, the results of this study are promising for providing mental training at the intercollegiate level. For mental training professionals developing a mental training mobile app, the results of this study can be used to guide marketing and sales strategies. Using results of market simulations as a guide, the little variation between subgroups in this study indicate the target market for selling a mental training mobile app is fairly homogenous and broad. Not surprisingly, this market encompasses any coach who feels a mental training mobile app would be valuable for their team and athletes. These results are evidence that a mobile app is appealing to both male and female coaches, revenue and non-revenue sport coaches, coaches of different ages and generations, and coaches from a wide range of NCAA sports. 
Using coaches' preferred profiles and the results of market simulations as guides, it is likely that coaches will purchase a mental training mobile app that is within their budgets, tracks athletes' usage, and is created by mental training professionals who work with other successful programs. Moreover, an app that includes daily functions and comes with an internal recommendation may add value to the marketability of the mobile app geared toward NCAA Division I head coaches.

\section{Interest in Mental Training versus Access to Mental Training}

Previous research has provided evidence that college coaches believe that mental skills are important to the success of their teams and indicate an interest in sport psychology services being available to their teams (Zakrajsek et al., 2013). In contrast, research inquiring about the use of mental training at the collegiate level indicates that between $24 \%$ and $53 \%$ of NCAA Division I institutions report utilizing mental training (Wrisberg et al., 2012a). This discrepancy prompts the question: to what degree is the underutilization of mental training at the NCAA level more a matter of coaches' interest and confidence in mental training or actual access to mental training? The results of this study are consistent with established findings that the majority of coaches feel that mental training is valuable. In this study, $78.6 \%$ of coaches reported that they believe a mental training mobile app would be valuable for their team and athletes. This study also provides further confirmation of the actual availability rates of mental training at the Division I level with $49.3 \%$ of coaches reporting that they have access to mental training. However, $65.9 \%$ of coaches in this study reported having previous experience with mental training. Based on this finding, coaches may be gaining mental training experience at some level of play or coaching, and that underutilization of mental training at the Division I level may be more a matter of access than interest in mental training. Although confidence in mental training services is currently the strongest identified predictor of a coach's decision to utilize mental training (Zakrajsek et al., 2011; Zakrajsek \& Zizzi, 
2007), the cost of mental training may limit many coaches' access and also be a strong factor for predicting a coaches' use of mental training. Previously it was assumed that "mo money" lead to "mo problems" (Smalls \& Combs, 1997). However, this study provides evidence that for coaches with limited budgets, it may be more of a "no money mo problems" situation related to access to mental training.

Because most coaches are working with limited budgets and cost has been shown to be a predictor of coaches' use of mental training (Kornspan \& Duve, 2006; Voight \& Callaghan, 2001), future research may also focus on assessing coaches' interest in mental training delivered in different forms. Given the innovative approach for utilizing conjoint analysis in mental training research, future studies could continue applying this methodological approach to assess coaches' preferences for various mental training services. In addition to cost, as newer forms of mental training delivery develop, these newer delivery methods may also influence coaches' access to and confidence in the effectiveness of mental training. Like other traditional services that are now offered via mobile app, the accessibility of mental training, the effectiveness, and the usage of mental training may improve with a mobile app. Overall, newer and more cost effective forms of mental training may improve coaches' perception of mental training. Future research should seek to explore coaches' confidence in and access to mental training as newer forms of providing mental training become more readily available.

\section{Limitations}

This study was designed to understand and project coaches' preferences for a newer form of mental training services and help improve our understanding of coaches' decisions to purchase mental training services. This study had some specific limitations. First, the nature of importance scores and utility scores associated with each characteristic was dependent upon the options within each characteristic (Orme, 1962). A review of sport psychology and mobile technology literature and a pilot study were essential for finalizing the characteristics 
and options presented to coaches in this study. These steps were taken to prevent researcher bias from affecting the characteristics and options that were used. However, the findings of this study are dependent on the differences in preferences that exist within each characteristic. Therefore, since Price was the most important mobile app characteristic in all participant subgroups, this may indicate that the cost of a mental training mobile app is truly the most essential trait for coaches when considering mental training services. Conversely, this same finding could also indicate that the differences in coaches' preferences between the options for Price were too wide ranging or out of so many coaches' budget range that it enhanced the attention paid to the less than $\$ 200$ option for Price. Although the options for Price were developed from price points based on design costs, marketing options, and operating costs of an actual mental training mobile app, taking into account the budget of NCAA programs may create different options for the same characteristic. Furthermore, based on open-responses in the survey and emails received from coaches related to the survey, it appears that many coaches read the less than $\$ 200$ option for Price as a price point of $\$ 200$. Although a Price option of less than $\$ 200$ encompasses all prices less than $\$ 200$, many coaches’ comments related to Price communicated that “\$200 dollars was not within the team’s budget." As such, coaches may have interpreted this option as a fixed price point and not a price range, which influenced coaches' preferences related to Price and the overall value of the app leading to more coaches choosing the "None" option.

Another limitation of using a conjoint analysis is that by exploring coaches' preferences for a mental training mobile app, the findings from this study are unlikely to completely encompass a coach's full range of tradeoffs made while considering the purchase of a mobile app (Orme, 1962). Consumer market analyses are commonly used to gain a more thorough understanding of the potential, and often likely, tradeoffs consumers encounter when making decisions. However, there are other potential factors, some which are unforeseen, 
outside of the characteristics and options presented to consumers that could influence consumer decisions. Because of the inevitable possibility of unforeseen factors, there are always likely to be other characteristics that could influence coaches' decisions to use mental training and/or purchase a mental training mobile app that this study could not account for. For example, factors such as the influence from athletic administrators, the use (or lack of use) of mental training by peers, and the culture of the sport coached were not assessed. The characteristics and options for a mental training mobile app were carefully considered based on previous research in sport psychology (Kornspan \& Duve, 2006; Lubker et al., 2012; Voight \& Callaghan, 2001; Wilson et al., 2009; Wrisberg et al., 2012), mobile technology (Bellman, Potter, Treleaven-Hassard, Robinson, \& Varan, 2011; Cameron, Gregory, \& Batagglia, 2012; Chappuis, Gaffey, \& Parvizi, 2011; Kaplan, 2012; Sexton, 2012), and a pilot study among athletic coaching graduate students, sport psychology graduate students, and small sample of NCAA Division I head coaches. As a result, the tradeoffs presented in this study likely to be tradeoffs that coaches will face when making the decision to purchase a mental training mobile app. However, this does not mean that the tradeoffs represented in this study are the most critical tradeoffs NCAA head coaches are actually considering. Future research should address other potential tradeoffs that coaches face when considering to purchase mental training services.

Level of education has been shown to influence coaches' attitudes and perceptions toward sport psychology services. Specifically, coaches with advanced degrees report more confidence in sport psychology services compared to coaches whose highest level of education is a bachelor's degree or high school diploma (Zakrajsek et al., 2011). This study failed to include a demographic question that inquired about coaches' level of education. Analyzing coaches' level of education may have provided important information for comparing demographic and descriptive statistics, as well as allowed for comparisons to other 
samples of coaches in order to better understand how coaches' interested in mental training may change.

Finally, because this study attempted to contact all NCAA Division I coaches it is, by definition, a census. As such it is particularly prone to nonresponse bias and voluntary repose bias. Nonresponse bias is the bias based on low response rates. Although the sample in this study is large enough for conjoint analysis results to be generalized, it reflects less than $6 \%$ of the total population of NCAA Division I coaches. Voluntary response bias relates to an increased likelihood for potential participants with strong opinions about the topic of the survey to respond compared to those with more neutral opinions about the topic. As such, the results of this study may reflect a more vocal minority of coaches than the total population of NCAA Division I coaches.

\section{Future Directions}

Given the results of this study, one of the next steps for future research is to present coaches with potential content (e.g., mental skills) for a mental training mobile app. Examining coaches' preferences for content may further influence the construction of the mobile app and give an indication of how the content of the app influences coaches' decisions to make the mobile app available to their teams and athletes. These content options may include different mental skills such as visualization and imagery or pre-performance routines, as well as more general mental toughness topics such as confidence or motivation. Examining coaches' preferences for content may also reveal different preferences based in many areas such as sport type, sport culture, and coach gender (Zakrajsek \& Zizzi, 2007; 2008). Previous research noting coaches' stigma tolerance highlights the belief that many coaches feel the use of mental training is an indication of weakness (Zakrajsek, Martin, \& Zizzi, 2011; Zakrajsek \& Zizzi, 2007; 2008). Using well formulated methodologies that include coaches' feedback to help develop the content of a mental training mobile app may help to decrease coaches' 
stigma tolerance and make a mental training mobile app more marketable. If mental training professionals collaborate with coaches who have influence over the mental skills and mental toughness concepts that are presented to their athletes, the view of mental training as a service for "weak athletes" may begin to change. In short, when coaches have direct influence over content presented to their athletes, they may place more value on mental training and using a mental training mobile app. Research presenting coaches with different options for content may prove invaluable for creating a mobile app that coaches will actually make available to their athletes.

In this study nearly $80 \%$ of coaches believed a mental training mobile app would be valuable to their team and athletes. Given the previously discussed usage rates of mental training at the NCAA level, future research should also compare the traditional, face-to-face delivery of mental training services to other forms of providing mental training. It is difficult to find an area of mental training that is not significantly enhanced by a form of digital technology (Schwartz \& Lamphere, 2012). However, the prospect of a mobile app as a means of providing mental training is not an indication that mental training delivered face-to-face is not valued. The rapid growth of technology has created new opportunities for delivering mental training, however, many of these still require empirical examination. Watson and colleagues (2000) noted many potential benefits for using technology in providing mental training services. These researchers accurately predicted the powerful influence technology would have over applied sport psychology. Though the authors could not have predicted how technology would continue to evolve, the benefits, (e.g., serving more clients in need), and concerns (e.g., threats to confidentiality, potential limited effectiveness of services) about the use of technology in applied sport psychology remain salient today. As such, the use of technology to provide mental training should continue to be evaluated as it evolves. Comparing the attractiveness and effectiveness of mental training delivered via mobile 
technology to the more traditional delivery forms of mental training may prove to be an appropriate measuring stick to assess the utilization and effectiveness of mental training services.

Based on the results from this study, it is clear that the cost of mental training is very important to coaches. As such, the market value for a mental training mobile app, and any form of mental training, will be partly determined by what coaches are willing to pay. Although the price ranges presented to coaches in this study were derived from the actual costs to develop and operate a mental training mobile app, the relationship between the "None" option and the "less than $\$ 200 "$ option as well as choice-simulation results are evidence that the options for Price presented to coaches were too high and too wide. Future research that presents coaches with lower and more specific options for Price will lead to more specific information about coaches' perceived financial value of mental training delivered via a mobile app and give a more accurate indication of the market value for mental training. This information will help guide mental training professionals to determine the price they can charge for mental training, the budgets they will need to develop mobile apps and other forms of mental training services, and help to advertise an appealing Price in order to successfully market mental training. Considering these necessary marketing components when creating a mental training app will allow more coaches with limited budgets to provide these services to their athletes.

Although coaches are the primary decisions makers related to mental training, athletes will be the primary users of a mental training mobile app. As such, the concept and potential content of a mental training mobile app should also be presented to athletes through empirical research. Coach-centered research will give valuable information related to the construction and marketing of the mobile app; however, content and usability that meets the needs of the athletes using the app is also important. For example, Tracking Athlete Use accounted for 
$18.58 \%$ of the total utility of the mobile app and coaches preferred the options to have comprehensive of limited tracking of athlete use. As such, working with coaches and athletes could help to navigate potential ethical concerns related to confidentiality if an app was to allow coaches to comprehensively track athlete use. The combination of coach-centered and athlete-centered research would provide more information to further influence the decisions of coaches to make the mobile app available to their athletes and improve the effectiveness of the mobile app by guiding its overall design and construction.

\section{Conclusions}

In recent research that explored different payment sources to athletic administrators, Connole (2013) suggests that analyzing the cost of mental training may be a vital component in the likelihood of mental training being more integrated at the collegiate level. To date, this study is one of the first empirical studies to present coaches with actual prices for the cost of any form of mental training service. At the NCAA Division I level, the cost of mental training services, specifically for a mental training mobile app, may be a stronger predictor of a coach's decision to utilize mental training than previously understood and a worthwhile topic of discussion and empirical evaluation for the field of sport psychology. Because Price was the most preferred characteristic for all subgroups, and less than $\$ 200$ was the most preferred option within Price, it is logical to conclude that cost is a vital component to coaches' decisions related to utilizing mental training. Most teams in the NCAA are considered nonrevenue teams, and operate on a limited budget. The coaches of these teams work with limited budgets and must choose between many services and products to help their teams compete (Chapman, Ridpath, \& Denhart, 2014). Moreover, the option not to purchase any of the mobile apps presented yielded the highest utility scores for all coach subgroups and may be a reflection that coaches' actual preferred option for Price was not included in this study. In short, options for Price presented in this study were considered too high for most coaches. 
Additionally, $78.7 \%$ of coaches reported they believed that a mental training mobile app would be valuable for their team and athletes. Based on market simulations, nearly $70 \%$ of coaches would purchase a mental training mobile app with their preferences, if given the chance (Furber et al., 2014; Orme, 1962). Market researchers assessing sample markets for mobile technology suggest a $35 \%$ to $50 \%$ likelihood of purchasing is a range of market simulations results is evidence that a product will be successful in an actual market (Furber et al., 2014; Fjeldsoe, Marshall, \& Miller, 2009). Moreover, 11 unprompted emails from participants were received informing the primary researcher that the option not to purchase any of the mobile apps presented was selected because the app was "too expensive" and seven participants reported "No" to the value of the mobile app, yet promoted the value of a mental training mobile app when asked to specify why they believed the app would not be of value. The combination of these results is evidence that NCAA Division I coaches find a mental training mobile app highly appealing on a conceptual level; a similar trend seen with many other traditional services now offered via mobile app (Fjeldsoe, Marshall, \& Miller, 2009). However, the cost of the mobile app as presented in this study was too high or may have been interpreted by coaches as a fixed price point of $\$ 200$ instead of a Price option that includes all price points included a less than $\$ 200$ price range.

The delivery of mental training is evolving with newer generations of athletes and coaches with different skills sets, values, and interests, particularly at the collegiate level. Head coaches remain the primary decision makers related to making mental training available to their teams and athletes. It is imperative for mental training professionals to understand the preferences and interests of NCAA coaches and athletes and consider newer forms of delivering mental training that may be more appealing to coaches and effective for reaching Millennial athletes. This study is one of the first empirical evaluations of coaches' preferences for mental training via a mobile app. Newer forms of mental training, specifically mobile 
apps, may also serve to decrease and even bypass identified barriers to traditional delivery of mental training such as stigma tolerance, personal openness, and cultural preference (Zakrajsek, Martin, \& Zizzi, 2011; Zakrajsek \& Zizzi, 2007; 2008). Mobile apps are discrete, used universally without negative stigma, and accessible anytime, presenting fewer barriers to use for coaches and athletes. As such, with continued efforts to develop more effective and cost efficient methods to deliver mental training, coaches may have more options to make mental training available to athletes at a wide range of markets. 


\section{References}

Astarita, V., Festa, D. C., Mongelli, D. W., Mongelli, N., Ruffolo, O., \& Servino, A. (2014). EcoSmart: A survey and sector analysis of mobile phone application market for fuel consumption reduction. Applied Mechanics and Materials, 519, 1546-1555.

Bailie, J. L. (2012). The criticality of verbal immediacy in online instruction: A modified delphi study. Journal of Educators Online, 9(2). Online publication only.

Bellman, S., Potter, R. F., Treleaven-Hassard, S., Robinson, J. A., \& Varan, D. (2011). The effectiveness of branded mobile phone apps. Journal of Interactive Marketing (Mergent, Inc.), 25(4), 191-200.

Bemiller, J. H. \& Wrisberg, C. A. (2011). An overview and critique of NCAA policy regarding the use of sport psychology consultants at the Division I level. Journal of Intercollegiate Sport, 4(2), 227-242.

Chapman, M., Ridpath, B., \& Denhart, M. (2014). An examination of increased NCAA Division I athletic department budgets: A case study of student perceptions of fee allocation for athletes. International Journal Of Sport Management, 15(1), 25-48.

Chappuis, B., Gaffey, B., \& Parvizi, P. (2011). Are your customers becoming digital junkies? Mckinsey Quarterly, 3, 20-23.

Coakley, J. (2008). Sports in society: Issues and controversies (10th ed.). New York, NY: McGraw-Hill.

Connole, I. (2013). Athletic administrators' preferred characteristics of sport psychology positions in NCAA athletics: A consumer market analysis. ETD Dissertation Submission.

Danish, S. J., Petitpas, A. J., \& Hale, B. D. (1992). A developmental-educational intervention model of sport psychology. Sport Psychologist, 6, 403-415. 
Dellaert, B. \& Häubl, G. (2012). Searching in choice mode: consumer decision processes in product search with recommendations. Journal Of Marketing Research (JMR), 49(2), 277-288. doi:10.1509/jmr.09.0481

Dieffenbach, K., Gould, D., \& Moffett, A. (2002). The coach's role in developing champions. International Journal of Volleyball Research, 5, 30-32.

Dillman, D. A. (2011). Mail and internet surveys: The tailored design method-2007 Update with new Internet, visual, and mixed-mode guide. New York, NY: Wiley.

Fjeldsoe, B. S., Marshall, A. L., \& Miller, Y. D. (2009). Behavior change interventions delivered by mobile telephone short-message service. American Journal of Preventive Medicine, 36(2), 165-173.

Furber, G., Segal, L., Leach, M., \& Cocks, J. (2014). Mapping scores from the Strengths and Difficulties Questionnaire (SDQ) to preference-based utility values. Quality Of Life Research, 23(2), 403-411. doi:10.1007/s11136-013-0494-6

Garg, R. \& Telang, R. (2013). Inferring app demand from publicly available data. MIS Quarterly, 37(4), 1253-1264.

Green, P., Krieger, A. M., \& Wind, Y. J. (2001). Thirty years of conjoint analysis: Reflections and prospects. Interfaces, 31, S56-S73.

Johnson, N. (2012). Strategy encourages more data sharing, mobile apps. Federal Times, $48(11), 18$.

Jowett, S. \& Cockerill, I. M. (2003). Olympic medalists' perceptive of the athlete-coach relationship. Psychology of Sport and Exercise, 4, 313-331.

Kaifi, B. A., Nafei, W. A., Khanfar, N. M., \& Kaifi, M. M. (2012). A multi-generational workforce: Managing and understanding millennials. International Journal of Business \& Management, 7(24), 88-93. doi: 10.5539/ijbm.v7n24p88 
Kaplan, A. M. (2012). If you love something, let it go mobile: Mobile marketing and mobile social media 4x4. Business Horizons, 55(2), 129-139.

Kelley, B. \& Carchina, C. (2013). "Hey, data data - swing!”: The hidden demographics of youth sport. ESPN, The Magazine. Retrieved from:

http://espn.go.com/espn/story/_id/9469252/hidden-demographics-youth-sports-espnmagazine

Kornspan, A. \& Duve, M. (2006). A niche in need: A summary of the need for sport psychology consultants in college sports. Annals of the American Psychotherapy Association, 9, 19-25.

Kourouthanassis, P. E. \& Giaglis, G. M. (2012). Introduction to the special issue mobile commerce: The past, present, and future of mobile commerce research. International Journal of Electronic Commerce, 16(4), 5-18. doi: 10.2753/JEC1086-4415160401

Lee, Y., Iyengar, S., Min, C., Ju, Y., Kang, S., Park, T., Lee, J., Rhee, Y., \& Song, J. (2012). MobiCon: A mobile context-monitoring platform. Communications of the ACM, 55(3), 54-65. doi: 10.1145/2093548.2093567

Lubker, J. R., Visek, A. J., Geer, J. R., \& Watson, J. C. (2008). Characteristics of an effective sport psychology consultant: Perspectives from athletes and consultants. Journal of Sport Behavior, 31, 147-165.

Lubker, J. R., Visek, A. J., Watson, J. C., \& Singpurwalla, D. (2012). Athletes’ preferred characteristics and qualifications of sport psychology practitioners: A consumer market analysis. Journal of Applied Sport Psychology, 24, 465-480.

McMahon, M. \& Pospisil, R. (2005). Laptops for a digital lifestyle: Millennial students and wireless mobile technologies. Proceedings of the Australasian Society for Computers in Learning in Tertiary Education, 17, 421-431. 
NCAA (2012a). About the NCAA. Retrieved from http://www.ncaa.org/wps/wcm/connect/public/ncaa/about+the+ncaa

NCAA (2012b). 2012-2013 NCAA Division I Manual. Text prepared by: NCAA Academic and Membership Affairs Staff. Indianapolis, IN: SO\&SO Co., LLC.

Nielson. (2012). The digital revolution: A look through the marketer's lens. MEDIA: U.S. Digital Consumer Report, Q3-Q4.

Nikirk, M. (2009). Today's millennial generation: A look ahead to the future they create. Techniques: Connecting Education and Careers, 84(5), 20-23.

Orme, B. (2006). Getting started with conjoint analysis: Strategies for product design and pricing research. Madison, WI: Research Publishers, LLC.

Orne, M. T. (1962). On the social psychology of the psychological experiment: With particular reference to demand characteristics and their implications. American Psychologist, 17, 776-783.

Pew Internet: Mobile (2013). Cell phone and smartphone ownership and use. Retrieved from http://pewinternet.org/Commentary/2013/February/Pew-Internet-Mobile.aspx

Portenga, S. (2012). iPerformance psychology releases new sports psychology app. Retrieved from http://www.prweb.com/releases/2012/7/prweb9701120.htm

Sahu, A. (2012). Betting on a bigger piece of the mobile app market. Siliconindia, 15(10), $18-21$.

Sawtooth (2014). Sawtooth discovery conjoint analysis software. Choice-based Conjoint Analysis Version 8.0. Retrieved from: https://sawtoothsoftware.com/download/techpap/cbctech.pdf

Schwartz, C. J. \& Lamphere, B. (2012). Ethics in sport and performance psychology: The use of e-therapy in athletics. Psychotherapy Bulletin, 47(4), 30-33. 
Subramanya, S. R. \& Farahani, A. (2012). Point-of-view article on: Design of a smartphone app for learning concepts in mathematics and engineering. International Journal of Innovation Science, 4(3), 173-184. doi: 10.1260/1757-2223.4.3.173

Taylor, D. G., Voelker, T. A., \& Pentina, I. (2011). Mobile application adoption by young adults: A social network perspective. International Journal of Mobile Marketing, 6(2), $60-70$.

Venkatesh, V. L., Thong, J. Y., \& Xu, X. (2012). Consumer acceptance and use of information technology: Extending the unified theory of acceptance and use of technology. MIS Quarterly, 36(1), 157-178.

Voight, M. \& Callaghan, J. (2001). The use of sport psychology services at NCAA Division I universities from 1998 - 1999. The Sport Psychologist, 15, 91-102.

Watson II, J. C., Tenenbaum, G., Lidor, R., \& Alfermann, D. (2001). Ethical uses of the Internet in sport psychology: A position stand. International Journal of Sport Psychology, 32, 207-222.

Wilson, K. A., Gilbert, J. N., Gilbert, W. D., \& Sailor, S. R. (2009). College athletic directors' perceptions of sport psychology consulting. The Sport Psychologist, 23, 405-424.

Wrisberg, C., Withycombe, J., Simpson, D., Loberg, L. A., \& Reed, A. (2012a). NCAA Division-I administrators' perceptions of the benefits of sport psychology services and possible roles for a consultant. The Sport Psychologist, 26(1), 16-28.

Wrisberg, C., Withycombe, J., Simpson, D., Loberg, L. A., \& Reed, A. (2012b). An exploratory investigation of NCAA Division-I coaches' support of sport psychology consultants and willingness to seek mental training services. The Sport Psychologist, $24,489-503$. 
Wrisberg, C. A., Loberg, L. A., Simpson, D., Withycombe, J. L., \& Reed, A. (2010). An exploratory investigation of NCAA division-I coaches' support of sport psychology consultants and willingness to seek mental training services. Sport Psychologist, 24(4), 489-503.

Zakrajsek, R. A., Martin, S. B., \& Zizzi, S. J. (2011). American high school football coaches' attitudes toward sport psychology consultation and intentions to use sport psychology services. International Journal of Sports Science \& Coaching, 6(3), 461-478. doi: $10.1260 / 1747-9541.6 .3 .461$

Zakrajsek, R. A., Steinfeldt, J. A., Bodey, K. J., Martin, S. B., \& Zizzi, S. J. (2013). NCAA Division I coaches' perceptions and preferred use of sport psychology services: A qualitative perspective. Sport Psychologist, 27(3).

Zakrajsek, R. A. \& Zizzi, S. J. (2007). Factors influencing track and swimming coaches intentions to use sport psychology services. The Online Journal of Sport Psychology, 9(2), Retrieved from http://www.athleticinsight.com/Vol9Iss2/ CoachingIntentions.htm

Zakrajsek, R. A. \& Zizzi, S. J. (2008). How do coaches' attitudes change when exposed to a sport psychology workshop? Journal of Coaching Education, 1(1). Retrieved from http://www.aahperd.org/naspe/jce/pdf_files/Zakrajsek_Zizzi_JCE_2008.pdf.

Zeithammer, R. \& Lenk, P. (2009). Statistical benefits of choices from subsets. Journal of Marketing Research, 46, 816-831.

Zizzi, S. J. \& Perna, F. M. (2002). Integrating web pages and e-mail into sport psychology consultations. Sport Psychologist, 16(4), 416.

Zizzi, S. \& Schmid, O. (2012). Reach out and text someone: The creative and effective use of text messaging in sport performance consultations. Athletic Insight's Writings in Sport Psychology, 317-327. 
Table 1

Conjoint Analysis Profiles Characteristics and Options

\begin{tabular}{|c|c|c|c|c|c|}
\hline Price & $\begin{array}{l}\text { Tracking } \\
\text { Athlete Use }\end{array}$ & $\begin{array}{l}\text { Recommendation } \\
\text { Source }\end{array}$ & Daily Functions & $\begin{array}{l}\text { Teams Using the } \\
\text { App }\end{array}$ & Content Creators \\
\hline $\begin{array}{l}\text { Less than } \\
\$ 200 \text { per } \\
\text { athlete }\end{array}$ & No tracking & No recommendation & $\begin{array}{l}\text { Does not include } \\
\text { daily functions }\end{array}$ & $\begin{array}{l}\text { Unaware of other } \\
\text { teams using the app }\end{array}$ & $\begin{array}{l}\text { Creators who do not work with other } \\
\text { successful programs }\end{array}$ \\
\hline $\begin{array}{l}\text { Between } \\
\$ 200-\$ 400 \\
\text { per athlete }\end{array}$ & $\begin{array}{l}\text { Limited } \\
\text { tracking }\end{array}$ & $\begin{array}{l}\text { External } \\
\text { recommendation }\end{array}$ & $\begin{array}{l}\text { Includes daily } \\
\text { functions }\end{array}$ & $\begin{array}{l}\text { Aware of other } \\
\text { teams using the app }\end{array}$ & $\begin{array}{l}\text { Creators who work with other successful } \\
\text { programs }\end{array}$ \\
\hline $\begin{array}{l}\text { More than } \\
\$ 400 \text { per } \\
\text { athlete }\end{array}$ & $\begin{array}{l}\text { Comprehensive } \\
\text { tracking }\end{array}$ & $\begin{array}{l}\text { Internal } \\
\text { recommendation }\end{array}$ & & & \\
\hline
\end{tabular}


Table 2

Participant Demographic and Descriptive Statistics

\begin{tabular}{|c|c|c|c|c|c|}
\hline Demographic/Descriptive & & Demographic/Descriptive & & & \\
\hline Gender & & Digital Device Use & & & \\
\hline Male & $221(58.9 \%)$ & Does not use a digital device & $4(1.1 \%)$ & & \\
\hline Female & $147(39.2 \%)$ & Once or twice a day & $5(1.3 \%)$ & & \\
\hline \multirow[t]{3}{*}{ Choose not to disclose } & $7(1.9)$ & A few times a day & $25(6.7 \%)$ & & \\
\hline & & Several times a day & $60(16.0 \%)$ & & \\
\hline & & Consistently throughout the day & $281(74.9 \%)$ & & \\
\hline Gender of Athletes Coached & & Mobile App Use & & & \\
\hline Male & $106(28.3 \%)$ & Does not use mobile apps & $13(3.5 \%)$ & & \\
\hline Female & $205(54.6 \%)$ & Once or twice a day & $54(14.4 \%)$ & & \\
\hline Coed & $8(2.2 \%)$ & A few times a day & $76(20.3 \%)$ & & \\
\hline \multirow[t]{2}{*}{ Both Men and Women } & $56(14.9 \%)$ & Several times a day & $89(23.7 \%)$ & & \\
\hline & & Consistently throughout the day & $143(38.1 \%)$ & & \\
\hline Revenue Classification & & Sport (s) Coached & & Sport (s) Coached & \\
\hline Revenue & $57(15.2 \%)$ & Baseball & $17(4.5 \%)$ & Outdoor Track \& Field & $39(10.4 \%)$ \\
\hline Non-Revenue & $309(82.4 \%)$ & Basketball & $36(9.6 \%)$ & Lacrosse & $16(4.3 \%)$ \\
\hline Unsure & $9(2.4 \%)$ & Bowling & $7(1.9 \%)$ & Rifle & $8(2.1 \%)$ \\
\hline Access to $M T$ & & Cross Country & $34(9.1 \%)$ & Rowing & $13(3.5 \%)$ \\
\hline Yes & $185(49.3 \%)$ & Diving & $14(3.7 \%)$ & Skiing & $2(0.5 \%)$ \\
\hline No & $167(44.5 \%)$ & Fencing & $1(0.3 \%)$ & Soccer & $26(6.9 \%)$ \\
\hline Unsure & $23(6.2 \%)$ & Field Hockey & $9(2.4 \%)$ & Softball & $26(6.9 \%)$ \\
\hline Previous MT Use & & Football & $11(2.9 \%)$ & Swimming & $27(7.2 \%)$ \\
\hline Yes & $247(65.9 \%)$ & Golf & $45(12.0 \%)$ & Tennis & $23(6.1 \%)$ \\
\hline No & $128(34.1 \%)$ & Gymnastics & $10(2.7 \%)$ & Volleyball & $40(10.7 \%)$ \\
\hline Satisfaction with $M T$ & & Ice Hockey & $7(1.9 \%)$ & Water Polo & $3(0.8 \%)$ \\
\hline Not at all satisfied & $7(2.8 \%)$ & Indoor Track \& Field & $38(10.1 \%)$ & Wrestling & $6(1.6 \%)$ \\
\hline Slightly satisfied & $83(33.6 \%)$ & & & & \\
\hline Very satisfied & $115(46.6 \%)$ & & & & \\
\hline Extremely satisfied & $42(17.0 \%)$ & & & & \\
\hline
\end{tabular}


Table 3

Results of a CBC-HB Analysis for NCAA Division I Head Coaches

\begin{tabular}{|c|c|c|}
\hline \multirow[b]{2}{*}{ Characteristics } & \multicolumn{2}{|c|}{ NCAA Division I Coaches } \\
\hline & $\begin{array}{c}\text { Relative Importance } \\
\text { Scores }\end{array}$ & $\begin{array}{c}\text { Utilities } \\
\text { (Part Worth) }\end{array}$ \\
\hline Price & $38.42 \pm 4.81 \%$ & \\
\hline Less than $\$ 200$ per athlete & $40.22 \% *$ & 100.46 \\
\hline Between $\$ 200-\$ 400$ per athlete & & 12.12 \\
\hline More than $\$ 400$ per athlete & & -112.58 \\
\hline Tracking Athlete Use & $19.40 \pm 2.63 \%$ & \\
\hline No tracking & $18.61 \% *$ & -62.99 \\
\hline Limited tracking & & 27.36 \\
\hline Comprehensive tracking & & 35.60 \\
\hline Recommendation Source & $9.57 \pm 1.83 \%$ & \\
\hline No recommendation & $7.53 \% *$ & -23.10 \\
\hline External recommendation & & 7.02 \\
\hline Internal recommendation & & 16.79 \\
\hline Daily Functions & $12.29 \pm 2.14 \%$ & \\
\hline Does not include daily functions & $12.85 \% *$ & -34.02 \\
\hline Includes daily functions & & 34.02 \\
\hline Teams Using the App & $3.62 \pm 1.19 \%$ & \\
\hline Unaware of other teams using the app & $2.64 \% *$ & -6.98 \\
\hline Aware of other teams using the app & & 6.98 \\
\hline Content Creators & $16.69 \pm 3.13 \%$ & \\
\hline $\begin{array}{l}\text { Creators who do not work } \\
\text { with other successful programs }\end{array}$ & $18.15 \% *$ & -48.08 \\
\hline $\begin{array}{l}\text { Creators who work with other } \\
\text { successful programs }\end{array}$ & & 48.08 \\
\hline None & & 136.23 \\
\hline
\end{tabular}


Table 4

Results of a CBC-HB Analysis for Male and Female Division I Head Coaches

\begin{tabular}{|c|c|c|c|c|}
\hline \multirow[b]{2}{*}{ Characteristics } & \multicolumn{2}{|c|}{ Male Coaches $(n=221)$} & \multicolumn{2}{|c|}{ Female Coaches $(n=147)$} \\
\hline & $\begin{array}{c}\text { Relative Importance } \\
\text { Scores }\end{array}$ & $\begin{array}{c}\text { Utilities } \\
\text { (Part Worth) }\end{array}$ & $\begin{array}{c}\text { Relative Importance } \\
\text { Scores }\end{array}$ & $\begin{array}{c}\text { Utilities } \\
\text { (Part Worth) }\end{array}$ \\
\hline Price & $39.09 \pm 8.47 \%$ & & $41.53 \pm 5.85 \%$ & \\
\hline Less than $\$ 200$ per athlete & $37.65 \% *$ & 94.84 & $44.92 \% *$ & 103.78 \\
\hline Between $\$ 200-\$ 400$ per athlete & & 9.46 & & 21.22 \\
\hline More than $\$ 400$ per athlete & & -104.30 & & -125.01 \\
\hline Tracking Athlete Use & $15.51 \pm 4.83 \%$ & & $19.84 \pm 3.62 \%$ & \\
\hline No tracking & $17.14 \% *$ & -57.73 & $19.48 \% *$ & -64.92 \\
\hline Limited tracking & & 24.80 & & 30.65 \\
\hline Comprehensive tracking & & 32.93 & & 34.27 \\
\hline Recommendation Source & $11.22 \pm 2.42 \%$ & & $8.75 \pm 3.35 \%$ & \\
\hline No recommendation & $9.75 \% *$ & -29.53 & $5.11 \% *$ & -13.95 \\
\hline External recommendation & & 7.47 & & 1.88 \\
\hline Internal recommendation & & 22.05 & & 12.06 \\
\hline Daily Functions & $12.32 \pm 3.39 \%$ & & $12.55 \pm 3.59 \%$ & \\
\hline Does not include daily functions & $13.37 \% *$ & -35.36 & $13.18 \% *$ & -33.56 \\
\hline Includes daily functions & & 35.36 & & 33.56 \\
\hline Teams Using the App & $5.50 \pm 2.04 \%$ & & $3.40 \pm 1.20 \%$ & \\
\hline Unaware of other teams using the app & $3.62 \% *$ & -9.58 & $1.36 \% *$ & -3.46 \\
\hline Aware of other teams using the app & & 9.58 & & 3.46 \\
\hline Content Creators & $17.36 \pm 4.75 \%$ & & $13.91 \pm 4.67 \%$ & \\
\hline $\begin{array}{l}\text { Creators who do not work } \\
\text { with other successful programs }\end{array}$ & $18.47 \% *$ & -48.85 & $15.96 \% *$ & -40.62 \\
\hline $\begin{array}{l}\text { Creators who work with other } \\
\text { successful programs }\end{array}$ & & 48.85 & & 40.62 \\
\hline None & & 132.04 & & 127.57 \\
\hline
\end{tabular}


Table 5

Results of a CBC-HB Analysis for Revenue and Non-Revenue sport Division I Head Coaches

\begin{tabular}{|c|c|c|c|c|}
\hline \multirow[b]{2}{*}{ Characteristics } & \multicolumn{2}{|c|}{$\begin{array}{l}\text { Revenue Sport Coaches } \\
\qquad(n=57)\end{array}$} & \multicolumn{2}{|c|}{$\begin{array}{l}\text { Non-Revenue Sport Coaches } \\
\qquad(n=309)\end{array}$} \\
\hline & $\begin{array}{c}\text { Relative Importance } \\
\text { Scores }\end{array}$ & $\begin{array}{c}\text { Utilities } \\
\text { (Part Worth) }\end{array}$ & $\begin{array}{l}\text { Relative Importance } \\
\text { Scores }\end{array}$ & $\begin{array}{c}\text { Utilities } \\
\text { (Part Worth) }\end{array}$ \\
\hline Price & $26.95 \pm 8.86 \%$ & & $40.87 \pm 5.50 \%$ & \\
\hline Less than $\$ 200$ per athlete & $30.01 \% *$ & 55.12 & $46.67 \% *$ & 107.83 \\
\hline Between $\$ 200-\$ 400$ per athlete & & 28.34 & & 14.04 \\
\hline More than $\$ 400$ per athlete & & -83.46 & & -121.87 \\
\hline Tracking Athlete Use & $24.37 \pm 7.12 \%$ & & $18.66 \pm 3.04 \%$ & \\
\hline No tracking & $27.10 \% *$ & -68.50 & $11.67 \% *$ & 23.55 \\
\hline Limited tracking & & 56.64 & & 38.30 \\
\hline Comprehensive tracking & & 11.85 & & -19.16 \\
\hline Recommendation Source & $13.59 \pm 6.56 \%$ & & $8.54 \pm 1.70 \%$ & \\
\hline No recommendation & $9.00 \% *$ & -21.34 & $6.86 \% *$ & -19.16 \\
\hline External recommendation & & 1.11 & & 4.41 \\
\hline Internal recommendation & & 20.23 & & 14.75 \\
\hline Daily Functions & $11.59 \pm 5.52 \%$ & & $12.28 \pm 2.38 \%$ & \\
\hline Does not include daily functions & $14.85 \% *$ & -34.29 & $13.24 \% *$ & -32.62 \\
\hline Includes daily functions & & 34.29 & & 32.62 \\
\hline Teams Using the App & $7.85 \pm 4.14 \%$ & & $3.79 \pm 1.08 \%$ & \\
\hline Unaware of other teams using the app & $1.01 \% *$ & -2.33 & $2.86 \% *$ & -7.04 \\
\hline Aware of other teams using the app & & 2.33 & & 7.04 \\
\hline Content Creators & $15.63 \pm 6.22 \%$ & & $15.86 \pm 3.54 \%$ & \\
\hline $\begin{array}{l}\text { Creators who do not work } \\
\text { with other successful programs }\end{array}$ & $18.03 \% *$ & -41.62 & $18.65 \% *$ & -45.91 \\
\hline $\begin{array}{l}\text { Creators who work with other } \\
\text { successful programs }\end{array}$ & & 41.62 & & 45.91 \\
\hline None & & 98.13 & & 143.97 \\
\hline
\end{tabular}


Table 6

Results of a CBC-HB Analysis for Generations of Division I Head Coaches

\begin{tabular}{|c|c|c|c|c|c|c|c|c|}
\hline \multirow[b]{2}{*}{ Characteristics } & \multicolumn{2}{|c|}{$\begin{array}{c}\text { Traditionalist }(n=7) \\
\text { Age 67+ }\end{array}$} & \multicolumn{2}{|c|}{$\begin{array}{c}\text { Baby Boomer }(n=106) \\
\text { Age 50-68 }\end{array}$} & \multicolumn{2}{|c|}{$\begin{array}{c}\text { Generation X }(n=201) \\
\text { Age 34-49 }\end{array}$} & \multicolumn{2}{|c|}{$\begin{array}{l}\text { Millennial }(n=61) \\
\text { Age 14-33 }\end{array}$} \\
\hline & $\begin{array}{c}\text { Relative } \\
\text { Importance } \\
\text { Scores }\end{array}$ & $\begin{array}{c}\text { Utilities } \\
\text { (Part } \\
\text { Worth) }\end{array}$ & $\begin{array}{c}\text { Relative } \\
\text { Importance } \\
\text { Scores }\end{array}$ & $\begin{array}{c}\text { Utilities } \\
\text { (Part } \\
\text { Worth) }\end{array}$ & $\begin{array}{c}\text { Relative } \\
\text { Importance } \\
\text { Scores }\end{array}$ & $\begin{array}{c}\text { Utilities } \\
\text { (Part } \\
\text { Worth) }\end{array}$ & $\begin{array}{c}\text { Relative } \\
\text { Importance } \\
\text { Scores }\end{array}$ & $\begin{array}{l}\text { Utilities } \\
\text { (Part } \\
\text { Worth) }\end{array}$ \\
\hline Price & $44.73 \pm 27.88 \%$ & & $34.70 \pm 8.27 \%$ & & $43.25 \pm 6.37 \%$ & & $25.85 \pm 9.05 \%$ & \\
\hline Less than $\$ 200$ per athlete & $55.83 \% *$ & 150.10 & $38.41 \% *$ & 86.78 & $45.14 \% *$ & 110.85 & $27.65 \% *$ & 66.70 \\
\hline Between $\$ 200$ - $\$ 400$ per athlete & & -31.83 & & 17.55 & & 19.23 & & 9.14 \\
\hline More than $\$ 400$ per athlete & & -118.27 & & -104.34 & & -130.09 & & -75.85 \\
\hline Tracking Athlete Use & $16.25 \pm 17.99 \%$ & & $20.57 \pm 5.15 \%$ & & $18.14 \pm 3.05 \%$ & & $21.35 \pm 6.32 \%$ & \\
\hline No tracking & $16.83 \% *$ & -51.16 & $18.20 \% *$ & -58.09 & $18.99 \% *$ & -62.33 & $19.39 \% *$ & -65.12 \\
\hline Limited tracking & & 21.43 & & 32.44 & & 23.39 & & 30.29 \\
\hline Comprehensive tracking & & 29.73 & & 25.65 & & 38.94 & & 34.83 \\
\hline Recommendation Source & $13.85 \pm 11.94 \%$ & & $11.54 \pm 4.88 \%$ & & $8.79 \pm 1.96 \%$ & & $11.55 \pm 5.29 \%$ & \\
\hline No recommendation & $7.73 \% *$ & -15.18 & $7.43 \% *$ & -20.68 & $6.65 \% *$ & -19.16 & $9.12 \% *$ & -27.59 \\
\hline External recommendation & & -6.78 & & 4.41 & & 2.86 & & 8.19 \\
\hline Internal recommendation & & 21.96 & & 16.27 & & 16.30 & & 19.40 \\
\hline Daily Functions & $14.71 \pm 14.97 \%$ & & $11.08 \pm 3.83 \%$ & & $10.77 \pm 2.86 \%$ & & $18.50 \pm 6.53 \%$ & \\
\hline Does not include daily & $14.59 \% *$ & -35.06 & $11.50 \% *$ & -28.61 & $10.97 \% *$ & -29.25 & $21.15 \% *$ & -54.50 \\
\hline functions & & 35.06 & & 28.61 & & 29.25 & & 54.50 \\
\hline Includes daily functions & & & & & & & & \\
\hline Teams Using the App & $3.54 \pm 4.69 \%$ & & $5.44 \pm 2.52 \%$ & & $3.82 \pm 1.48 \%$ & & $5.45 \pm 3.28 \%$ & \\
\hline $\begin{array}{l}\text { Unaware of other teams } \\
\text { using the app }\end{array}$ & $1.02 \% *$ & -2.46 & $4.95 \% *$ & -12.32 & $1.69 \% *$ & -4.50 & $3.87 \% *$ & -9.97 \\
\hline $\begin{array}{l}\text { Aware of other teams } \\
\text { using the app }\end{array}$ & & 2.46 & & 12.32 & & 4.50 & & 9.97 \\
\hline Content Creators & $6.92 \pm 16.47 \%$ & & $16.66 \pm 5.70$ & & $15.22 \pm 4.19 \%$ & & $17.31 \pm 7.17 \%$ & \\
\hline $\begin{array}{l}\text { Creators who do not work with } \\
\text { other successful programs }\end{array}$ & $4.01 \% *$ & -9.63 & $19.51 \% *$ & -48.53 & $18.19 \% *$ & -44.11 & $18.83 \% *$ & -48.52 \\
\hline $\begin{array}{l}\text { Creators who work with other } \\
\text { successful programs }\end{array}$ & & 9.63 & & 48.53 & & 44.11 & & 48.52 \\
\hline None & & 220.35 & & 150.93 & & 132.59 & & 160.13 \\
\hline
\end{tabular}


Table 7

Results of a CBC-HB Analysis for Years of Collegiate Coaching Experience for Division I Head Coaches

\begin{tabular}{|c|c|c|c|c|c|c|c|c|}
\hline \multirow[b]{2}{*}{ Characteristics } & \multicolumn{2}{|c|}{$<10$ years $(n=94)$} & \multicolumn{2}{|c|}{$10-19$ years $(n=149)$} & \multicolumn{2}{|c|}{$20-29$ years $(n=91)$} & \multicolumn{2}{|c|}{$>30$ years $(n=41)$} \\
\hline & $\begin{array}{c}\text { Relative } \\
\text { Importance } \\
\text { Scores } \\
\end{array}$ & $\begin{array}{c}\text { Utilities } \\
\text { (Part } \\
\text { Worth) } \\
\end{array}$ & $\begin{array}{c}\text { Relative } \\
\text { Importance } \\
\text { Scores } \\
\end{array}$ & $\begin{array}{c}\text { Utilities } \\
\text { (Part } \\
\text { Worth) } \\
\end{array}$ & $\begin{array}{c}\text { Relative } \\
\text { Importance } \\
\text { Scores } \\
\end{array}$ & $\begin{array}{c}\text { Utilities } \\
\text { (Part } \\
\text { Worth) } \\
\end{array}$ & $\begin{array}{c}\text { Relative } \\
\text { Importance } \\
\text { Scores } \\
\end{array}$ & $\begin{array}{c}\text { Utilities } \\
\text { (Part } \\
\text { Worth) }\end{array}$ \\
\hline Price & $32.91 \pm 8.31 \%$ & & $40.95 \pm 7.54 \%$ & & $38.30 \pm 10.65 \%$ & & $33.75 \pm 10.55 \%$ & \\
\hline Less than $\$ 200$ per athlete & $35.24 \% *$ & 87.08 & $44.51 \% *$ & 106.40 & $44.44 \% *$ & 93.26 & $34.91 \% *$ & 107.20 \\
\hline Between $\$ 200-\$ 400$ per athlete & & 11.66 & & 16.09 & & 21.37 & & -28.99 \\
\hline More than $\$ 400$ per athlete & & -98.75 & & -122.50 & & -114.63 & & -78.23 \\
\hline Tracking Athlete Use & $20.49 \pm 4.95 \%$ & & $19.80 \pm 3.66 \%$ & & $17.41 \pm 6.59 \%$ & & $20.55 \pm 6.02 \%$ & \\
\hline No tracking & $14.51 \% *$ & -67.18 & $19.40 \% *$ & -63.95 & $15.84 \% *$ & -47.38 & $21.39 \% *$ & -68.11 \\
\hline Limited tracking & & 31.14 & & 28.12 & & 20.66 & & 22.60 \\
\hline Comprehensive tracking & & 36.04 & & 35.83 & & 26.72 & & 45.51 \\
\hline Recommendation Source & $10.73 \pm 3.23 \%$ & & $8.31 \pm 2.71 \%$ & & $13.67 \pm 5.29 \%$ & & $12.99 \pm 3.72 \%$ & \\
\hline No recommendation & $8.40 \% *$ & -28.09 & $4.26 \% *$ & -11.45 & $8.81 \% *$ & -21.96 & $8.89 \% *$ & -8.05 \\
\hline External recommendation & & 11.89 & & 0.99 & & 2.71 & & -19.58 \\
\hline Internal recommendation & & 16.19 & & 10.46 & & 19.25 & & 27.63 \\
\hline Daily Functions & $17.39 \pm 5.02 \%$ & & $10.11 \pm 3.78 \%$ & & $8.73 \pm 3.20 \%$ & & $10.01 \pm 6.58 \%$ & \\
\hline Does not include daily functions & $19.08 \% *$ & -50.30 & $10.47 \% *$ & -26.93 & $9.74 \% *$ & -22.79 & $9.63 \% *$ & -25.58 \\
\hline Includes daily functions & & 50.30 & & 26.93 & & 22.79 & & 25.58 \\
\hline Teams Using the App & $4.43 \pm 2.52 \%$ & & $4.47 \pm 1.63 \%$ & & $5.17 \pm 2.91 \%$ & & $5.63 \pm 5.86 \%$ & \\
\hline $\begin{array}{l}\text { Unaware of other teams } \\
\text { using the app }\end{array}$ & $3.14 \% *$ & -8.29 & $2.85 \% *$ & -7.33 & $0.89 \% *$ & -2.07 & $5.92 \% *$ & -15.72 \\
\hline $\begin{array}{l}\text { Aware of other teams } \\
\text { using the app }\end{array}$ & & 8.29 & & 7.33 & & 2.07 & & 15.72 \\
\hline Content Creators & $14.05 \pm 5.86 \%$ & & $16.40 \pm 4.94 \%$ & & $16.70 \pm 6.32 \%$ & & $17.05 \pm 6.72 \%$ & \\
\hline $\begin{array}{l}\text { Creators who do not work with } \\
\text { other successful programs }\end{array}$ & $14.56 \% *$ & -38.40 & $18.50 \% *$ & -47.57 & $20.28 \% *$ & -47.42 & $19.26 \% *$ & -51.16 \\
\hline $\begin{array}{l}\text { Creators who work with other } \\
\text { successful programs }\end{array}$ & & 38.40 & & 47.57 & & 47.42 & & 51.16 \\
\hline None & & 146.83 & & 178.69 & & 83.50 & & 228.46 \\
\hline
\end{tabular}


Table 8

Results of a CBC-HB Analysis for Division I Coaches who report "Yes" and "No" to Value in a Mental Training Mobile App

\begin{tabular}{|c|c|c|c|c|}
\hline \multirow[b]{2}{*}{ Characteristics } & \multicolumn{2}{|c|}{ "Yes" to App Value $(n=295)$} & \multicolumn{2}{|c|}{ "No" to App Value $(n=80)$} \\
\hline & $\begin{array}{c}\text { Relative Importance } \\
\text { Scores }\end{array}$ & $\begin{array}{c}\text { Utilities } \\
\text { (Part Worth) }\end{array}$ & $\begin{array}{c}\text { Relative Importance } \\
\text { Scores }\end{array}$ & $\begin{array}{c}\text { Utilities } \\
\text { (Part Worth) }\end{array}$ \\
\hline Price & $38.37 \pm 6.08 \%$ & & $46.39 \pm 5.80 \%$ & \\
\hline Less than $\$ 200$ per athlete & $39.97 \% *$ & 96.92 & $48.92 \% *$ & 120.53 \\
\hline Between $\$ 200-\$ 400$ per athlete & & 14.68 & & 53.57 \\
\hline More than $\$ 400$ per athlete & & -111.61 & & -156.10 \\
\hline Tracking Athlete Use & $20.17 \pm 3.19 \%$ & & $10.89 \pm 3.39 \%$ & \\
\hline No tracking & $20.38 \% *$ & -65.28 & $7.97 \% *$ & -12.84 \\
\hline Limited tracking & & 24.15 & & 28.21 \\
\hline Comprehensive tracking & & 41.13 & & -15.38 \\
\hline Recommendation Source & $10.80 \pm 2.28 \%$ & & $3.66 \pm 2.65 \%$ & \\
\hline No recommendation & $8.48 \% *$ & -25.67 & $2.07 \% *$ & -3.14 \\
\hline External recommendation & & 7.13 & & 7.24 \\
\hline Internal recommendation & & 18.55 & & -4.09 \\
\hline Daily Functions & $11.69 \pm 2.67 \%$ & & $16.78 \pm 3.22 \%$ & \\
\hline Does not include daily functions & $12.06 \% *$ & -31.45 & $18.28 \% *$ & -50.00 \\
\hline Includes daily functions & & 31.45 & & 50.00 \\
\hline Teams Using the App & $4.27 \pm 1.37 \%$ & & $3.46 \pm 1.88 \%$ & \\
\hline Unaware of other teams using the app & $3.09 \% *$ & -8.07 & $2.17 \% *$ & 5.93 \\
\hline Aware of other teams using the app & & 8.07 & & -5.93 \\
\hline Content Creators & $14.70 \pm 3.52 \%$ & & $18.82 \pm 4.49 \%$ & \\
\hline $\begin{array}{l}\text { Creators who do not work } \\
\text { with other successful programs }\end{array}$ & $16.00 \% *$ & -41.74 & $20.59 \% *$ & -56.31 \\
\hline $\begin{array}{l}\text { Creators who work with other } \\
\text { successful programs }\end{array}$ & & -41.74 & & 56.31 \\
\hline None & & 72.21 & & 422.41 \\
\hline
\end{tabular}


Table 9

List of Preferred Profiles and Results of Market Simulations

\begin{tabular}{|c|c|c|c|}
\hline $\begin{array}{l}\text { Preferred } \\
\text { Profile Title }\end{array}$ & $\begin{array}{l}\text { Mobile App } \\
\text { Characteristics }\end{array}$ & Preferred Profile & $\begin{array}{l}\text { Likelihood of } \\
\text { Purchasing Preferred } \\
\text { Profile }\end{array}$ \\
\hline $\begin{array}{l}\text { NCAA DI } \\
\text { Head Coaches }\end{array}$ & $\begin{array}{l}\text { Price } \\
\text { Tracking Athlete Use } \\
\text { Recommendation Source } \\
\text { Daily Functions } \\
\text { Teams Using the App } \\
\text { Content Creators }\end{array}$ & $\begin{array}{l}\text { Less than } \$ 200 \text { per athlete } \\
\text { Comprehensive tracking } \\
\text { Internal recommendation } \\
\text { Includes daily functions } \\
\text { Aware of other teams using the app } \\
\text { Creators who work with other } \\
\text { successful programs }\end{array}$ & $68.16 \pm 2.26 \%$ \\
\hline $\begin{array}{l}\text { Male NCAA } \\
\text { DI Head } \\
\text { Coaches }\end{array}$ & $\begin{array}{l}\text { Price } \\
\text { Tracking Athlete Use } \\
\text { Recommendation Source } \\
\text { Daily Functions } \\
\text { Teams Using the App } \\
\text { Content Creators }\end{array}$ & $\begin{array}{l}\text { Less than } \$ 200 \text { per athlete } \\
\text { Comprehensive tracking } \\
\text { Internal recommendation } \\
\text { Includes Daily Functions } \\
\text { Aware of other teams using the app } \\
\text { Creators who work with other } \\
\text { successful programs }\end{array}$ & $72.42 \pm 3.26 \%$ \\
\hline $\begin{array}{l}\text { Female } \\
\text { NCAA DI } \\
\text { Head Coaches }\end{array}$ & $\begin{array}{l}\text { Price } \\
\text { Tracking Athlete Use } \\
\text { Recommendation Source } \\
\text { Daily Functions } \\
\text { Teams Using the App } \\
\text { Content Creators }\end{array}$ & $\begin{array}{l}\text { Less than } \$ 200 \text { per athlete } \\
\text { Comprehensive tracking } \\
\text { Internal recommendation } \\
\text { Includes Daily Functions } \\
\text { Aware of other teams using the app } \\
\text { Creators who work with other } \\
\text { successful programs }\end{array}$ & $62.12 \pm 3.03 \%$ \\
\hline
\end{tabular}




\begin{tabular}{|c|c|c|c|}
\hline $\begin{array}{l}\text { NCAA DI } \\
\text { Revenue Head } \\
\text { Coaches }\end{array}$ & $\begin{array}{l}\text { Price } \\
\text { Tracking Athlete Use } \\
\text { Recommendation Source } \\
\text { Daily Functions } \\
\text { Teams Using the App } \\
\text { Content Creators }\end{array}$ & $\begin{array}{l}\text { Less than } \$ 200 \text { per athlete } \\
\text { Limited tracking } \\
\text { Internal recommendation } \\
\text { Includes Daily Functions } \\
\text { Aware of other teams using the app } \\
\text { Creators who work with other } \\
\text { successful programs }\end{array}$ & $62.64 \pm 5.86 \%$ \\
\hline $\begin{array}{l}\text { NCAA DI } \\
\text { Non-Revenue } \\
\text { Head Coaches }\end{array}$ & $\begin{array}{l}\text { Price } \\
\text { Tracking Athlete Use } \\
\text { Recommendation Source } \\
\text { Daily Functions } \\
\text { Teams Using the App } \\
\text { Content Creators }\end{array}$ & $\begin{array}{l}\text { Less than } \$ 200 \text { per athlete } \\
\text { Limited tracking } \\
\text { Internal recommendation } \\
\text { Includes Daily Functions } \\
\text { Aware of other teams using the app } \\
\text { Creators who work with other } \\
\text { successful programs }\end{array}$ & $65.48 \pm 2.43 \%$ \\
\hline $\begin{array}{l}\text { Traditionalist } \\
\text { Coaches }\end{array}$ & $\begin{array}{l}\text { Price } \\
\text { Tracking Athlete Use } \\
\text { Recommendation Source } \\
\text { Daily Functions } \\
\text { Teams Using the App } \\
\text { Content Creators }\end{array}$ & $\begin{array}{l}\text { Less than } \$ 200 \text { per athlete } \\
\text { Comprehensive tracking } \\
\text { Internal recommendation } \\
\text { Includes Daily Functions } \\
\text { Aware of other teams using the app } \\
\text { Creators who work with other } \\
\text { successful programs }\end{array}$ & $49.61 \pm 16.66 \%$ \\
\hline $\begin{array}{l}\text { Baby Boomer } \\
\text { Coaches }\end{array}$ & $\begin{array}{l}\text { Price } \\
\text { Tracking Athlete Use } \\
\text { Recommendation Source } \\
\text { Daily Functions } \\
\text { Teams Using the App } \\
\text { Content Creators }\end{array}$ & $\begin{array}{l}\text { Less than } \$ 200 \text { per athlete } \\
\text { Limited tracking } \\
\text { Internal recommendation } \\
\text { Includes Daily Functions } \\
\text { Aware of other teams using the app } \\
\text { Creators who work with other } \\
\text { successful programs }\end{array}$ & $60.42 \pm 4.17 \%$ \\
\hline
\end{tabular}




\begin{tabular}{|c|c|c|c|}
\hline $\begin{array}{l}\text { Generation X } \\
\text { Coaches }\end{array}$ & $\begin{array}{l}\text { Price } \\
\text { Tracking Athlete Use } \\
\text { Recommendation Source } \\
\text { Daily Functions } \\
\text { Teams Using the App } \\
\text { Content Creators }\end{array}$ & $\begin{array}{l}\text { Less than } \$ 200 \text { per athlete } \\
\text { Comprehensive tracking } \\
\text { Internal recommendation } \\
\text { Includes Daily Functions } \\
\text { Aware of other teams using the app } \\
\text { Creators who work with other } \\
\text { successful programs }\end{array}$ & $68.38 \pm 3.10 \%$ \\
\hline $\begin{array}{l}\text { Millennial } \\
\text { Coaches }\end{array}$ & $\begin{array}{l}\text { Price } \\
\text { Tracking Athlete Use } \\
\text { Recommendation Source } \\
\text { Daily Functions } \\
\text { Teams Using the App } \\
\text { Content Creators }\end{array}$ & $\begin{array}{l}\text { Less than } \$ 200 \text { per athlete } \\
\text { Comprehensive tracking } \\
\text { Internal recommendation } \\
\text { Includes Daily Functions } \\
\text { Aware of other teams using the app } \\
\text { Creators who work with other } \\
\text { successful programs }\end{array}$ & $69.35 \pm 5.42 \%$ \\
\hline $\begin{array}{l}\text { Coaches with } \\
\text { less than } 10 \\
\text { years of } \\
\text { collegiate } \\
\text { coaching } \\
\text { experience }\end{array}$ & $\begin{array}{l}\text { Price } \\
\text { Tracking Athlete Use } \\
\text { Recommendation Source } \\
\text { Daily Functions } \\
\text { Teams Using the App } \\
\text { Content Creators }\end{array}$ & $\begin{array}{l}\text { Less than } \$ 200 \text { per athlete } \\
\text { Comprehensive tracking } \\
\text { Internal recommendation } \\
\text { Includes Daily Functions } \\
\text { Aware of other teams using the app } \\
\text { Creators who work with other } \\
\text { successful programs }\end{array}$ & $70.38 \pm 4.21 \%$ \\
\hline $\begin{array}{l}\text { Coaches with } \\
10-19 \text { years of } \\
\text { collegiate } \\
\text { coaching } \\
\text { experience }\end{array}$ & $\begin{array}{l}\text { Price } \\
\text { Tracking Athlete Use } \\
\text { Recommendation Source } \\
\text { Daily Functions } \\
\text { Teams Using the App } \\
\text { Content Creators }\end{array}$ & $\begin{array}{l}\text { Less than } \$ 200 \text { per athlete } \\
\text { Comprehensive tracking } \\
\text { Internal recommendation } \\
\text { Includes Daily Functions } \\
\text { Aware of other teams using the app } \\
\text { Creators who work with other } \\
\text { successful programs }\end{array}$ & $62.11 \pm 3.75 \%$ \\
\hline
\end{tabular}




\begin{tabular}{|c|c|c|c|}
\hline $\begin{array}{l}\text { Coaches with } \\
\text { 20-29 years of } \\
\text { collegiate } \\
\text { coaching } \\
\text { experience }\end{array}$ & $\begin{array}{l}\text { Price } \\
\text { Tracking Athlete Use } \\
\text { Recommendation Source } \\
\text { Daily Functions } \\
\text { Teams Using the App } \\
\text { Content Creators }\end{array}$ & $\begin{array}{l}\text { Less than } \$ 200 \text { per athlete } \\
\text { Comprehensive tracking } \\
\text { Internal recommendation } \\
\text { Includes Daily Functions } \\
\text { Aware of other teams using the app } \\
\text { Creators who work with other } \\
\text { successful programs }\end{array}$ & $68.12 \pm 4.43 \%$ \\
\hline $\begin{array}{l}\text { Coaches with } \\
\text { more than } 30 \\
\text { years of } \\
\text { collegiate } \\
\text { coaching } \\
\text { experience }\end{array}$ & $\begin{array}{l}\text { Price } \\
\text { Tracking Athlete Use } \\
\text { Recommendation Source } \\
\text { Daily Functions } \\
\text { Teams Using the App } \\
\text { Content Creators }\end{array}$ & $\begin{array}{l}\text { Less than } \$ 200 \text { per athlete } \\
\text { Comprehensive tracking } \\
\text { Internal recommendation } \\
\text { Includes Daily Functions } \\
\text { Aware of other teams using the app } \\
\text { Creators who work with other } \\
\text { successful programs }\end{array}$ & $56.74 \pm 7.19 \%$ \\
\hline $\begin{array}{l}\text { "Yes" to App } \\
\text { Value } \\
\text { Coaches }\end{array}$ & $\begin{array}{l}\text { Price } \\
\text { Tracking Athlete Use } \\
\text { Recommendation Source } \\
\text { Daily Functions } \\
\text { Teams Using the App } \\
\text { Content Creators }\end{array}$ & $\begin{array}{l}\text { Less than } \$ 200 \text { per athlete } \\
\text { Comprehensive tracking } \\
\text { Internal recommendation } \\
\text { Includes Daily Functions } \\
\text { Aware of other teams using the app } \\
\text { Creators who work with other } \\
\text { successful programs }\end{array}$ & $78.84 \pm 2.05 \%$ \\
\hline $\begin{array}{l}\text { "No" to App } \\
\text { Value } \\
\text { Coaches }\end{array}$ & $\begin{array}{l}\text { Price } \\
\text { Tracking Athlete Use } \\
\text { Recommendation Source } \\
\text { Daily Functions } \\
\text { Teams Using the App } \\
\text { Content Creators }\end{array}$ & $\begin{array}{l}\text { Less than } \$ 200 \text { per athlete } \\
\text { Limited tracking } \\
\text { External recommendation } \\
\text { Includes Daily Functions } \\
\text { Aware of other teams using the app } \\
\text { Creators who work with other } \\
\text { successful programs }\end{array}$ & $20.03 \pm 4.24 \%$ \\
\hline
\end{tabular}


Table 10

Coaches' Choice-Simulation Selections

\begin{tabular}{|c|c|c|}
\hline Characteristics & $N$ & Percent \\
\hline \multicolumn{3}{|l|}{ Price } \\
\hline Less than $\$ 200$ per athlete & 344 & $91.7 \%$ \\
\hline Between $\$ 200-\$ 400$ per athlete & 28 & $7.5 \%$ \\
\hline More than $\$ 400$ per athlete & 3 & $0.8 \%$ \\
\hline \multicolumn{3}{|l|}{ Tracking Athlete Use } \\
\hline No tracking & 29 & $7.7 \%$ \\
\hline Limited tracking & 147 & $39.2 \%$ \\
\hline Comprehensive tracking & 199 & $53.1 \%$ \\
\hline \multicolumn{3}{|l|}{ Recommendation Source } \\
\hline No recommendation & 85 & $22.6 \%$ \\
\hline External recommendation & 154 & $41.1 \%$ \\
\hline Internal recommendation & 136 & $36.3 \%$ \\
\hline \multicolumn{3}{|l|}{ Daily Functions } \\
\hline Does not include daily functions & 54 & $14.4 \%$ \\
\hline Includes daily functions & 321 & $85.6 \%$ \\
\hline \multicolumn{3}{|l|}{ Teams Using the App } \\
\hline Unaware of other teams using the app & 146 & $38.9 \%$ \\
\hline Aware of other teams using the app & 229 & $61.1 \%$ \\
\hline \multicolumn{3}{|l|}{ Content Creators } \\
\hline Creators who do not work with other successful programs & 22 & $5.9 \%$ \\
\hline Creators who work with other successful programs & 353 & $94.1 \%$ \\
\hline
\end{tabular}

Note. Coaches' preferred level in within each characteristic is bolded in the percent column. 


\title{
Appendix A
}

\author{
Internet-based Survey Part 1: CBC Introduction
}

\section{MENTAL TRAINING MOBILE APP}

Mental toughness is vital to consistent performance, especially under pressure and more and more coaches are making mental training available to their teams and athletes. In order to obtain a clearer picture of how mental training can be best delivered within the NCAA, we are inviting you to complete a short survey introducing a mental training mobile app. Your input is very important to this research.

First, you will be presented with six possible options of a mental training mobile app designed for student-athletes that coaches will be able to make available to their teams. The mental training mobile app is an interactive mobile app that uses training videos to introduce and teach athletes a series of mental skills designed to help improve commitment, motivation, confidence, focus, and composure. Athletes will then personalize their mental skills to fit their performance.

Second, you will be asked about your preferences for various combinations of these options. Please take a minute to familiarize yourself with these possible options.

1) Price includes three options for one year's use of the mental training mobile app:

- Less than $\$ 200$ per athlete

- Between \$200-\$400 per athlete

- More than $\$ \mathbf{4 0 0}$ per athlete

2) Tracking Athlete Use includes three options for the mental training mobile app to allow coaches the ability to track athletes' use of the mental training app:

- No Tracking = Does not track athletes' use of the app

- Limited Tracking $=$ Tracks athletes' use of the app by giving coaches restricted access to athletes' use including time spent on the app and mental skills accessed

- Comprehensive Tracking = Tracks athletes' use of the app by giving coaches unrestricted access to athletes use and personalized mental skills

3) Recommendation Source includes three possible options for recommendations from others to use the mental training mobile app:

- No Recommendation $=$ No recommendation was received related to using the mental training mobile app

- Recommendation from coach or AD from another institution = A recommendation to use the mental training mobile app from an athletic director or coach from another institution

- Recommendation from coach or AD from your institution = A recommendation to use the mental training mobile app from an athletic director or coach from your institution 
4) Daily Functions includes two options for coaches to use the mental training mobile app as a calendar, to message athletes, post team bulletins, and send out mental skill reminders to the team or individual athletes:

- Does not include daily functions

- Includes daily functions

5) Teams Using the App includes two options for your awareness of other teams using the mental training mobile app:

- Unaware of any other teams using the app

- Aware of other teams using the app

6) Content Creators includes two options for the credibility of the creators of the mental training mobile app:

- Creators who do not work with any successful teams

- Creators who work with other successful teams

A mental training mobile app will allow athletes an interactive and personalized method to develop mental toughness and connect with other athletes. By combining the options presented to you above, several versions of a mental training mobile app have been formed. You will be presented with a series of three mental training mobile apps at a time and asked to choose the one you would be most interested in purchasing for your team's use. For the remainder of the survey, you may move your cursor over the six characteristics to see the descriptions again. The survey should take less than 10 minutes to complete, but please complete all of the questions so that your valuable option can be taken into account.

Thank you! You may click the arrow to begin! 
Appendix $B$

Survey Review Step One

Prompt: What characteristics of a mental training mobile app would most strongly influence your decision to purchase a mental training mobile app for your team to use?

Table B1

Survey Review Step One: Conjoint Analysis Profiles Characteristics and Levels I

\begin{tabular}{ccccc}
\hline Price & Tracking & $\begin{array}{c}\text { Daily } \\
\text { Functions }\end{array}$ & $\begin{array}{c}\text { AD } \\
\text { Recommendation }\end{array}$ & $\begin{array}{c}\text { Coach } \\
\text { Recommendation }\end{array}$ \\
\hline $\begin{array}{c}\text { Less than } \\
\text { \$200 per } \\
\text { athlete }\end{array}$ & $\begin{array}{c}\text { No tracking of } \\
\text { athlete use }\end{array}$ & $\begin{array}{c}\text { Does not } \\
\text { include any } \\
\text { daily } \\
\text { functions }\end{array}$ & $\begin{array}{c}\text { No AD } \\
\text { recommendation }\end{array}$ & $\begin{array}{c}\text { No coach } \\
\text { recommendation }\end{array}$ \\
\hline $\begin{array}{c}\text { Between } \\
\text { \$200-\$400 }\end{array}$ & $\begin{array}{c}\text { Tracks athlete use in } \\
\text { time spent on the } \\
\text { per athlete } \\
\text { app and what mental } \\
\text { skills were accessed }\end{array}$ & $\begin{array}{c}\text { Includes } \\
\text { daily } \\
\text { functions }\end{array}$ & $\begin{array}{c}\text { Recommendation } \\
\text { from an AD from } \\
\text { another institution }\end{array}$ & $\begin{array}{c}\text { Recommendation } \\
\text { from a coach from } \\
\text { another institution }\end{array}$ \\
\hline $\begin{array}{c}\text { More than } \\
\text { \$400 per } \\
\text { athlete }\end{array}$ & $\begin{array}{c}\text { Allows complete } \\
\text { tracking and access } \\
\text { to athletes use }\end{array}$ & & $\begin{array}{c}\text { Recommendation } \\
\text { from an AD from } \\
\text { your institution }\end{array}$ & $\begin{array}{c}\text { Recommendation } \\
\text { from a coach from } \\
\text { your institution }\end{array}$ \\
\hline $\begin{array}{l}\text { Note. Primary characteristics are bolded at the head of each column, followed by the levels or } \\
\text { options that will be provided for each characteristic. }\end{array}$ &
\end{tabular}

Price: The cost per athlete of a mental training mobile app for one calendar year's use.

Tracking: The mental training mobile app offers coaches the ability to track athletes' usage of the app. Coaches will be able to see the skills offered to athletes, how much time athletes spend using the app, how athletes have personalized mental skills, and when athletes updates their skills.

Daily Utilities: The mental training mobile app allows coaches to use the app for daily functions including a full calendar, messaging with athletes, posting team bulletins, and sending mental skill reminders to athletes. 
Table B2

Survey Review Step One: Conjoint Analysis Profiles Characteristics and Levels II

\begin{tabular}{ccccc}
\hline $\begin{array}{c}\text { Teams Already } \\
\text { Using the Mental } \\
\text { Training Mobile } \\
\text { App }\end{array}$ & $\begin{array}{c}\text { Credibility of } \\
\text { Content } \\
\text { Creators }\end{array}$ & Interactivity & Personalization & $\begin{array}{c}\text { Social } \\
\text { Networking }\end{array}$ \\
\hline $\begin{array}{c}\text { Unaware of any } \\
\text { other teams using } \\
\text { the app }\end{array}$ & $\begin{array}{c}\text { Creators who do } \\
\text { not work with any } \\
\text { successful } \\
\text { programs }\end{array}$ & $\begin{array}{c}\text { Low } \\
\text { Interactivity }\end{array}$ & $\begin{array}{c}\text { Not } \\
\text { personalized }\end{array}$ & $\begin{array}{c}\text { Not social } \\
\text { networking }\end{array}$ \\
\hline $\begin{array}{c}\text { Aware that other } \\
\text { teams are using the } \\
\text { app }\end{array}$ & $\begin{array}{c}\text { Creators who work } \\
\text { with other } \\
\text { successful } \\
\text { programs }\end{array}$ & $\begin{array}{c}\text { Somewhat } \\
\text { Interactive }\end{array}$ & $\begin{array}{c}\text { Somewhat } \\
\text { personalized }\end{array}$ & $\begin{array}{c}\text { Limited social } \\
\text { networking }\end{array}$ \\
\hline & & $\begin{array}{c}\text { Highly } \\
\text { Interactive }\end{array}$ & $\begin{array}{c}\text { Versonalized } \\
\text { Persong }\end{array}$ & $\begin{array}{c}\text { Social } \\
\text { networking }\end{array}$ \\
\hline
\end{tabular}

Interactivity: The level to which athletes can interact with and use the mental training mobile app by personalizing mental skills, receiving reminders and updates, and accessing their personal profiles.

Personalization: The level to which athletes can personalize their personal profiles and mental skills on the mental training mobile app. Potential personalization includes team colors, jersey number, position, and tracking stats, as well as personalizing mental skills such as a performance routine to fit the athlete's preferences.

Social Networking: The mental training mobile app allows athletes to connect socially with other college athletes and share information related to mental skills and performance. 
Table B3

Potential Conjoint Factors Mean Rankings: Sport Psychology Graduate Students

\begin{tabular}{lccccc}
\hline & \multicolumn{2}{c}{$(n=6)$} & \multicolumn{3}{c}{ Level Selections } \\
& $M$ & $S D$ & 1 & 2 & 3 \\
\hline Price & 2.50 & 3.20 & 6 & 2 & 0 \\
Credibility of Content Creators & 2.83 & 1.67 & 0 & 6 & - \\
Daily Functions & 4.66 & 3.01 & 0 & 6 & - \\
Coach Recommendation & 5.00 & 1.90 & 0 & 5 & 1 \\
Interactivity & 5.16 & 1.47 & 0 & 1 & 5 \\
Personalization & 5.33 & 2.07 & 0 & 1 & 5 \\
Tracking & 5.83 & 1.72 & 0 & 4 & 2 \\
AD Recommendation & 7.00 & 3.28 & 0 & 1 & 5 \\
Teams Using App & 8.00 & 3.03 & 1 & 5 & - \\
Social Networking & 8.66 & 1.51 & 0 & 5 & 1 \\
\hline Note. AD = Athletic Director & & & & & \\
\hline
\end{tabular}

Note. $\mathrm{AD}=$ Athletic Director 
Table B4

Potential Conjoint Factors Mean Rankings: Athletic Coaching Education Graduate Students

\begin{tabular}{lccccc}
\hline & \multicolumn{2}{c}{$(n=9)$} & \multicolumn{3}{c}{ Level Selections } \\
& $M$ & $S D$ & 1 & 2 & 3 \\
\hline Price & 2.20 & 1.64 & 8 & 1 & 0 \\
Tracking & 2.66 & 1.41 & 0 & 1 & 8 \\
Daily Functions & 4.33 & 1.41 & 0 & 9 & - \\
Credibility of Content Creators & 4.44 & 2.65 & 0 & 9 & - \\
Interactivity & 4.77 & 2.49 & 0 & 2 & 7 \\
Personalization & 5.66 & 2.78 & 0 & 0 & 9 \\
Teams Using App & 6.66 & 2.24 & 0 & 9 & - \\
Coach Recommendation & 7.22 & 2.11 & 0 & 6 & 3 \\
AD Recommendation & 8.22 & 1.78 & 6 & 0 & 3 \\
Social Networking & 8.44 & 1.51 & 0 & 6 & 3 \\
\hline Note. AD = Athletic Director & & & & & \\
\hline
\end{tabular}

Note. $\mathrm{AD}=$ Athletic Director 
Table B5

Potential Conjoint Factors Mean Rankings: NCAA Division I Coaches

\begin{tabular}{lccccc}
\hline & \multicolumn{2}{c}{$(n=10)$} & \multicolumn{3}{c}{ Level Selections } \\
& $M$ & $S D$ & 1 & 2 & 3 \\
\hline Price & 2.10 & 1.27 & 8 & 2 & 0 \\
Teams Using App & 2.80 & 1.62 & 0 & 10 & - \\
Tracking & 2.90 & 0.74 & 0 & 0 & 10 \\
Coach Recommendation & 3.10 & 1.60 & 0 & 6 & 4 \\
Daily Functions & 4.90 & 0.99 & 0 & 10 & - \\
Credibility of Content Creators & 5.40 & 1.71 & 0 & 10 & - \\
AD Recommendation & 7.60 & 1.35 & 0 & 2 & 8 \\
Interactivity & 7.77 & 0.95 & 0 & 2 & 8 \\
Personalization & 9.30 & 0.48 & 0 & 0 & 10 \\
Social Networking & 9.30 & 0.82 & 0 & 9 & 1 \\
\hline Note. AD = Athletic Director & & & & & \\
\hline
\end{tabular}

Note. $\mathrm{AD}=$ Athletic Director 
Table B6

Potential Conjoint Factors Mean Rankings: Total Sample

\begin{tabular}{lccccc}
\hline & \multicolumn{2}{c}{$(n=25)$} & \multicolumn{3}{c}{ Level Selections } \\
& $M$ & $S D$ & 1 & 2 & 3 \\
\hline Price & 2.24 & 1.92 & 20 & 5 & 0 \\
Tracking & 3.52 & 1.81 & 0 & 5 & 20 \\
Credibility of Content Creators & 4.44 & 2.18 & 0 & 25 & - \\
Daily Functions & 4.64 & 1.73 & 1 & 24 & - \\
Coach Recommendation & 5.04 & 2.65 & 0 & 17 & 8 \\
Teams Already Using App & 5.44 & 3.11 & 9 & 16 & - \\
Interactivity & 6.04 & 2.19 & 0 & 5 & 20 \\
Personalization & 7.04 & 2.67 & 0 & 1 & 24 \\
AD Recommendation & 7.68 & 2.10 & 6 & 3 & 16 \\
Social Networking & 8.84 & 1.28 & 1 & 20 & 5 \\
\hline Note. AD Athletic Director & & & & & \\
\hline
\end{tabular}

Note. $\mathrm{AD}=$ Athletic Director 
Appendix $C$

Recruitment Email 1: Pre-Notice Email

Dear Coach,

The mental training team at West Virginia University is continually working to better understand how to provide the highest quality mental training to intercollegiate coaches, athletes, and teams. We believe that with effective delivery that athletes will be able to utilize mental skills more effectively and ultimately improve their athletic performance. Your position and involvement in NCAA athletics directly impacts the form of delivery and the overall availability of mental training for your team and athletes. To ensure that intercollegiate athletes are receiving mental training in forms that are effective, we are seeking your expert opinions in this important research study.

On Monday, June $23^{\text {rd }}$, you will receive and email with the subject line: "Study for NCAA Coaches." The short survey in this email will allow you to provide your preferences related to mental training available to your team and athletes via a mobile app. Your expert opinion as a coach is important and greatly appreciated.

If you would like to complete the short survey now, please click:

http://coachsurvey.cloudssi.com/login.html

We are happy to share the findings from this study with. Thank you in advance for your time and continued dedication to your team and athletes. Best wishes to you and your program.

Sincerely,

The WVU Mental Training Research Team

Raymond Prior, Doctoral Candidate

Jack Watson, Department Chair \& Former Association of Applied Sport Psychology

President

If you have any questions about the survey, please contact Raymond Prior, Doctoral Candidate, at rprior@mix.wvu.edu or 505-235-4486, or Dr. Jack Watson, Department Chair, at jack.watson@mail.wvu.edu or 304-293-0873. Please note, participation in this study is voluntary and responses are completely confidential. The West Virginia University Institutional Review Board has approved this study and has acknowledgement of this study on file.

If you do not wish to receive further emails from us, please click the link below, and you will be automatically removed from our emailing list. [Remove Link] 
Appendix D

Recruitment Email 2: Email Invitation to Participate

Dear Coach,

Many NCAA coaches are currently utilizing mental training services to help improve athletic performance for their teams and athletes. The WVU mental training research team is dedicated to improving mental training services and forms of delivery for providing mental training to NCAA athletic programs.

In an effort to better serve NCAA programs, it is critical that we understand your preferences for how to best delivery mental training. Your participation in our short online survey, which can be completed in less than 10 minutes, ensures that your expert views are guiding the delivery of mental training to NCAA programs. We are happy to provide you with a summary of the findings.

Please click the link below to activate your survey:

http://coachsurvey.cloudssi.com/login.html

Your responses are anonymous and completely confidential. Opening the survey above will automatically remove your email address from our email list.

If you have already completed the survey, this official invite is that last email that you will receive.

Thank you for your time and dedication to your team and athletes.

Sincerely,

The WVU Mental Training Research Team

Raymond Prior, Doctoral Candidate

Jack Watson, Department Chair \& Former Association of Applied Sport Psychology

President

If you have any questions about the survey, please contact Raymond Prior, Doctoral

Candidate at rprior@mix.wvu.edu or 505-235-4486, or Dr. Jack Watson, Department Chair at jack.watson@mail.wvu.edu or 304-293-0873. Please note, participation in this study is voluntary and responses are completely confidential. The West Virginia University Institutional Review Board has approved this study and has acknowledgement of this study on file.

If you do not wish to receive further emails from us, please click the link below, and you will be automatically removed from our emailing list. [Remove Link] 
Appendix E

Recruitment Email 3: Email Reminder

Dear Coach,

Over the past few weeks we have sent you two emails regarding your preferences for a new form of delivery for mental training services to NCAA teams and athletes. We are writing again because your expert response is important for gaining an accurate representation of NCAA programs like yours. Your views are important so your team and athletes can be better served. Please take less than 10 minutes to complete a short online survey. We are happy to share the results of this study with you which we believe will benefit mental training professionals, coaches, and athletes alike.

Please click the link below to activate your survey:

http://coachsurvey.cloudssi.com/login.html

Your responses are anonymous and completely confidential.

Thank you for your time and dedication to your team and athletes.

Sincerely,

The WVU Mental Training Research Team

Raymond Prior, Doctoral Candidate

Jack Watson Department Chair \& Former Association of Applied Sport Psychology President

If you have any questions about the survey, please contact Raymond Prior, Doctoral Candidate at rprior@mix.wvu.edu or 505-235-4486, or Dr. Jack Watson, Department Chair at jack.watson@mail.wvu.edu or 304-293-0873. Please note, participation in this study is voluntary and responses are completely confidential. The West Virginia University

Institutional Review Board has approved this study and has acknowledgement of this study on file.

If you do not wish to receive further emails from us, please click the link below, and you will be automatically removed from our emailing list. [Remove Link] 
Appendix $F$

Recruitment Email 4: Final Email Contact

Dear Coach,

We have sent you a couple of emails about an important research study we are conducting with NCAA coaches around the country and would love to hear from you. The study is drawing to a close, and this is the last contact that will be made.

In an effort to better understand how mental training can be delivered to NCAA teams and athletes we are seeing your expert opinion on the matter. As a participant, we will be happy to provide you with a summary of findings related to NCAA coaches' preferences for delivering mental training.

The short online survey takes less than 10 minutes to complete. Please click the following link: http://coachsurvey.cloudssi.com/login.html

You responses in this study are completely voluntary and confidential. We appreciate your willingness to consider our request as we conclude this study to better understand NCAA coaches' preferences for a new form of providing mental training services.

Thank you for your time and dedication to your team and athletes.

Sincerely,

The WVU Mental Training Research Team

Raymond Prior, Doctoral Candidate

Jack Watson, Department Chair \& Former Association of Applied Sport Psychology

President

If you have any questions about the survey, please contact Raymond Prior, Doctoral Candidate at rprior@mix.wvu.edu or 505-235-4486, or Dr. Jack Watson, Department Chair at jack.watson@mail.wvu.edu or 304-293-0873. Please note, participation in this study is voluntary and responses are completely confidential. The West Virginia University Institutional Review Board has approved this study and has acknowledgement of this study on file.

If you do not wish to receive further emails from us, please click the link below, and you will be automatically removed from our emailing list. [Remove Link] 
Appendix $G$

Cover Letter

Dear Coach,

This letter is a request for you to take part in a research project to address NCAA coaches' preferences for a new form of delivering mental training in intercollegiate athletics. The project is being conducted by Raymond Prior in completion of his doctoral degree in Sport and Exercise Psychology at West Virginia University under the supervision of Dr. Jack Watson. To complete the short online survey, click the lick below. Your participation in the project is greatly appreciated and it should that less than 10 minutes.

\section{http://coachsurvey.cloudssi.com/login.html}

You involvement in this project is voluntary and will be kept completely confidential. Your name and institution will not be ask for at any point and any publications or presentations resulting from this project will report a summary of statistics only. You must be 18 years of age or older to participate in the study. The short online survey will not ask for any information that should lead back to your identity as a participant. You may skip any questions that you do not wish to answer and you may discontinue at any time. The West Virginia University Institutional Review Board has approved this study and has acknowledgement of this study on file.

Once again, your participation in this study is greatly appreciated, as it will help understand how to improve the delivery of mental training services to intercollegiate athletics. Thank you very much for your time. Should you have any questions, feel free to contact Raymond Prior, at rprior@mix.wvu.edu or 505-235-4486, or Dr. Jack Watson at jack.watson@ mail.wvu.edu or 304-293-0873. 


\section{Appendix $H$}

Internet-based Survey Part 2: CBC Sample Choice Set

If these three mental training mobile apps were available to your team's use which would you prefer?

(1 of 12)

\begin{tabular}{|c|c|c|c|c|}
\hline Price & Less than $\$ 200$ & Between $\$ 200-\$ 400$ & Less than $\$ 200$ & None \\
\hline $\begin{array}{r}\text { Tracking Athlete } \\
\text { Use }\end{array}$ & No Tracking & Limited Tracking & $\begin{array}{c}\text { Comprehensive } \\
\text { Tracking }\end{array}$ & \\
\hline $\begin{array}{r}\text { Recommendation } \\
\text { Source }\end{array}$ & $\begin{array}{c}\text { No } \\
\text { Recommendation }\end{array}$ & $\begin{array}{c}\text { External } \\
\text { Recommendation }\end{array}$ & $\begin{array}{c}\text { Internal } \\
\text { Recommendation }\end{array}$ & \\
\hline Daily Functions & $\begin{array}{l}\text { Does Not Include } \\
\text { Daily Functions }\end{array}$ & $\begin{array}{c}\text { Includes Daily } \\
\text { Functions }\end{array}$ & $\begin{array}{l}\text { Includes Daily } \\
\text { Functions }\end{array}$ & \\
\hline $\begin{array}{r}\text { Teams Using the } \\
\text { App }\end{array}$ & $\begin{array}{l}\text { Unaware of Any } \\
\text { Other Teams Using } \\
\text { the App }\end{array}$ & $\begin{array}{c}\text { Aware of Other } \\
\text { Teams Using the App }\end{array}$ & $\begin{array}{c}\text { Unaware of Any } \\
\text { Other Teams Using } \\
\text { the App }\end{array}$ & \\
\hline Content Creators & $\begin{array}{c}\text { Content Creators } \\
\text { Who Work With } \\
\text { Other Successful } \\
\text { Teams }\end{array}$ & $\begin{array}{c}\text { Content Creators } \\
\text { Who Do Not work } \\
\text { With Any Successful } \\
\text { Teams }\end{array}$ & $\begin{array}{c}\text { Content Creators } \\
\text { Who Do Not Work } \\
\text { With Any } \\
\text { Successful Teams }\end{array}$ & \\
\hline Please select one: & 0 & 0 & 0 & 0 \\
\hline
\end{tabular}

Would you purchase the mental training mobile app that you chose above for your team?

$\begin{array}{ll}\circ & \text { Yes } \\ \circ & \text { No }\end{array}$

To view descriptions of the mental training mobile app variations, move your cursor over the text in the left column. When completed, please click the next arrow. 


\section{Appendix I}

\section{Internet-based Survey Part 3: Demographics Questionnaire}

1. If you were purchasing a mental training mobile app, what option related to Price would you prefer most?
a) Less than $\$ 200$ per athlete
b) Between $\$ 200$ - $\$ 400$ per athlete
c) More than $\$ 400$ per athlete

2. If you were purchasing a mental training mobile app, what option related to Tracking Athlete Use would you prefer most?
a) No tracking of athlete use
b) Limited tracking of athlete use
c) Comprehensive tracking of athlete use

3. If you were purchasing a mental training mobile app, what option related to Recommendation Source would you prefer most?
a) No recommendation
b) Recommendation from a coach or athletic director from another institution
c) Recommendation from a coach or athletic director from your institution

4. If you were purchasing a mental training mobile app, what option related to Daily Functions would you prefer most?
a) Does not include daily functions
b) Includes daily functions

5. If you were purchasing a mental training mobile app, what option related to Teams Using the App would you prefer most?
a) Unaware of other teams using the app
b) Aware of other teams using the app

6. If you were purchasing a mental training mobile app, what option related to Content Creators would you prefer most?
a) Content creators who do not work with any successful teams
b) Content creators who do work with other successful teams

7. Do you think a mental training mobile app with the preferred options you have just selected would be beneficial for your team and athletes?
a) Yes
b) No. Please explain.

8. What is your gender?
a. Male
b. Female
c. Choose not to disclose 
9. What year were you born?

a.

10. How many years have you been coaching at the NCAA level?

a.

11. What is the gender of the NCAA student- athletes you are currently coaching?
a. Male
b. Female
c. Coed
d. Coach both a men's and women's team

12. What NCAA sport(s) are you currently coaching?
a. Baseball
m. Outdoor Track \& Field
b. Basketball
n. Lacrosse
c. Bowling
o. Rifle
d. Cross Country
p. Rowing
e. Diving
q. Skiing
f. Fencing
r. Soccer
g. Field Hockey
s. Softball
h. Football
t. Swimming
i. Golf
u. Tennis
j. Gymnastics
v. Volleyball
k. Ice Hockey
w. Water Polo
1. Indoor Track \& Field
x. Wrestling

13. Is the NCAA sport you are currently coaching classified as a revenue sport at your institution?
a. Yes
b. No

14. Does your current institution have access to mental training (sport psychology) services or a mental training professional?
a. Yes
b. No
c. Unsure

15. Have you ever personally utilized the services of a mental training (sport psychology) professional?
a. Yes
i. If yes, go to question \#8
b. No
i. If no, go to question \#9 
16. In general, how satisfied were you with your experience working with a mental training (sport psychology) professional?
a. Not at all satisfied
b. Slightly satisfied
c. Very satisfied
d. Extremely satisfied

17. How frequently in a typical day do you use a digital device such as a smartphone or a tablet?
a. I do not use a digital device
b. Only once or twice a day
c. A few times a day
d. Several times a day
e. Consistently throughout the day

18. How frequently in a typical day do you use a digital device to access mobile apps?
a. I do not use a digital device
b. Only once or twice a day
c. A few times a day
d. Several times a day
e. Consistently throughout the day 
Appendix $J$

Internet-based Survey Part 4: Separate Follow-Up Page

Dear Coach,

Thank you for completing our survey! We wish you and your program the very best.

To receive a summary of the final results of this study, please provide your email address below:

Email:

Thank you again.

The WVU Mental Training Research Team

If you have any questions about the survey, please contact Raymond Prior, Doctoral Candidate at rprior@mix.wvu.edu or 505-235-4486, or Dr. Jack Watson, Department Chair at jack.watson@mail.wvu.edu or 304-293-0873.

Thank you again.

The WVU Mental Training Research Team

Raymond Prior, Doctoral Candidate

Jack Watson, Department Chair \& Former Association of Applied Sport Psychology

President 
Appendix $K$

Expanded Review of Literature

\section{Sport Psychology in Intercollegiate Athletics}

Since its inception in 1906, the National Collegiate Athletic Association (NCAA) has become the primary governing body for intercollegiate athletics and aims to protect the approximately 430,000 student-athletes (NCAA, 2012a) that compete at the 1,066 active member institutions (Cockley, 2008; NCAA, 2012b). Although intercollegiate athletes are classified as amateur, the demands for student-athletes to excel athletically and academically are high (Ferrante \& Etzel, 2009) and are often tied to significant financial profits for the athletic departments, institutions, and the NCAA. To help athletes meet these demands the NCAA provides a number of services and resources to student-athletes to assist them in the classroom, on the playing field, and with their personal lives (Jae Ko, Durrant, \& Mangiantini, 2008). Often these services and resources include coaches, academic advisers, tutors, strength and conditioning services, athletic trainers, doctors, career counselors, mental health professionals, and sport psychology professionals. Many of these services have been fully integrated into intercollegiate athletics for many years (Weinberg \& Williams, 2010). Sport psychology services aim to provide student-athletes with assistance building skills that improve performance under pressure, motivation, self-control, communication, leadership, decision making, appropriate focus, and self-awareness (Danish, Petitpas, \& Hale, 1992). However, despite these potential benefits to utilizing sport psychology services, less than half of NCAA Division I athletic departments report having sport psychology services available for their student-athletes and even fewer Division II and III athletics departments offer these services to their student-athletes (Kornspan \& Duve, 2006; Wrisberg, Withycombe, Simpson, Loberg, \& Reed, 2012). The mismatch between sport psychology services and other services offered to NCAA student-athletes requires more investigation. Continued examination of 
those that control the sport psychology services available to student-athletes and the methods of delivery of those services may improve the integration of sport psychology services within intercollegiate athletics.

Individual institutions. Although the NCAA has rules and regulations outlining fair competition, recruiting academic standards, and the services that are available to studentathletes, individual institutions and athletic departments are expected to enforce and selfmonitor their respective compliance with the NCAA's rules and regulations (Hamilton, 2005). With the power to self-regulate, the role of athletes and the priority placed upon competition and student-athletes often differs from institution to institution. To keep up with the growth of competitive NCAA athletics financially, competitively, and organizationally, individual institutions and their respective athletic departments have adopted detailed administrative structures and positions with a variety of departmental affiliations and responsibilities. Common positions include athletic directors, associate athletic directors, academic advisors, marketing directors, athletic trainers, and coaches. These positions are in place to meet the NCAA's cores values related to protecting and serving student-athletes by providing them with resources and services to succeed academically, athletically, and socially (NCAA, 2012b). However, because the NCAA provides individual institutions the power to act independently within NCAA guidelines, many institutions create their own organizational structures, administrative positions, and philosophical approaches to athletics (NCAA, 2012b). As such, not every institution has the same positions and services available to student-athletes. The decisions to select and offer services to student-athletes often lies with key members of the administrative structure within athletic departments, namely athletic directors and coaches. 


\section{Delivery of Sport Psychology Services in Intercollegiate Athletics}

Despite the continued growth of applied sport psychology as a profession, sport psychology services and positions remain underutilized in intercollegiate athletics (Connole, 2013). Over the last 25 years, applied sport psychology has evolved and gained increased interest from athletes, coaches, and the public (AASP, 2012). Yet even with this growth and increased interest, the number of sport psychology professionals placed within athletic organizations remains low. Several research studies examining sport psychology association members and graduates of sport psychology academic programs have found that finding fulltime sport psychology work is rare (Meyers, Coleman, Whelan, \& Mehlenbeck, 2001; Williams \& Scherzer, 2003). Although applied sport psychology has become more popular in many fields including business and organization settings, performing arts (Hays, 2009), the military (Dewiggins, Hite, \& Alston, 2010), and exercise settings (Landers \& Arent, 2001), work in applied sport psychology remains largely a part-time vocation for the vast majority of sport psychology professionals (Williams \& Scherzer, 2003).

The part-time use of sport psychology services is no more apparent than in intercollegiate athletics. Intercollegiate athletics continue to become more demanding on athletes and coaches and more competitive from year to year placing more and more importance on mental toughness and sustained performance. Yet even with this continued evolution, sport psychology services are not available at many institutions within the NCAA. More than a decade ago, an examination of the use of sport psychology services in 96 NCAA Division I athletic departments revealed that only about $50 \%$ had some form of sport psychology services available (Voight \& Callaghan, 2001). Not only did Voight and Callaghan (2001) find that sport psychology services were underutilized compared to other performance related services, but they also found a wide range of employment types for sport psychology professionals at the institutions with sport psychology services available. 
Specifically, $20 \%$ of sport psychology professionals were hired on a part-time basis by individual teams, while other sport psychology professionals were hired by athletic departments in part-time (10\%) or full-time (7\%) positions. In total, Voight and Callaghan found ten different positions providing sport psychology services within the institutions sampled. At some institutions the role of sport psychology professional was filled by individuals affiliated with the university that may not have had any training in applied sport psychology such as faculty, graduate students, practicum students, counselors, academic counselors, and sports medicine professionals. These findings are informative considering Voight and Callaghan only sampled Division I institutions citing the financial resources and emphasis placed on winning within the larger, more competitive athletic conferences would lead to more use of sport psychology services.

Building upon Voight and Callaghan's (2001) initial survey of Division I institutions, Kornspan and Duve (2006) investigated the use of sport psychology services in all three divisions of intercollegiate athletics and found that only $30 \%$ of the athletic directors surveyed reported having sport psychology services available in one form or another. Of the 286 athletic directors surveyed, $24 \%$ reported access to a sport psychology professional at their respective institutions and $6 \%$ reported access to sport psychology services via another professional position (e.g., other staff member, volunteer). Moreover, Kornspan and Duve also found a significant discrepancy between NCAA Division I institutions' use of sport psychology services and NCAA Division II and III institutions' use of sport psychology services. Specifically, $48 \%$ of Division I institutions reported having sport psychology services available compared to only $11 \%$ of Division II and III institutions. These results provided evidence supporting the contention made by Voight and Callaghan that limited resources lead to a decreased use sport psychology services. 
Given the demanding and competitive nature of intercollegiate athletics, the underutilization of sport psychology services in all the divisions of NCAA athletics is concerning. Results from surveys of NCAA institutions highlight the underutilization of sport psychology services within NCAA athletics, specifically, within institutions with limited financial resources (Kornspan \& Duve, 2006; Voight \& Callaghan, 2001). These seminal surveys of intercollegiate athletes related to sport psychology were among the first to provide a picture of sport psychology services in the NCAA (Bemiller \& Wrisberg, 2011). Although these results are valuable and have guided subsequent research examining sport psychology positions in intercollegiate athletics (Connole, 2013), the scope of sport psychology services has evolved significantly since these studies were completed. These studies also highlight an empirical emphasis on a traditional sport psychology position within intercollegiate athletics (e.g., employed by athletic department, private contractor) and sport psychology services delivered in person. The lack of access to sport psychology services in intercollegiate athletics may be better addressed by presenting and evaluating newer forms of delivering sport psychology services. Newer forms of sport psychology services may serve to improve both athletic directors' and coaches' perceptions of these services and improve access to NCAA student-athletes.

\section{NCAA Athletic Administrators' and Sport Psychology Services}

A large body of literature provides evidence for the positive effects of sport psychology services and the use of mental skills for individual athletes, coaches, and teams (Sheard \& Golby, 2006). However, sport psychology services remain underutilized within university athletic settings (Bemiller \& Wrisberg, 2011; Zakrajsek, Steinfeldt, Bodey, Martin, \& Zizzi, 2013). Unlike strength and conditioning and athletic training services that are fully integrated into sport at nearly every level (Weidner \& Henning, 2002), there is no empirical literature indicating that sport psychology services are nearing full integration at any level of 
sport. The most recent research examining the use of sport psychology services at the intercollegiate level show that between 24\% (Wilson, Gilbert, Gilbert, \& Sailor, 2009) and 53\% (Voight \& Callaghan, 2001) of NCAA Division I athletic departments report using sport psychology services in some form. Of the positions that have the power to influence the use of sport psychology services in intercollegiate athletics, athletic directors in the NCAA are perhaps the most powerful and their perceptions of sport psychology services are a significant factor influencing the placement of sport psychology professionals in NCAA athletic departments (Connole, 2013)

Like Kornspan and Duve (2006) before them, Wilson and colleagues (2009) targeted NCAA athletic directors. Athletic directors at 376 NCAA institutions with at least one NCAA Division I sport were surveyed about their perceptions of sport psychology services and employment of sport psychology professionals. Of the 72 athletic directors who completed the survey, less than a fourth (23.6\%) reported having a sport psychology professional employed by their athletic department. Although this finding supports previous research highlighting the lack of sport psychology positions in intercollegiate athletics, Wilson et al. (2009) also revealed important information about athletic directors' attitudes toward sport psychology. Specifically, Wilson and colleagues found that athletic directors with previous exposure to sport psychology were more likely to report confidence in sport psychology services and a higher importance of sport psychology services than athletic directors with no previous exposure. Overall, results from the survey indicate that athletic directors believe that sport psychology professionals could increase athletes' ability to perform under pressure, fine-tune performance, and improve overall mental toughness. In short, Wilson et al. (2009) suggest that athletic directors have an interest in sport psychology services and report a variety of perceived benefits to using services. However, Wilson et al. (2009) also note a discrepancy 
between positive attitudes toward sport psychology services and availability of sport psychology services at their respective institutions.

More recently, when asked about their perceived benefits of using sport psychology services, NCAA Division I athletic administrators reported that they see value that these services improve athletic performance in athletes (Wrisberg, et al., 2012). Wrisberg and colleagues (2012) surveyed NCAA Division I athletic directors related to their perceptions of sport psychology services. These researchers found that of the 96 NCAA athletic departments surveyed, only $37.5 \%$ had sport psychology services available. Along with another report of the underutilization of sport psychology services in the NCAA, these researchers also note that athletic directors viewed sport psychology services related to performance enhancement higher than services related to personal issues. Moreover, athletic directors' highest rated services included improving focus, building confidence, controlling anxiety, performing under pressure, and controlling emotions as the most important services. Additionally, three times as many athletic directors were willing to encourage the use of sport psychology services if they were available compared to those who were unwilling. However, like previous survey research related to athletic directors and sport psychology services (Wilson et al., 2009), Wrisberg et al. (2009) also noted a discrepancy between the attitudes of athletic directors toward sport psychology services and a reluctance to employ sport psychology professionals.

Like Wrisberg and colleagues (2012) the most recent study targeting athletic directors found that two thirds of NCAA athletic administrators reported interest in hiring a sport psychology professional, provided the position met their preferences (Connole, 2013). Specifically, Connole (2013) found that athletic administrators found positions that were designed for part-time athletic department employees, providing both mental health and performance focused services, paid via annual salary, and working with athletes, teams, and 
athletics staff members as the most attractive positions. These results confirmed previous research but also provided context for athletic directors' sport psychology position preferences. The perceptions of athletic administrators are also important given their influence over the resources and services provided to coaches, athletes, and teams at the collegiate level (Wrisberg et al., 2012). Athletic directors hold significant influence related to making sport psychology services available within NCAA athletic departments. However, the studies targeting athletic directors' attitudes and perceptions of sport psychology services are limited by the form of delivery of sport psychology services. Specifically, Wilson et al. (2009), Wrisberg et al. (2012), and Connole (2013) surveyed athletic directors about availability and interest toward employing a sport psychology professional. None of these studies presented alternate forms of providing sport psychology services that may greatly influence the gap between athletic directors' attitudes toward sport psychology services and actually making the services available.

\section{Coaches' Perceptions of Sport Psychology Services}

The perceptions of athletic administrators are important because of their roles and influence over the resources and services provided to coaches, athletes, and teams at the collegiate level (Wrisberg et al., 2012). In many cases, athletic administrators may find ways to include sport psychology services to a team at the request of a coach or coaches (Kornspan \& Duve, 2006). As such, the most important perceptions related to sport psychology services likely lie with coaches given their unique roles within sport and their relationships with athletic administrators and athletes (Voight \& Callaghan, 2001).

Given their relationships with athletes and integral roles within sport (Voight \& Callaghan, 2001), perhaps the most important perceptions related to sport psychology services lie with coaches. Information about coaches' perceptions of sport psychology services and the factors leading to coaches utilizing sport psychology services for themselves and their athletes 
are limited. Specifically, only a handful of studies have investigated coaches' perceptions of sport psychology services and coaches' preferred use of sport psychology. The majority of empirical investigation related to assessing attitudes and perceptions of sport psychology services are targeted toward assessing athletes. Athletes' attitudes and perceptions of sport psychology services are important, however, athletes' attitudes and beliefs are often impacted by the influence of coaches' attitudes and perceptions (Dieffenbach, Gould, \& Moffett, 2002). The examination of coaches' attitudes and perceptions of sport psychology services is an integral area of research for the field and continued examination will help provide sport psychology professionals with information to improve service provision to coaches and athletes (Zakrajsek et al., 2013).

\section{Measuring Coaches’ Perceptions of Sport Psychology Services}

Research examining coaches' attitudes and perceptions of sport psychology services is limited but increasing in effectiveness and informational value through the development of the Sport Psychology Attitudes Revised-2 form (SPARC-2; see Zakrajsek, Martin, \& Zizzi, 2011; Zakrajsek \& Zizzi, 2007; 2008). The SPARC-2 was modified from the Sport Psychology Attitudes Revised form that measures athletes' attitudes toward sport psychology consulting services (see Martin, Kellmann, Lavalle, \& Paige, 2002; Martin, Wrisberg, Beitel, \& Lounsbury, 1997). The SPARC-2 measures coaches' attitudes and perceptions of sport psychology consulting services and assesses additional constructs including stigma tolerance, confidence in sport psychology consultation, personal openness, and cultural preference.

Stigma tolerance. Stigma tolerance reflects a negative attitude toward sport psychology and a belief that others will label athletes or coaches using sport psychology services as having mental problems (Martin et al., 1997; Zakrajsek \& Zizzi, 2007). In a study using the SPARC-2 to examine track and swimming coaches' intentions to use sport psychology services, Zakrajsek and Zizzi (2007) found that stigma tolerance predicted 
coaches' intentions to utilize sport psychology services. Specifically, as stigma tolerance increased, coaches' intentions to utilize sport psychology services decreased. These results are consistent with previous research that suggests coaches at all levels of sport continue to report negative undertones related to sport psychology and that stigma tolerance is a significant barrier to coaches utilizing sport psychology services (Kremer \& Merchant, 2002; Pain \& Harwood, 2004).

Confidence in sport psychology consultation. Confidence in sport psychology consultation reflects an individual's belief that sport psychology consulting services can be effective for improving performance (Martin et al., 1997; Zakrajsek \& Zizzi, 2007). The level of confidence in sport psychology consulting services is a representation of the amount to which an individual believes mental skills training will be a useful investment (Anderson, Hodges, Lavalle, \& Martin, 2004). Recently, researchers have found that the most significant predictor of intentions to use sport psychology services is confidence in sport psychology consulting services (Anderson et al., 2004; Zakrajsek \& Zizzi, 2007; Zakrajsek et al., 2011). Thus, a lack of confidence in sport psychology consulting services is likely the strongest barrier to utilization of sport psychology services.

Personal openness. Personal openness is a person's willingness to try sport psychology consulting services and mental skills training (Martin et al., 1994; Zakrajsek \& Zizzi, 2007). Personal openness directly pertains to an athlete's or coach's willingness to discuss concerns, goals, fears, and other potential issues with a sport psychology consultant (Nelson, 2008; Zakrajsek et al., 2011). Personal openness has also been shown to predict coaches' intentions to use sport psychology services (Zakrajsek et al., 2011). Specifically, coaches with higher levels of personal openness had stronger intentions to utilize sport psychology services. 
Cultural preference. Cultural preference is referred to as the amount to which an individual identifies with his or her own cultural background as well as a preference for working with a sport psychology professional with a similar background and experiences (Martin et al.,1994; Zakrajsek \& Zizzi, 2007). Identification with one's own culture, race, ethnicity, or country of origin is an influential factor in one's attitude toward and perceptions of sport psychology services (Martin, 2005; Martin et al., 2002). Zakrajsek and Zizzi (2007; 2008) suggest that some coaches' preferences for working with a sport psychology professional may be influenced by their own cultural background, the cultural background of their athletes, and the culture of their respective sports.

\section{Coaches' Use of Sport Psychology Services}

Assessing the coaches' attitudes and perceptions of sport psychology services and the factors that influence coaches' decisions to utilize these continues to be an important topic. According to Zakrajsek and Zizzi (2007), only about $20 \%$ of coaches sampled currently use sport psychology services in some form. Moreover, Zakrajsek and Zizzi (2008) suggested that this low percentage of coaches' who utilized sport psychology services highlights the fact that many coaches have yet to make the transition from an interest in sport psychology services to actually using mental training as part of their practice and training.

Barriers to utilizing sport psychology services. Athletic departments and coaches have commonly reported limited funds and lack of time as significant barriers to using mental training services (Gould, Medberry, Damarjian, \& Lauer, 1999; Haslam, 2004; Kremer \& Marchant, 2002; Pain \& Harwood, 2004; Voight \& Callaghan, 2001). Previous research also indicates that accessibility to sport psychology services, such as knowing how to find and contact a sport psychology professional, may also be limiting coaches' use of sport psychology services (Scully \& Hume, 1995). As such, the limited forms of delivery that sport psychology services have traditionally, and are currently being offered, may continue to 
contribute to coaches' limited exposure and familiarity to sport psychology services. Given the scope of coaches' attitudes and perceptions of sport psychology services and the documented barriers to utilizing sport psychology services, it is logical to consider how the method of service delivery may influence coaches' attitudes and perceptions toward sport psychology services. Newer forms of delivering sport psychology services may help to circumvent barriers such as time and money, as well as, limit barriers in the form of stigma tolerance and cultural preferences.

\section{Coach characteristics and utilization of sport psychology services. Established}

research examining factors that influence coaches' decisions to utilize sport psychology services have also examined coaches' characteristics. In general, compared to coaches with no experience with sport psychology services, coaches with previous experiences and exposure to sport psychology services are more open to utilizing these services, less likely to stigmatize sport psychology services, are more likely to encourage their athletes to utilize sport psychology services, and have expectations that are more accurate related to the potential benefits of sport psychology services (Wrisberg et al., 2010; Zakrajsek \& Zizzi, 2007). Level of education and years of coaching experience also influenced coaches' attitudes and perceptions toward the use of sport psychology services. Specifically, coaches holding doctorate or master's degrees reported more confidence in sport psychology services compared to coaches with a bachelor's degree or high school diploma (Zakrajsek et al., 2011). Further, older coaches (i.e., age 50 and older) and coaches with more years of experience (i.e., more than 15 years of coaching experience) were more open to utilizing sport psychology services and associated less of a negative stigma with sport psychology services compared to younger (i.e., age 20-29) and less experienced coaches (i.e., less than 7 years of coaching experience; Zakrajsek et al., 2011). Finally, female coaches reported more personal openness toward utilizing sport psychology services, associate less of a negative stigma related to sport 
psychology services, and more confidence in sport psychology services than male coaches (Wrisberg et al., 2010; Zakrajsek \& Zizzi, 2007). Identifying the personal characteristics and factors that influence coaches' attitudes and perceptions of sport psychology services and influence their decisions to utilize these services is important and provides valuable insights for sport psychology professionals to consider. However, to date, coaches' attitudes and perceptions toward the delivery method of sport psychology services is relatively unexamined.

NCAA coaches and sport psychology services. The existing research related to college coaches' perceptions of sport psychology services provides valuable information about college coaches' intended and actual use of sport psychology services. In a survey of 815 NCAA Divisions I coaches perceptions of sport psychology services, Wrisberg and colleagues (2010) found that most coaches were in favor of a sport psychology consultant as a full-time member of the athletic department and that nearly $90 \%$ of coaches were willing to encourage their athletes to utilize sport psychology services. Although this information is promising for sport psychology professionals, coaches encouraging athletes to use sport psychology services takes minimal effort from coaches and does not require the coaches to invest any of their own money or allot practice time to sport psychology services. In the same study, only $43 \%$ of coaches reported wanting a sport psychology consultant present at practices and competitions (Wrisberg et al., 2010). These results further illustrate an interesting dynamic between coaches wanting sport psychology services to be available, but a reluctance to utilize those services. Reasoning for coaches' support or lack of support related to having a sport psychology consultant readily available for their respective team and athletes remains unclear. However, to date, researchers have identified several key factors that influence coaches' decisions to start and continue sport psychology services including: positive perceptions of the value of mental skills use and training, confidence in the positive 
effects of utilizing sport psychology services, and frequent and consistent exposure to sport psychology and mental training services (Wrisberg et al., 2010; Zakrajsek, Martin, \& Zizzi, 2011). Given these factors, it is reasonable to assume that coaches who value mental training, feel confident in sport psychology services, and have positive experiences with sport psychology services will be more likely to make sport psychology services available to their teams and endorse sport psychology services to other coaches (Zakrajsek et al., 2013). Recommendations from other respected coaches are often a powerful factor for influencing decisions relative to the utilization of sport psychology services for coaches with limited access or understanding of sport psychology (Haslam, 2004). These identified factors and the vast network of coach-to-coach relationships demonstrate the importance of continued examination of coaches' perceptions of sport psychology services. It also sheds light on the need to further examine methods of delivery in which sport psychology services can meet the needs of coaches and improve their perceptions and utilization of sport psychology services. This research stands to benefit athletes, coaches, and sport psychology consultants by helping to increase the quality and form of delivery of sport psychology services and reduce the number of real or perceived barriers to sport psychology service provision.

Factors influencing coaches' decisions to use sport psychology services. Coaches hold a uniquely powerful role within sport at any level and especially within intercollegiate athletic departments because of their relationship to athletes who are ultimately the beneficiaries of sport psychology services and mental training. Research examining relationships between coaches and athletes suggest that the coach-athlete relationship is one of the most significant within sport and has a strong influence in an athlete's development (Jowett \& Cockerill, 2003). By the nature of the position, coaches have tremendous influence and even control over an athlete or team's performance, skill development, attitudes, values, beliefs, and structure of daily life, often manufacturing a unique and powerful bond between 
coaches and their athletes (Jowett \& Chaundy, 2004; Yang \& Jowett, 2013). Additionally, coaches are the gatekeepers to their teams and individual athletes and control who is allowed to provide resources and services to their respective teams. If coaches have knowledge of a resource or service and find it valuable, the coach is more likely to utilize that resource or service and make it available to his or her athletes (Voight \& Callaghan, 2001). Most often, coaches are the final decision makers related to starting and maintaining sport psychology services offered to their teams (Voight \& Callaghan, 2001). More recent research suggests that college coaches report that mental skills are important to the success of their respective teams, and indicate that they have an interest in sport psychology services being available to their teams. However, despite the indicated importance of mental skills and the value of having sport psychology services available, usage rates of sport psychology at the intercollegiate level hover between $20 \%$ and 30\% (Wrisberg et al., 2010; Zizzi, 2007). This discrepancy, like that of athletic directors, between what coaches report and what they do related to usage of sport psychology services and the use of mental skills, highlights the need for more specific information related to coaches perceptions of sport psychology services.

Sport type and culture. Although more information about what influences coaches' decisions to use or not use sport psychology services is needed, there are a few factors that have been empirically examined. One area of interest is sport type. Research examining sport types indicates that physical contact sport athletes are less likely to utilize sport psychology services than non-contact sports (Martin, 2005). Researchers suggest that physical contact sports such as wrestling and hockey place higher value on toughness and traditional male gender roles within their sports (Martin, Lavelle, Kellmann, \& Page, 2004). Compared to noncontact sports where utilizing sport psychology services is generally more accepted, physical contact sports often see utilizing sport psychology services with a negative stigma and thus poses a threat to maintaining an image of toughness and masculinity (Good \& Wood, 1995; 
Martin et al., 1997). As such, seeking sport psychology services is less likely for these coaches and athletes because utilizing these services would be perceived as an indication of weakness or femininity (Steinfeldt et al., 2011; Steinfeldt, Steinfeldt, Speight, \& England, 2009). Given the cultural values of physical contact sports and the negative stigmas attached to sport psychology services, underutilization of sport psychology services is not surprising within these sports.

Coaches' attitudes toward sport psychology services. Coaches' attitudes play an integral role in creating and maintaining the culture of sport and the teams they coach, as well as the development of mental toughness within their athletes (Gucciardi, Gordon, Dimmock, \& Mallet, 2009). Specifically, coaches' attitudes toward mental toughness and sport psychology services likely directly influence their teams and athletes' perceptions and utilization of sport psychology services (Wrisberg et al., 2012). This influence can lead to a continued cycle of negative attitudes and underutilization of a variety of helping services in certain sports. For example, Zakrajsek, Martin, and Zizzi (2011) surveyed American highschool football coaches' attitudes toward sport psychology consultation and found that only $3 \%$ of coaches have used sport psychology services and that $62 \%$ of coaches did not intend to use sport psychology services in the next six months. This study highlighted the cultural values of a physical contact sport and the lack of utilization of sport psychology services likely to exist in a similar capacity at the intercollegiate level.

After understanding the link between coaches, sport type, and the use of sport psychology services, it is important to understand the factors that might influence coaches' intentions of utilizing sport psychology services. Zakrajsek and Zizzi (2007) found that confidence in sport psychology services, stigma tolerance, and expectations of sport psychology services significantly influenced college swimming and college track and field coaches' intentions to utilize sport psychology services. Specifically, confidence in sport 
psychology services contributed more to the difference in the intent to utilize sport psychology services than stigma tolerance and expectations of sport psychology services. Additionally, Anderson and colleagues (2004) found that in a mixed sample of world-class, international, developmental, and junior level athletes, confidence in sport psychology services predicted intentions to use sport psychology services. These two studies highlight the importance of the perceived effectiveness of sport psychology services toward the intentions of utilizing such services. Coaches' and athletes' confidence in sport psychology services is likely influenced by a variety of factors such as positive exposure to mental skills training and a recommendation from a respected coach (Martin, 2005). For example, in a survey of junior tennis coaches, Gould, Medberry, Damarjian, and Lauer (1999) found that coaches reported that availability of mental toughness resources and mental skills delivered in a time-efficient form would influence their confidence in sport psychology services. There is evidence to show that confidence in sport psychology services and the method of delivering sport psychology services influences coaches' intentions to utilize sport psychology services. However, none of these studies tracked the actual behavior of coaches relative to utilizing sport psychology services. More research is needed that investigates coaches' confidence in sport psychology services related to the delivery method of those services.

Information gathering about clients' and potential clients' perceptions, attitudes, expectations, and willingness to utilize sport psychology services is vital to providing better sport psychology services to a wide array of clients, and to increasing the effectiveness of marketing and delivery of sport psychology services (Zakrajsek, Martin, \& Zizzi, 2011). Given the value of gaining information for clients and potential clients and the unique position that coaches hold in the use of sport psychology services, understanding coaches perceptions related to newer forms of delivery for sport psychology services is crucial for providing services to the athletes they coach. 
Initial research directed toward coaches' perceptions of sport psychology services was limited and focused on Olympic level coaches' evaluation of sport psychology services. In these studies, coaches' reported the importance of a sport psychology consultant's ability to "fit in" and work in a non-intrusive manner (Gould, Murphy, Tammen, \& May (1991). More recent research has identified more specific factors related to coaches' perceptions of sport psychology services such as exposure to sport psychology services (Zakrajsek, Martin, \& Zizzi, 2011). As such, the perception of the quality of sport psychology services is apparent. What makes understanding coaches' perceptions of sport psychology services even more interesting and complicated is the infusion of technology. With the rapid growth and ability for technology to influence the delivery of sport psychology services, it is logical to examine coaches' perceptions of different delivery methods that may be cheaper, easier, and more coach friendly. Given that coaches remain the gatekeepers, especially at the intercollegiate level, for providing services to a tech-savvy generation of athletes, gaining more insight into their perceptions of these services delivered in newer forms is likely to benefit athletes, coaches, and sport psychology professionals alike.

\section{Athletes' Perceptions of Sport Psychology Services}

Like research directed toward athletic directors and coaches, research examining athletes' perceptions of sport psychology services have identified a variety of variables that influence athletes' attitudes toward sport psychology. The most prominent variables influencing athletes' attitudes toward sport psychology include athlete gender, racial and cultural background, previous experience with sport psychology, the sport type, and the level of competition (Anderson et al., 2004; Martin, 2005; Martin et al., 1997; 2002; Wrisberg, Simpson, Loberg, \& Withycombe, 2009). Several studies have found that female athletes are more receptive to and likely to seek sport psychology services than male athletes (Anderson et al., 2004; Martin, 2005; Martin et al., 1997; 2002; Wrisberg et al., 2009). Moreover, athletes 
with previous experiences with sport psychology report greater confidence in sport psychology services and are more likely to seek out sport psychology services (Anderson et al., 2004; Lubker et al., 2008; Martin et al., 2012; Wrisberg et al., 2009). However, researchers also note that the previous exposure to sport psychology services may be dependent upon the quality of the previous experiences (Wrisberg et al., 2009). Researchers have also found mixed results when examining differences of how various racial and ethnic groups view sport psychology. Early research by Martin et al. (1997) found that Black athletes were less receptive to sport psychology services compared to their White teammates. More recently, Wrisberg and colleagues (2009) found no significant differences when comparing Caucasian and racial minority student-athletes' receptivity of sport psychology services. However, the authors note that the change in racial minority athletes' receptivity to sport psychology services may be due to the changes in sport culture and attitudes related to race in sport in the time between the two publications. An examination of sport specific variables that influence athletes' attitudes toward sport psychology services also indicates that college athletes in non-contact sports reported higher confidence in sport psychology and fewer negative stigmas related to sport psychology than athletes in contact-sports (Martin, 2005).

Researchers have also examined athlete's perceptions of sport psychology professionals. In line with research indicating that professional appearance, specifically dress and physical build, play an important role and influences the perceptions of personal qualities, professional competence, and effectiveness of services offered (Hash, Munna, Vogel, \& Bason, 2003), Luker et al. (2005) examined athletes' perceptions of sport psychology professionals' body build and dress. In the study, researchers explored the impact of four personal characteristics of a potential sport psychology professional. These personal characteristics were classified into two categories: unchangeable and changeable. 
Unchangeable personal characteristics included ethnicity and gender, and changeable characteristics included body build and clothing. Using these personal characteristics, 86 Division I student-athletes were shown pictures of 11 difference combinations of sport psychology professionals displaying different combinations of the unchangeable and changeable personal characteristics. Participants rated each of the 11 pictures they were shown and then rated the strength of influence of the personal characteristics. The results of the study revealed that athletes' first impressions of sport psychology professionals were impacted by the sport psychology professionals' physical characteristics. Additionally, athletes' reported the changeable characteristics; build and dress, were more influential than unchangeable characteristics; gender and ethnicity. Specifically, athletes rated sport psychology professionals with a lean build and athletic clothing higher on perceived sport knowledge. Athletes also indicated they were more likely to seek sport psychology services from a sport psychology professional with a lean build and athletic dress than from a sport psychology professional with a large build and academic dress (Lubker et al., 2005). These results are important for understanding the more important factors that influence athletes' initial perceptions of sport psychology professionals. However, these results also offer practical implication for sport psychology professional looking to manufacture a positive first impression by giving direction for dress and body build.

In another study related to athletes' perceptions of sport psychology professionals, Lubker et al. (2009) investigated both athletes' and sport psychology professionals' perceptions of the characteristics that comprise an effective sport psychology professional. Lubker and colleagues asked 124 NCAA Division I and II student-athletes from a variety of sports and 80 sport psychology professionals with consulting experience to rate the importance of 31 qualities of sport psychology professionals. Through factor analysis, the 31 qualities were consolidated into five factors labeled as Positive Interpersonal Skills, Athletic 
Background, Sport Culture, Professional Status, and Physical Characteristics. Results indicated that both athletes and sport psychology professionals consider Positive Interpersonal Skills, Knowledge, and Sport Culture to be important to the effectiveness of sport psychology services provided to a team or athletes. However, results also indicated that compared to sport psychology professionals, athletes placed higher importance on factors and qualities related to professional status (is certified to work with athlete related to mental skills), athletic background (has experience playing competitive sport), and physical characteristics (body build) (Lubker et al., 2009). Researchers note that the results indicate an importance for sport psychology professionals to be aware of the differences between how their perceptions of effective sport psychology professionals may differ from those of the athletes they serve. The results from Lubker and colleagues investigation also support previous research indicating that athletes prefer sport psychology professionals perceived by them to be someone they can relate to and who is knowledgeable about their respective sport (Anderson, Miles, \& Robinson, 2004).

Although the research addressing athlete perceptions of sport psychology professionals provides valuable and practical insight for improving training of sport psychology professionals and decreasing the magnitude of barriers to providing sport psychology services, the form of delivering these services continues to illuminate many of these barriers. For example, physical appearance, although sometimes changeable, still requires a first impression of personal characteristics (Lubker et al., 2005). Moreover, characteristics such as professional status in the form of training and certification continue to evolve with the field of sport psychology. By examining newer forms of delivering sport psychology services, the perceptions of athletes' related to sport psychology services and effective sport psychology professionals may be improved and result in increased access to athletes in a variety of competitive realms. 


\section{Conjoint Analysis in Sport Psychology}

Recently, sport psychology researchers have used conjoint analysis to examine potential consumer preferences for sport psychology services in order to eliminate ceiling effects that appear in Likert-type data analysis (Connole, 2013; Lubker et al., 2012). Using a conjoint analysis also allows for the elimination of additional steps in data management to avoid overly positive ratings. This limitation is highlighted by sport psychology research examining athlete, coach, and administrator attitudes and perceptions of sport psychology services where researchers were forced to modify 5-point Likert-type scales to 3-point Likerttype scales during their analysis due to a lack of distribution across all five points (Wrisberg et al., 2009; 2010; 2011). Wrisberg et al. (2012) noted that the proportion of 'high' rating was disproportionately more than the 'moderate' or 'low' ratings leading to results that were difficult to generalize and use to make effective conclusions. By using a conjoint analysis rather than a Likert-scale, positive bias is eliminated as a confounding variable. Moreover, using a conjoint analysis allows researchers to evaluate multiple opinions from those utilizing services (e.g., athletes, coaches, and athletic administrators) for a variety of reasons and with different levels of importance on various components.

In a study using a conjoint analysis, Lubker et al. (2012) assessed a variety of changeable (attire, body build, interpersonal skills) and unchangeable (gender, race/ethnicity) attributes of a sport psychology professional by presenting college athletes with different conjoint profiles of potential sport psychology professionals. In contrast to a Likert-scale, a conjoint analysis allowed Lubker et al. (2012) to not only assess the importance of each attribute presented, but also assess the importance of each of the presented attributes in relation to each other. Using a conjoint design, researchers presented a variety of sport psychology attributes identified by previous research (Lubker et al., 2005; Lubker et al., 2008) and found that participants believed changeable attributes to be more important than 
unchangeable attributes. Specifically, participants' order of preferred attributes was professional status, athletic background, interpersonal skills, sport knowledge, attire, bodybuild, gender, and race/ethnicity. These responses provide a ranking of attributes in relation to each other and created the framework of what a preferred sport psychology professional profile would be (Lubker et al., 2012). Lubker and colleagues presented the first published sport psychology study using a conjoint analysis and highlighted how a market analysis methodology can provide greater depth of information related to consumer preferences, as well as eliminate limitations and confounding variables associated with of Likert-scale analysis.

In another sport psychology study utilizing a conjoint analysis, Connole (2013) examined the preferences of athletic administrators related to hiring a sport psychology professional. Connole designed a consumer marketing approach to investigate the NCAA market for sport psychology positions within athletic departments. Athletic administrators' preferences for sport psychology positions were compared based on characteristics that included time commitment, affiliation, payment, services, and clients. Results indicated that services and affiliation were the most important characteristics. Specifically, participants' order of preferred characteristics was services provided, affiliation to university, payment type, clients served, and time commitment. In terms of the most ideal profile, athletic administrators found positions that were designed for part-time athletic department employees, providing both mental health and performance focused services, paid via annual salary, and working with athletes, teams, and athletics staff members as the most attractive positions (Connole, 2013). A market simulation suggested over two-thirds of the sample would be interested in hiring a sport psychology professional fitting the aforementioned position profile. These results provide a more in-depth understanding of NCAA athletic administrators' preferred profile characteristics as well as provides evidence that sport 
psychology positions are valued in all forms, but may become more prevalent in the NCAA with continued effort to meet the desired characteristics for positions by athletic administrators.

Lukber et al. (2012) and Connole (2013) are the first sport psychology studies to use conjoint analysis in order to gain a more accurate assessment of consumer preferences related to sport psychology professionals and positions within intercollegiate athletics. With this better defined picture of characteristics for sport psychology professionals and positions, also comes a clear course of application with respect to marketing sport psychology services, curriculum development, supervision, the actual provision of services, and future research (Lubker et al., 2012). Perhaps the most important contribution from these studies is the use of a methodological design that views the participants as free market consumers of sport psychology services. By implementing a methodology and statistical approach that accounts for the perspective of the participant, direct application can be more accurately assessed. Examining consumer choice among a variety of possible products or services, while also accounting for trade-offs made based on variability of products and services, further strengthens this approach and maximizes marketability of a service or product (Green \& Srinivasin, 1978). In terms of sport psychology services, viewing athletes, coaches, and administrators as consumers and more than just clients, offers a wide array of benefits by serving them through more consumer-directed services. It also provides benefits in the form of direct application to sport psychology professionals offering applied sport psychology services to a free market of consumers. Although Lubker et al. (2012) provides a portrait of the preferred characteristics of a sport psychology professional and Connole (2013) provides a portrait of the preferred characteristics of a sport psychology position within the NCAA, they have not yet considered the methods in which sport psychology services are delivered. 
Literature related to the delivery of sport psychology services to college athletes and coaches' perceptions of sport psychology services is common, but limited given the constant growth of technology and number of tech savvy athletes. Several studies have provided valuable information related to sport psychology services over time. Researchers have explored potential barriers to service provision (Kornspan \& Duve, 2006), attitudes toward sport psychology consultants (Willson et al., 2009), and perceptions of benefits of sport psychology services and roles (Wrisberg et al., 2012). There is also a good deal of literature detailing the development of sport psychology professionals' positions and the services they provide (Bennett, 2007; Carr, 2007; Chamberlain, 2007; Etzel \& Watson, 2007; Flowers, 2007; Hack, 2007; Zillmer \& Gigli, 2007). In short, larger survey studies of NCAA athletics provide a foundational understanding of the services that have existed over the past decade and the perceptions of those services by the consumers. Unfortunately, these individual narratives and studies only examine sport psychology services delivered in person by a sport psychology consultant or mental health professional. Given the identified barriers to sport psychology service provision, the discrepancies between coaches' perceptions of sport psychology services and actual use of these services, and the use of mobile technology as a preferred communication style of the Millennial generation, it is important to question whether there are more effective methods of delivering sport psychology services. Utilizing more tailored methods of delivering sport psychology services may prove to reduce existing barriers to service provision, improve coaches' and athletes' perceptions of services, and improve the use of sport psychology services within intercollegiate athletics.

Recent research has identified athletes and coaches as consumers who have varying levels of interest in utilizing traditional forms of sport psychology services (Lubker et al., 2012; Wrisberg et al., 2009; 2010). Moreover, research examining the integration of sport psychology services and positions in intercollegiate athletics has called for more appropriate 
methodologies and studies that focus on the individuals with the influence to initiate, maintain, or terminate sport psychology services and positions (Connole, 2013). Seeing as the NCAA is a billion dollar business that oversee a large number of teams and athletes (Coakley, 2008), it is vital to examine newer and potentially more effective methods of delivering sport psychology services to such a robust population of well-funded consumers.

\section{Growth of Mobile Technology}

In the last few years, mobile technology has developed at an exponential rate and the market has exploded. Mobile technology is defined as technology that connects consumers to goods or services via a mobile device (i.e., iPad, Tablet, Smartphone; Garg \& Telang, 2013). At its inception, the standard mobile device was a simple two-way paging and messaging tool. Today, a standard mobile device is connected to high speed mobile network and has evolved into a cellular phone, GPS navigation device, a web browser, instant messaging device, and handheld gaming console (Nielsen, 2011). Most recently, mobile devices have become a convenient and effective tool to utilize a variety of traditional services through connection to mobile applications (mobile apps; Finn \& Barak, 2010). For example, individuals can now deposit a check, check-in to a flight, or track their caloric intake on a mobile device. Based on the ease and amount of information that consumers can access through mobile technology, ownership of mobile devices that connect to a wireless server have become commonplace (Nielson, 2012).

It is not surprising that mobile devices have become commonplace because of the many different functions they offer. Standard mobile devices have powerful operating systems that can run computer programs and mobile apps quickly and efficiently in addition to the standard features of mobile phones (Lee et al., 2012). Among mobile devices, the most popular are smartphones created by Apple, Android, Google, Samsung, and Windows. These devices are notable because third parties have been able to create mobile apps for these 
mobile devices' operating systems and distribute them to the public through websites. For example, mobile apps for the Apple iPhone can be downloaded from the Apple iTunes store. To date, the Apple iTunes store has released more than 500,000 iPhone mobile apps; these applications have been downloaded by consumers more than 3 billion times (Pew, 2013). Through the innovation of mobile apps, service providers are now able to offer a variety of "traditional services" at the tap of a touch screen (Fjeldsoe, Marshall, \& Miller, 2009).

Mobile apps provide access to many services and are becoming a requirement for offering services in a competitive marketplace. Many professions are growing with the pace of mobile technology and require nearly every employee to use a mobile device to complete daily tasks such as sending email, tracking shipments, or connecting with consumers (Liqiong \& Poole, 2010). Overall, there is a global increase in mobile technology across all professions (Kourouthanassis \& Giaglis, 2012). In 2009, the United States alone had an estimated 285 million wireless subscribers using mobile devices, and there were an estimated 4.6 billion mobile cellular device subscriptions worldwide (Lee et al., 2012). These statistics are evidence of an explosion of the mobile app market that is creating massive economic opportunities for countless mobile app developers in a variety of fields (Sahu, 2012).

The extensive increase in mobile devices not only benefits users, but also creates a global market for professionals who can provide services via mobile apps. Mobile apps are allowing service providers to bypass the traditional methods of marketing, and are providing services utilizing new online mobile app stores (Pew, 2013). Market research shows 17.7 billion mobile apps were downloaded in 2011, and predicts that downloads will reach 185 billion by 2014 (Venkatesh, Thong, \& Xu, 2012). In 2011 alone, mobile app developers saw $\$ 15$ billion in revenue from their mobile apps through download fees and advertising linked to downloads (Subramanya \& Farahani, 2012). Along with the massive number of downloads, mobile app developers are taking advantage of the same rewards that online stores benefit 
from, which include low costs for development, marketing, distribution, support, and low capital requirements for breaking into the mobile technology market (Kourouthanassis \& Giaglis, 2012). To date, the mobile technology market place is the largest and most cost effective in history (Subramanya \& Farahani, 2012).

The size of the mobile technology market is the result of technological growth; however, it is also important to note the cultural factors contributing to the growth of mobile app use. A recent market research study found that in a sample of American adults $(n=$ 2,261), 87\% owned a cellular telephone and $45 \%$ owned a smartphone (Pew, 2013). Data from this study also provides evidence that there is a strong correlation between mobile technology use and household income, as $68 \%$ of participants earning more than $\$ 75,000$ were smartphone owners. This data leads one to believe that it may be easier to access mobile technology and the Internet with a higher income. However, other research shows that social media websites and mobile apps are being checked and updated (e.g.., Facebook, Twitter) with the same frequency in lower and higher income nations (Agnihotri, Kothandaraman, Kashyap, \& Singh, 2012). This consistent usage suggests that staying connected to social networks through mobile technology is highly valued despite varying income levels.

Individuals with higher education levels have been found to be more likely to own a smartphone, with $61 \%$ of participants who completed college reporting they owned a smartphone compared to $50 \%$ among those who completed some college, $36 \%$ among those who were high school graduates, and $21 \%$ of those who did not earn a high school diploma (Pew, 2013). Additionally, younger participants were significantly more likely to own a smartphone. Only $11 \%$ of participants 65 or older owned a smartphone, while $34 \%$ of participants age 50-64, and 59\% of participants age 30-49 owned smartphones (Pew, 2013). The largest percentage of ownership belonged to participants between the ages of 18 and 29, 
with $66 \%$ owning smartphones. These trends were also reflected in other research examining demographics and technology use (Taylor, Voelker, \& Pentina, 2011).

Examining the demographic composition of the mobile market also sheds light onto possible future mobile market trends. Though there are many factors correlated with smartphone ownership, there is no evidence to suggest that there is a significant correlation between smartphone ownership and gender or race/ethnicity. Forty-six percent of male participants and $45 \%$ of female participants of all ages owned a smartphone, while $42 \%$ of White, $47 \%$ of Black, and $49 \%$ of Hispanic participants owned smartphones (Pew, 2013). In short, the use of smartphones is widespread. Given the scope of smartphone users, statistics related to mobile app use reflect many similar trends.

In 2010, 18 to 29 -year-olds comprise only $23 \%$ of the U.S. adult population but constitute $44 \%$ of the mobile app-using population (Nielson, 2012). By contrast, $41 \%$ of the adult population is age 50 and older; however, this group makes up just $14 \%$ of mobile app users. Younger smartphone users use mobile apps including games and social media more frequently (Taylor, Voelker, \& Pentina, 2011).

Gender differences in mobile app use also exist. Women have been found to be more likely to rely on social networking mobile apps such as Facebook and Twitter while men are more inclined to use productivity and financial mobile apps (Nielson, 2012). Overall, mobile device and app adoption is growing rapidly. The Nielsen Company (2012) found that the average number of mobile apps downloaded on an individual smartphone has increased from 22 in 2009 to 27 in 2012. iPhone owners top the list of number of apps with an average of 40 mobile apps, while Android users claim 25 apps, and BlackBerry owners 14 apps (Neilson, 2012). Market researchers examining mobile device usage and the market composition are expecting a widening acceptance of mobile technology, specifically mobile app usage, by a global population leading to an increase in the mobile market size and profits for mobile 
device and mobile app developers (Anthes, 2011). To keep up with the growth of mobile technology service, providers must understand mobile technology, most importantly mobile apps, to effectively provide services to a larger market that relies on mobile technology.

\section{Mobile App Market}

The number of consumers using mobile devices for purposes beyond personal communication is exploding worldwide. In a 2011 study, $44 \%$ of US mobile subscribers over the age of 13 reported using their mobile devices to access the Internet and $33 \%$ used them to access social networking sites or blogs, while 72.6\% sent text messages (Pew, 2013). For mobile technology developers and marketers, this growth has created an increase in advertising expenditures as they seek to capitalize on this emerging communications channel. By 2016, global mobile ad spending is estimated to reach as much as $\$ 22.6$ billion compared to $\$ 3.4$ billion in 2010 (Eddy, 2012). Web browsing advertisements represent the majority of mobile advertising, but media and information rich formats, such as mobile apps, are predicted to surpass web browser advertising as the predominant format of advertising in 2014 (Eddy, 2012; Patel, 2010).

As promising as some longer-standing forms of mobile devices are, another form of mobile technology may hold even more promise for service providers and mobile device developers. Mobile apps circumvent an Internet browser, cut through the clutter of domainname servers and uncalibrated information services, and take the user directly to the content he or she values (Johnson, 2012). Of adult cell phone users in the U.S., an estimated 44\% are smartphone users. Of those users, $62 \%$ reported downloading a mobile app to their phones within the last 30 days (Nielson, 2012). Additionally, among users 25 to 35 years old, 65\% owned a smartphone (Nielson, 2012). The market for mobile apps is already large and continuing to grow at a rapid pace. Over the span of two years, the mobile app market grew 
from essentially nothing to a $\$ 2$ billion market in the United States alone (Garg \& Telang, 2013; Moore, 2012).

In addition to representing an opportunity for advertising and branding, mobile apps hold tremendous potential as a channel for electronic commerce. Electronic commerce, commonly known as e-commerce, is a type of industry where the buying and selling of products or services is conducted over electronic systems such as the Internet and other computer networks (Turban, et al., 2009). Electronic commerce draws on technologies such as mobile commerce, electronic funds transfer, supply chain management, Internet marketing, online transaction processing, electronic data interchange, inventory management systems, and automated data collection systems. Modern electronic commerce typically uses the Internet at least at one point in the transaction's life-cycle, although it may encompass a wider range of technologies such as e-mail, mobile devices, social media, and telephones as well (Turban et al., 2009). Survey research showed that approximately $21 \%$ of smartphone owners reported using retail mobile apps during the preceding 30 days (Nielson, 2012). Furthermore, $87 \%$ of smartphone users used "deal of the day" sites like Groupon or Living Social, while $54 \%$ frequently used their smartphones while actually shopping (Nielson, 2012). The most popular category of mobile apps is games, followed by weather, navigation, and social networking apps (Nielson, 2012). In short, research examining mobile app use indicates consumers are downloading mobile apps in a variety of categories that provide them with a wide array of services, entertainment, and information. To effectively provide sport psychology services to a larger market that relies on mobile technology and keep up with the growth of mobile technology service providers, sport psychology professionals, must understand mobile technology, especially mobile apps. 


\section{Millennial Market}

The use of mobile apps by the Millennial generation is widespread (Taylor, 2012). The Millennial generation is classified as the segment of the world's population born between 1980 and 2000 (Kaifi, Nafei, Khanfar, \& Kaifi, 2012). What makes the Millennial generation unique in terms of mobile technology use is that it is the first generation to grow up with technology as a predominant force in homes, schools, work places, and personal lives.

With the explosion of technological development in the last 25 years, the majority of the Millennial generation has been born into and grown up in a world that has utilized technology in nearly every facet of life. Millennials have reaped the benefits of technology in the classroom in forms such as digital presentation devices, personal laptops, and personal digital devices that promote multimodal and interactive learning (Ritzhaupt, Dawson, \& Cavanaugh, 2012; Taylor, 2012). Many Millennial students also have experienced classroom learning and other educational opportunities from remote locations through Skype and webbased classrooms (Bailie, 2012). Overall, instructors at a variety of levels of education report the benefits of technology in the classroom, including the use of technology to create digital classrooms. Teachers $(n=126)$ cite the high levels of interactive learning possibilities, immediate feedback, increased levels of connectivity to people and educational information, and the real world application that technology provides as the most valuable reasons for using technology (Tunks, 2012). Additionally, a study examining teachers' perceptions of the use of technology with grades K-12 revealed that teachers believe technology significantly improved learning for their students (Wright \& Wilson, 2011). Specifically, these teachers reported that because their students used technology so frequently outside of the classroom, integrating technology into the classroom was vital to real life application of educational principles. Teachers also reported encouragement from parents and administrators to integrate digital technology into the classroom to supplement traditional learning and teaching strategies (An 
\& Reigeluth, 2012; Wright \& Wilson, 2011). In short, the Millennial generation has had mobile technology fully integrated into their lives, leaving them familiar and comfortable with mobile technology in a wide array of uses and settings.

Digital technology in the workplace. The workplace mirrors a similar experience to educational settings with regard to the use of technology. The most common uses of technology include interactive presentations, video conferencing, and website advertising (Holt \& Brockett, 2012). Research examining the use of technology in the workplace suggests that employers in a wide range of companies and organizations expect employees to be familiar with digital technology and are more likely to hire a younger employee who is technologically savvy than an older, more experienced employee who is less technologically savvy (Holt \& Brockett, 2012). Employers are becoming more aware of the importance of connecting to employees, other companies and organizations, and consumers through mobile technology. Not only is mobile technology use providing opportunities for a variety of service and product providers, but technology has also become a requirement for many organizations to adequately serve consumers (Kaifi et al., 2012). More than ever, technology is the connection between services providers and consumers requiring both service providers and consumers to be able to access and use technology effectively. The increase and wide variety of technology being developed almost daily, creates opportunities, accessibilities, and revenue that has been unmatched in the past. Experience, knowledge, and comfort with technology is quickly becoming a requirement in the workplace for employers, employees, and consumers to conduct business (Filipowski, Kazienko, Brodka, \& Kajdanowicz, 2012).

Although technology use is commonplace in the classroom and workplace for Millennials, personal use of technology by the Millennial generation is even more prevalent, especially compared to previous generations. In a 2012 study from the Pew Research Center, every country surveyed $(n=21)$ yielded similar results with regard to age and mobile 
technology use. Specifically, half of the countries surveyed presented a 50\% difference between those participants under the age of 30 and over the age of 50 with regard to the utilization of technology (Pew, 2013). Specifically, in the U.S., 73\% of 18-29 year-olds reported using their cellular phone to connect to the Internet and browse the web compared to $49 \%$ of $30-49$ year-olds, and $21 \%$ of those 50 years or older. Along with accessing the Internet, young people were more likely to use their cell phones for texting, taking pictures or video, accessing social networking sites, using mobile apps, and accessing email (Eddy, 2011). Smartphones are now the leading device for accessing social networks, playing games, tweeting, and sending email (Chappuis, Gaffey, \& Parvizi, 2011; Kaplan, 2012).

Based upon the preceding information, it is clear that the vast majority of members of the Millennial generation have fully integrated mobile apps into their lives. Younger adults and children are using personal computers and mobile devices to perform personal tasks ranging from gaming, banking, connecting to social media, and web browsing at an incredible rate (Zur, Williams, Lehavot, \& Knapp, 2009). The rate at which children and young adults are using smartphones and mobile apps is expected to continue to grow at a similar pace (Cameron, Gregory, \& Batagglia, 2012). Over the past five years, the mobile app market has grown from non-existent to a multi-billion dollar market targeting mostly Millennial users (Gupta, 2013). Naturally, the booming financial profits have led to increased market research and empirical investigation from many other fields. Research identifying reasons for the increased use of technology, specifically mobile apps by the Millennial generation, has mostly focused on greater cultural influences, such as being introduced to technology at a young age and using technology in many different ways every day (Cameron et al., 2012). This research has also examined Millennial users' mobile app usage trends in an attempt to understand the preferences of the Millennial market (Gupta, 2013). 


\section{Popular Mobile App Characteristics}

Researchers have identified three tangible and pragmatic characteristics of mobile apps that have strong correlations to increased mobile app use by adolescents and young adults (Gupta, 2013).

Personalization. The first characteristic is the personalization that mobile apps provide to users. Mobile app personalization has revolutionized the interaction between consumers, service and product providers, and advertisers. An example of personalization is mobile apps that offer coupons or discounts for mobile app subscribers (e.g., Groupon, RetailMeNot). Before the age of digital technology, consumers could only find media geared toward their interests in advertisements and coupons by searching for coupons in print ads. Currently, mobile apps offering coupons and discounts for products and services get personalization in three ways: 1) getting instant and easy access to a discount, 2) connecting consumers and retailers directly through digital platforms, and 3) helping individual consumers find discounts to the products and services they have identified as personal preferences (Cameron et al., 2012). This personalization offers cost effective benefits to consumers, retailers, and manufactures alike by streamlining services and creating a more accurate communication medium. Many researchers agree that personalization allows mobile app users to take personal ownership of not only apps, but the products and services they are associated with and make them their own. In short, a mobile app empowers a user with the ability to personalize many facets of his/her life through mobile devices.

Social networking. The second characteristic that is correlated with the use of mobile apps by the Millennial generation is social networking. Humans are social by nature and have historically found ways to connect with other humans. Throughout history, many of the greatest advances in technology have been means by which humans can communicate and connect with each other more effectively (e.g., printing press, telephone, email). With the 
emergence of mobile technology, humans have been able to connect with each other with more ease and frequency than ever before. Through social networking websites and mobile apps, users can create personalized profiles to connect with people across the globe instantly and easily. Many researchers believe that the pervasive use of social networking has fundamentally changed the way people communicate and form relationships (Coyle \& Vaughn, 2008). Specifically, social networks have become a prominent and acceptable staging ground Millennials use as a forum for self-expression and to share intimate, private information (Livingstone, 2008).

The value of social networking among the Millennial generation can be seen in the evolution of websites and more recently mobile apps. Before the emergence of mobile apps, websites with the primary purpose of providing user-to-user connection (e.g., MySpace and Facebook) began to grow in popularity. Now it is difficult to find a Millennial that does not use at least one social networking website or mobile app to connect to family, friends, and strangers (Kaplan, 2012). According to research examining generational social networking, Millennials compared to all other generations are more active and spend more time on social networking websites and mobile apps, have significantly larger friend networks, and were more likely to connect with someone from another country (Pew, 2013). A study of international digital technology and social networking provides data that early adopters of new digital technologies tend to be young men, while women are often noticeably heavy users of online social networks and mobile apps (Taylor, Voelker, \& Pentina, 2011). Moreover, Facebook and other social networks have become the preferred means of digital communication for people under the age of 34 (Chappuis et al., 2011). Social networks are also becoming increasingly popular ways of accessing online content including games, products and services, and email (Kaplan, 2012). 
Researchers also note the reliance on social networks for many other websites, services, and products as a means of marketing and advertising. As online and mobile social networking has exploded in popularity, many websites began to follow their lead by offering social connection or at least some connection to a social networking site (Sexton, 2012). For example, many service providers and companies use Facebook login information for users to create accounts, such as Pinterest and Spotify. This allows companies to gain valuable marketing information about potential customers and offer social networking as part of their website. In addition to connecting social networking sites to non-social media sites, many organizations such as Google and Southwest Airlines offer mobile apps that allow mobile app users to access the features of the website without using an Internet browser. These mobile apps that offer functionality and allow for convenient and instant social networking are extremely popular with Millennials (Sexton, 2012). In sum, mobile apps that allow users to connect with others through social media are extremely popular with users, retailers, manufacturers, service providers, and advertisers alike.

Interaction. The third characteristic that is correlated with the use of mobile apps by the Millennial generation is interaction. Although many forms of gathering information other than mobile apps are often interactive, researchers believe people build highly interactive and personal connections with their mobile devices (Bellman, et al., 2011). According to the researchers examining consumer approval or branded mobile apps, retailers who develop apps overcome challenges being presented by dramatic shifts in television viewing and barriers to advertising on mobile devices through interaction with the user (Bellman et al., 2011). The authors suggest that interactive apps offer consumers the power to interact with the brand and the mobile app, not the other way around (Bellman et al., 2011). This consumer-lead interaction leaves consumers feeling comfortable controlling how much information they reveal and consume when they personalize the mobile app. The personal nature of a mobile 
app and high levels of interaction between users and a mobile app make smartphones and mobile devices practically extensions of their owners (Bellman et al., 2011; Sexton, 2012). After examining the most popular mobile gaming apps, researchers reported that these apps had high levels of user interaction leading to increased levels of enjoyment and entertainment (Christensen \& Prax, 2012). Specifically, in a study comparing generational use of interactive mobile apps, Millennial participants indicated significantly higher usage of interactive mobile apps compared to both Generation X and Baby Boomers across 14 apps (Moore, 2012). The same author suggests that the results of this study indicate that Millennials use interactive technologies for utilitarian, information gathering purposes, as well as for entertainment and they value mobile apps that are highly interactive (2012). In a recent study tracking Millennials using mobile apps to search for information $(n=80)$, Millennials preferred interactive mobile apps that provided information to less interactive webpage searches regardless of the creditability of information offered by either information source (Taylor, 2012). This finding supports data tracking mobile app downloads and age, showing that many of the most downloaded mobile apps available for devices are becoming increasingly interactive (Bellman et al., 2011).

In sum, research shows that in order to optimally access the most technologically progressive population, mobile apps must allow users to personalize the app and the information linked to it, connect to other people and information through social networking, and have high levels of user interaction and entertainment. As such, the expansion of the mobile market and advancements in wireless technology are driving forces for mobile app developers and users. Many of these mobile apps are marketed toward Millennial generation consumers, indicating the potential for an unprecedented rate of uptake of mobile technologies due to the use among essentially all socioeconomic classes and the reduced barriers for imaginative mobile app developers. Researchers suggest that understanding how 
to maximize the impact of mobile apps will be a key topic for future research in many academic and professional fields (Bellman et al., 2011).

\section{Technology in Applied Sport Psychology}

The study and practice of sport psychology is evolving to keep pace with the technology-driven world we live in. The literature discussing the use of technology in applied sport psychology has continued to grow as the cultivation of technology continues to place more information and services at the fingertips of consumers (Finn \& Barak, 2010). It is difficult to find an area of sport psychology that is not significantly enhanced by a form of digital technology (Schwartz \& Lamphere, 2012). The rapid growth of technology has created new opportunities that improve sport psychology teaching, research, and applied practice. Watson and colleagues (2000) noted many potential benefits for using technology in providing sport psychology services. These researchers accurately predicted the powerful influence technology would have over applied sport psychology. Though the authors could not have predicted how technology would continue to evolve, the benefits, (e.g., serving more

clients in need) and concerns (e.g., threats to confidentiality, potential limited effectiveness of services) about the use of technology in applied sport psychology remain salient today.

Much of today's applied sport psychology practice relies on the use of technology. As digital technology becomes the norm, it is no surprise that practitioners, like researchers and educators, are utilizing digital technology as a means of providing or at least aiding in the provision of sport psychology services. Not only is the amount of technology increasing, but technology continues to become more dynamic and interactive, creating more possibilities for service providers in a variety of fields to effectively reach clients (Wang, 2012).

Some uses for technology among sport psychology professionals and professionals in other psychology related fields include: information collection and dissemination, providing online assessment (DeFreese \& Smith, 2013), and contacting clients to provide sport 
psychology services (Kanani \& Regehr, 2003). A review of listservs in sport psychology and related fields show that practitioners most commonly use technology to organize information and keep records, consult with clients, and develop skills or provide training to clients (Watson \& Halbrook, 2014).

Although the uses of technology by sport psychology professionals will likely fall under these intended purposes, the form of technology utilized to meet these purposes may vary and change with continued technological growth. For example, many forms of business related technologies (e.g., TurboTax) and programs are available for practitioners providing sport psychology services that make the daily tasks of providing these services easier and more secure. It is important to note that continued growth of technology and its use in sport psychology has not only provided advantages to clients, but also to practitioners by helping them more efficiently and securely complete the logistical day-to-day consulting tasks.

Communicating with clients in remote locations is vital to providing sport psychology services. As sport continues to evolve, many athletes are traveling more, which makes it more difficult for clients and sport psychology practitioners to communicate face-to-face. Moreover, research examining communication between clients and sport psychology service providers indicate that many Millennial athletes prefer communicating with sport psychology professionals through technological means (Zizzi \& Perna, 2002; Zizzi \& Schmid, 2012). Many researchers believe that clients' preference for technological communication, such as speaking over the phone or communicating via Skype, is a product of a generation that is familiar, skilled, and trusting when it comes to technology (Kaplan, 2012; Zizzi \& Schmid, 2012). Moreover, research also shows that clients feel comfortable and willing to openly share information in a technological consultation, such as email or text messaging that provides a safe and anonymous avenue for a consulting relationship (Shandley, et al., 2011), even if it is not possible to ensure complete confidentiality. Overall, Millennials make up a 
large portion of the potential clients for sport psychologists, and they are often tech savvy and prefer using technology as a means to communicate with sport psychology professionals. These findings make the Millennial generation an attractive and accessible population of potential clients to utilize technology-based services. From information related to the Millennial generation and the use of technology in sport psychology, it is logical to expect continued development and utilization of digital technology and mobile apps as a means to provide sport psychology services.

Current utilization of technology, specifically digital technology, by sport psychology professionals appears in a variety of forms. An established form of mental training that relies heavily of technology and has grown in popularity with intercollegiate and Olympic athletes is biofeedback and neurofeedback (Perry, 2012). Biofeedback and neurofeedback systems read the body's vital functions and brainwaves and provide users with instant feedback to any changes in brain or body activity. During a biofeedback session, electrodes are attached to a user's skin. These electrodes send signals to a monitor, which displays a sound, flash of light, or image that represents the user's heart and breathing rate, blood pressure, skin temperature, sweating, or muscle activity (Perry, Shaw, \& Zaichkowsky, 2011). During a biofeedback session, a biofeedback therapist or consultant may help a user practice relaxation exercises to maintain focus on a certain task. Although shown to be an effective means to develop imagery, relaxation, and focus skills, biofeedback and neurofeedback systems are costly and require a practitioner who is trained to conduct sessions, and therefore, are limited to a small population of clients with these resources available to them (Perry, 2012).

Despite the growing popularity of biofeedback and neurofeedback systems, practitioners are also utilizing a variety of other technological methods to provide sport psychology services that are cheaper, more accessible, and easier for clients to use. Like coaches, sport psychology practitioners are using digital devices to video tape or log athletic 
performances to provide assessment and feedback to clients about mental skill development. Many practitioners are using websites and online videos to provide mental toughness assessments, instructional videos, and to create a forum for athletes and coaches to connect and communicate with each other. In the last year, the insurgence of sport psychology online mental training program videos and mobile apps has become apparent. These online programs and mobile apps are designed to help practitioners provide services to a larger population of tech-savvy clients at a cheaper price than in-person consulting and can supplement personal consulting. A review of existing sport psychology mobile apps shows that these apps, created by a variety of professionals, provide information about sport psychology and mental toughness, basic mental skill assessment, and basic instruction about how to develop and track mental skills (Watson \& Halbrook, 2014). For example, the most notable sport psychology mobile app is the iPerformance Sport and Performance Psychology Mental Skills Trainer App that was used by several Olympic Athletes in the 2012 Summer Olympics in London (Portenga, 2012). The mobile app offers athletes handheld mental training and specifically contains assessments, worksheets, games, and routines to improve mental preparation and focus for sporting events (Portenga, 2012). Following the 2012 Summer Olympics, the iPerformance Sport and Performance Psychology Mental Skills Trainer App was made available to the public and is available for download on iTunes.

The availability of sport psychology mobile apps is growing. With the growth of the mobile market, the Millennial generation's use of technology, and the infusion of technology into sport psychology, mobile apps are likely to become a staple for providing sport psychology services. This growth will also warrant a strong connection between empirical research and practice in order to provide effective services to a wide range of clients. 


\section{Technology Use in Related Fields}

Sport psychology has roots in several fields of study and practice. Among the most influential fields to contribute to the development of sport psychology are clinical psychology and counseling psychology. Though these fields are primarily rooted in the traditional provision of services through face-to-face interaction between clients and practitioners, technology has provided a myriad of options for delivery of therapeutic services.

Initially, technology proved a valuable tool for contacting clients via email or even providing therapeutic services via telephone. The provision of services later evolved to telepsychology systems that were restricted because of the cost of the equipment and the lack of adequate infrastructure or protocols regarding telecommunications (Nelson, Bui, \& Velasquez, 2011). The most important technical constraints were due to limitations in the bandwidth of networks and the absence of technology that was able to compress audio/video files in real time. However, in recent years, new high bandwidth technologies have become more common in European countries and in the US (Alcañiz, et al., 2009). As technology has continued to make telepsychology effective and more affordable, telepsychology systems offer capabilities such as bidirectionality, that is, they offer a high bandwidth both in the ascendant and in the descendent channel, allowing two-way real-time communication to clients. With more advanced technology, telehealth has started to have more diffusion within the population. Telehealth is the standard term chosen by the Standing Committee of Family and Community Affairs to refer to the 'remote provision of health' (Nelson, Bui, \& Velasquez, 2011). Telehealth may be defined as any application that implies carrying out activities related to health (i.e., a health, education, and/or information service) remotely, using computers and mobile technology. However, telehealth is a broad term that includes several related disciplines such as telemedicine, telepsychiatry and e-therapy. All these services have in common the geographical distance between the person that provides the 
service and the user, and the use of telecommunication technologies to facilitate the interaction, which can be done with videoconferences, telephones, computers, Internet, fax, radio, and television (Maheu, Pulier, McMenamin, \& Posen, 2012).

Recently, many researchers and practitioners have been calling for research to evaluate the innovation of e-therapy systems that establish a new genre of e-therapy tools that use the most innovative technologies. New technologies are obtaining good results in clinical psychology and health psychology (Alcaniz et al., 2009). Any advance in this respect will encourage the scientific community to continue investigating new technologies (Maheu, et al., 2012). Evidence suggests E-therapy will have an important financial and social impact for redefining the provision models of basic services into the future (Alcaniz et al., 2009).

Currently, technology allows for practitioners to market their services, contact clients, digitally store client records, provide services to clients in remote locations (e.g., Skype and FaceTime), connect with other professionals for supervision and training, and use apps to reach a larger market of clients (Kanani \& Regehr, 2003). Popular services offered include online psychological assessments, online informational intake forms, and practitioner evaluations (Kolmes, 2012). Among the fastest growing forms of providing psychology services via technology is using social media (Kolmes, 2012). Although a polarizing topic for many practitioners, the use of social media as a technology to connect with clients, market services, and provide therapeutic services is becoming an important ethical discussion because it allows potential clients to located and contact practitioners and gain access to effective therapeutic services (Veretilo \& Billick, 2012). However, this new trend lacks an indepth empirical investigation. The ever-evolving social media network and related practical and ethical implications provide an example of a need for increased depth and speed of empirical investigation, as many technologies become outdated faster than effective empirical investigations can be completed and published. 


\section{Ethical Considerations}

The benefits of technology to the field of sport psychology have been well documented (Watson, Tenenbaum, Lidor, \& Alfermann, 2001) and continue to evolve with technology. However, many believe that for the field to continue to grow and benefit from a strong technological influence, ethical guidelines for use of technology must be clearly established for providing services to clients, as well as training and supervising professionals (Watson \& Etzel, 2000; Watson, et al., 2001). Ideally, these ethical guidelines would be created to protect clients and ensure a high standard of services being provided (Watson et al., 2001). Furthermore, as technologies, specifically mobile technologies, continue to develop, practitioners will face new possibilities and new ethical challenges. Established and accepted ethical guidelines for integrating technology into the delivery of services would help practitioners appropriately respond to the ethical concerns that arise.

Presently, sport psychology practice is often guided ethically by the Association for Applied Sport Psychology's (AASP) ethics code. The guidelines set forth by AASP address a variety of ethical and legal concerns that sport psychology professionals will face in academic and applied sport psychology settings. However, AASP's ethics code offers limited guidance for practice that is rooted in technology developed within the last 15 years (i.e., web or mobile based sport psychology). Although AASP's ethical guidelines for using technology are limited, practitioners can rely on a few other sources of guidance for ethics in practice. “Telepsychology Guidelines" offered by the Ohio Psychological Association (OPA) were drafted with the specific purpose of guiding psychology practice rooted in long-distance and remote technology. These guidelines offer direction for practitioners related to confidentiality, competence, and informed consent when providing services to clients. Although the OPA offers some guidance to practitioners, like AASP's ethics code, the guidelines lack information and direction related to newer technologies such as mobile apps and online 
mental training programs. Finally, the American Psychological Association (APA) also has addressed ethical concerns for using technology in psychological practice. Recently, APA released the "Guidelines for the Practice of Telepsychology" to provide practitioners with direction in an effort to protect both clients and practitioners. To date, APA's document represents the most recent guidelines related to providing psychological services through the use of distance technology. Making conclusions about the state of sport psychology and related fields regarding the relationship between technology and ethics is difficult without more empirical investigation. However, it is clear that up-to-date and comprehensive guidelines for any field related to psychology services delivered via technology are lacking. This deficit may be due to technology growing at a rate that is difficult for ethical codes and training to keep pace with. In short, although ethical guidelines are lacking, new technologies present new ethical concerns that are yet to be addressed. The remainder of this section will discuss some established ethical concerns related to sport psychology services delivered via technology.

Ethical principles. Literature to guide sport psychology professionals using technology to deliver services is limited (Schwartz \& Lamphere, 2012). As such, the discussion of ethics is related to addressing the long-standing ethical concerns of in-person sport psychology services, to services delivered via technology. The most prominent of these concerns include: informed consent, confidentiality, competence, and effectiveness of practice (Behnke, 2008; Watson \& Halbrook, 2014).

Informed consent and confidentiality. The use of technology to deliver sport psychology services offers a variety of possibilities to obtain informed consent. Gaining informed consent is important to the therapeutic process because it provides educational information to the clients being served, as well as allowing the client to ask for any clarification about the services being offered. In addition, gaining informed consent is an 
ethical obligation of the practitioner and also protects any service provider legally (Varnhagen et al., 2005). Informed consent in other helping and medical fields using technology to deliver services is gained from clients and legal guardians through email, text, Skype, web-based informed consent forms, or simply by purchasing services (Vayena, Mastroianni, \& Kahn, 2012). However, these possibilities for gaining informed consent for services also pose some ethical concerns, such as who is giving consent or purchasing the services, and the effectiveness of the information being communicated and absorbed through common technological methods (i.e., social media, websites; Varnhagen et al., 2005). In a study assessing the amount of information participants recalled after delivery of an informed consent form online, Varnhagen and colleagues (2005) found that there was no significance difference in recall and understanding of informed consent for participants who received an informed consent form in person versus receiving the same form online. Although this may be promising for gaining effective informed consent, the results are not necessarily generalizable to other forms of online informed consent (i.e., via purchase) and have yet to be replicated. To date, little is understood about gaining informed consent through technology, specifically mobile technology and mobile apps. However, literature discussing informed consent warns practitioners about the dangers of not knowing who is actually giving consent for services and to what level consent is informed (Vayena et al., 2012). Similarly, once informed consent is gained, there is concern about not only the client's understanding of the services being offered, but also the confidentiality of the client's personal information.

Confidentiality remains a significant ethical concern for sport psychology professionals, regardless of the method of service delivery (Watson, Lubker, Zakrajsek, \& Quartiroli, 2012). Advancements in technology, such as secure websites and "smart" technology, make protecting client confidentiality easier. Many websites and mobile apps require a username and password for access to a personal account and personal information. 
Although it is easier to protect client confidentiality through mobile technology, no server is completely secure and identity theft remains a major concern for many people using mobile technology. In many cases, it is impossible to guarantee confidentiality simply based on the nature of technology and the associated risks.

Protecting a client's privacy can be more difficult when consulting from a distance for a variety of reasons. Ethical discussions related to confidentiality note the limitations associated with even the most secure servers where personal information is contained (Behnke, 2008; Watson et al., 2012). First, many services offered online (i.e., onlinementaltraininer.com) require a user to register for an account with the website that includes personal information related to the client, as well as personal financial information. Data encryption technology can be used, but has the potential to be bypassed by skilled hackers. Second, and perhaps more of a threat, a client's personal communication through digital devices or personal computers is also susceptible to being the source of broken confidentiality. It is important for practitioners to communicate the risks to confidentiality associated with using technology for delivering psychology services to clients (APA Ethics Code 4.02). Moreover, it is the responsibility of practitioners to contact clients when there is a real or potential breach of confidentiality, regardless of the mode in which services are being delivered (Watson et al., 2001).

Competence. Practitioner competence is a primary concern of sport psychology and related profession's governing bodies. Overall, the purpose of providing sport psychology services is to help clients improve their performance and well-being. However, as with any helping profession, there is always a risk of doing harm to clients, especially by practitioners who lack competence (Watson \& Etzel, 2000). Ensuring a minimum level of competence is the purpose of training, supervision, ethical guidelines, and certification and licensure. In the case of using technology to provide sport psychology services, the dynamic nature of 
technology, the environments created by technology (i.e., chat rooms, social media), and the rapidly evolving technological growth creates difficult conditions to establish and maintain practitioner competency (Behnke, 2008). For example, many technologies being used to deliver sport psychology services, such as mobile apps, were created to offer other services, but have been adapted for sport psychology use. Thus, it is difficult to establish a level of competency, training, supervision, or certification for such a technology without thorough empirical investigation on multiple levels. First, it requires a practitioner who is competent in sport psychology information and service delivery. Second, it also requires a practitioner who is also competent in understanding the technology that can be used to provide sport psychology services as well as being competent at using technologies to provide those services (Sullivan \& Arthur, 2006). Based on the speed at which technology is evolving, the field of sport psychology will need to consider adding technological competence as part of training curricula, supervision, and updated ethical codes. These dual competencies specifically make competencies related to the use of technology, especially digital technology, a topical discussion and concern for sport psychology researchers and practitioners.

Effectiveness of practice. Along with practitioner competencies, the quality of the services delivered via mobile technology is also an ethical concern. As mobile technology continues to make communicating with potential clients easier and cheaper, many Millennial Generation athletes and their coaches will likely be attracted to sport psychology services delivered through mobile technology. From an ethical standpoint this calls into question the effectiveness of sport psychology services offered through mobile technology. As previously mentioned, many forms of technology were not developed with telepsychology opportunities in mind (i.e., Skype, Facebook). Once practitioners become competent in using a form of technology to provide psychology-related services, the next step is to empirically evaluate the effectiveness of such modes of delivery. Although many forms of telepsychology have been 
empirically evaluated and shown to be effective therapeutically (Alcanez et al., 2009), continued growth of technology creates a dynamic environment for service providers to navigate, and continued evaluation is needed. Moreover, most forms of graduate education in sport psychology and related fields offer training and supervision in traditional, in-person consulting but lack in-depth training and supervision for services offered through technology (Schwartz \& Lamphere, 2012). As such, there are few, if any, ethical guidelines or supervised training for effective use of technology in sport psychology, which provides more evidence for the need for research examining the provision of services delivered via mobile technology.

It is also important to note that although there is strong evidence to suggest that the Millennial generation of tech savvy athletes and their coaches would be more likely to use psychology services offered online or via mobile app, these services may not be appropriate or preferred by all athletes and coaches. The OPA (2010) ethical guidelines for telepsychology suggest that practitioners should consider a variety of personal and situational factors to make case-by-case decisions about which clients are best suited for telepsychology services. To date, there is no research to suggest that services delivered via technology are more effective than in-person services overall, or for specific clients or presenting concerns. Furthermore, it is likely just as many clients will prefer and even be more comfortable with services delivered via mobile technology, many other clients will prefer and feel more comfortable with in-person services. From an ethical standpoint, it is important to note that sport psychology services offer another form of service provision that may suit the current generation's preferences, but is lacking empirical evaluation to support this claim.

Certification and licensure. Licensure in sport psychology is available in some countries outside of the United States. Moreover, licensure is required for psychology and counseling professionals to practice in most countries including the United States. However, the field of sport psychology remains without a statutory certification or licensure in the 
United States. As a result, anyone can create sport psychology services and deliver them via mobile technology. Because sport psychology services can be delivered with no restriction from any governing bodies, it is important for practitioners using technology to deliver services to be aware of legal restrictions. Legal restrictions define where practitioners can provide psychological services, determine the scope of insurance coverage a practitioner has, and whether a practitioner is practicing competently. Many professionals believe that in order to practice telepsychology and provide services via technology specialized training and certification is required. Although legal restrictions do not apply to all forms of psychologyrelated services, they can influence where practitioners can provide services, what type services they can provide, and what treatments they can use.

In psychology and counseling, practice laws restrict practice without license across international, provincial, and state lines (Barnett, 2005). For example, a North American psychologist's practice is limited to the states and provinces where he or she gained licensure. This limitation means that psychologists cannot legally provide services to clients outside of their licensure jurisdiction. This poses a difficult ethical question: When using technology to reach clients in a remote location, where is the psychology professional practicing? Many practitioners would say that remote practice is practice within the state or provinces in which the psychologist is actually located. Other professionals would say that using technology to provide services to clients outside of a licensed state or province is practicing outside of licensure. Limited empirical discussion related to legal restrictions and certifications for technology based services suggests that those providing these types of services pursue an interjurisdictional practice certificate offered by the Association of State and Provincial Psychology Boards (DeAngelis, 2012).

It is unclear how legal and certification restrictions will apply to sport psychology professionals who offer services via mobile technology. However, until sport psychology 
holds a legally recognized certification, licensure, or training, it is vital for sport psychology professionals to be aware of relevant ethical concerns related to using technology to provide services.

In summary, sport psychology services delivered via technology, specifically mobile apps, present a variety of possibilities for athletes, coaches, and service providers. There is a discussion about using technology to deliver sport psychology services that addresses many ethical concerns. Ethical guidelines from governing bodies in sport psychology and its related fields are mostly outdated and unapproved and struggle to keep up with the growth of technology. Practitioners using technology to deliver services should also consider legal and ethical issues associated with this form of service delivery to protect themselves and their clients. However, there are many ethical concerns that require more empirical evaluation to fully understand while training, supervision, and ethical codes to guide practice in this area are being developed.

Mobile App Use for Behavior Modification.

The use of mobile apps to delivery behavior modification strategies is growing rapidly. Most notably behavior modification in the form of weight loss and smoking cessation has a wide variety of mobile apps available for consumers. Although these apps are plentiful, empirically evaluated behavior modification mobile apps are limited, if not rare. In fact, several publications have noted concern over the lack of evidence-based behavior modification strategies presented to consumers through digital technology (Backinger \& Augustson, 2011). A review of 47 smoking cessation mobile apps revealed that not only were the majority of the mobile apps reviewed not evidence-based, but that the most downloaded and highest rated smoking cessation apps were not evidence-based (Abroms, Padmanabhan, Thaweethai, \& Phillips, 2011). Similarly, a review of mobile apps directed toward weight loss also revealed a lack of evidence-based strategies and information (Turner-McGrievy, \& Tate, 
2011). Specifically, in the content review of weight loss mobile apps, only $15 \%$ were rooted in empirically tested weight loss interventions (Turner-McGrievy, \& Tate, 2011). The limited examination of behavior modification apps suggests that mobile apps can be effective for helping improve health behaviors, but that more research is needed to determine the impact of mobile technology over health behavior (Turner-McGrievy, et al., 2013). In a study comparing physical activity and body mass index of behavior modification mobile apps users and non-users, Turner-McGrievy and colleagues (2013) found that in a six month trial, mobile app users self-monitored exercise more frequently, reported greater intentional physical activity, and had lower body mass index. Although this study provides evidence to support the use of mobile apps to improve health behavior, the authors note that the effectiveness of mobile apps is still in need of empirical evaluation. To date, the effectiveness of behavior modification mobile apps is largely unknown, which is likely do to a lack of evidence-based behavior modification mobile apps and a lack of understanding related to how they are being used once downloaded.

Although an empirical review of mobile apps for behavior modification indicates a lack of evidence-based content, experts in health related fields note the positive potential for mobile technology to reach a vast array of people who could benefit from improved health habits (Backinger \& Augustson, 2011). For example, the American Journal of Preventative Medicine notes strategies for improving the health of the American public: 1) redesigning evidence-based products and services to better meet consumers' needs and wants, and 2) marketing and promoting health-related products and services in ways that reach those in need of improved health habits (Abroms et al., 2011) in an effort to increase the use of mobile technology to reach a broader audience of consumers. Researchers note the value of using mobile technology to help improve health. Noted benefits include reaching more people, reaching people through a preferred and pervasive form of communication, and the ease and 
convenience of use (Backinger \& Augustson, 2011). However, researchers also note concerns for using mobile technology to improve health such as ensuring that content disseminated is evidence based, ensuring that consumers engage with the product or service (i.e., mobile app), and ensuring that consumers engage with the product or service properly (Backinger \& Augustson, 2011). The aforementioned benefits and concerns provide a significant foundation for empirically evaluated mobile apps directed toward improving health behaviors. Given the results from content and analysis and academic discussion related to potential benefits and concerns of using mobile apps to improve health, empirical evaluation of services and products in other fields (i.e., sport psychology) it is possible that using mobile technology may help to improve the effectiveness of those services.

\section{Study Purpose}

As technology maintains its prominent role in the ever-evolving consumer-oriented market (Zur et al., 2009), it is becoming essential for all areas of study and practice to expand with the development of technology, including the field of sport psychology (Schwartz \& Lamphere, 2012). Currently, technology-based sport psychology services are varied and include, but are not limited to, email, phone, social media, Skype correspondence, DVD and online training videos, and biofeedback and neurofeedback (Perry, Shaw, \& Zaichkowsky, 2011; Shandley et al., 2011). Given the dynamic nature of providing sport psychology services (Aoyagi \& Portenga, 2010) and the characteristics of Millennial generations that rely heavily on technology in many facets of day-to-day life (Anthes, 2011; Neilson, 2012), it is no wonder that the discussion about the use of technology in sport psychology is growing and feeding both research and practice (Schwartz \& Lamphere, 2012; Watson \& Etzel, 2000).

The digital market is already being utilized by sport psychology service providers who have created websites, podcasts, and apps that are available to athletes and coaches. Although these services provided through digital media have been available for years, there is little 
empirical investigation about the effectiveness of these services, athletes' and coaches' perceptions of these services, or market specs (i.e., prices, digital interface options) that will optimize the quality of services.

The influence of technology for guiding sport psychology research and application poses many questions worthy of discussion related to a variety of important topics (Schwartz \& Lamphere, 2012). Although there is an ongoing discourse about the use of technology as a means of providing sport psychology services, the dialogue is largely related to ethical considerations and guidelines (Aoyagi \& Portenga, 2010; Watson \& Etzel, 2000), education and training of sport psychology students and professionals (Watson \& Etzel, 2000), and the general benefits and potential pitfalls for clients and practitioners alike (Aoyagi \& Portenga, 2010; Watson \& Etzel, 2000). However, there is little discussion that includes the clients being served, and there is limited empirical research examining what digital-based sport psychology services athletes and coaches want. Through this discussion, many sport psychology professionals and professionals in related fields have suggested guidelines for using technology as a means to provide services (Aoyagi \& Portenga, 2010; Watson \& Etzel, 2000; Watson et al.,, 2001), as well as parameters for training to keep up with the rate at which technology continues to grow and present more possibilities for our field (Schwartz \& Lamphere, 2012). Although the use of technology as a means of providing sport psychology services to clients continues to be a topic of research among sport psychology students and professionals, it is likely beneficial for all parties involved to include the clients in the discussion. Bringing consumers into the discussion through empirical investigation may provide invaluable insight into the types of services that are most attractive and beneficial to clients. Using an empirical approach could provide objective information about the forms and features of technologically based services that customers and clients can use to apply sport 
psychology skills, and shed light onto any ethical concerns related to using technology to provide services.

Ideally, coaches and athletes would have access to sport psychology services delivered via mobile technology. The infusion of mobile technology as a means to provide sport psychology services has already begun and is a growing topic for sport psychology professionals, despite the lack of input from the coaches and athletes being served. Bringing coaches and athletes into the discussion about using mobile technology to provide sport psychology services may offer information relevant to this generation of athletes and their coaches. 


\section{Works Cited}

Abroms, L. C., Padmanabhan, N., Thaweethai, L., \& Phillips, T. (2011). iPhone apps for smoking cessation: A content analysis. American Journal of Preventive Medicine, 40(3), 279-285.

Agnihotri, R., Kothandaraman, P., Kashyap, R., \& Singh, R. (2012). Bringing "social" into sales: The impact of salespeople's social media use on service behaviors and value creation. Journal of Personal Selling \& Sales Management, 32(3), 333-348. doi: 10.2753/PSS0885-3134320304

Alcañiz, M. M., Botella, C. C., Baños, R. M., Zaragoza, I. I., \& Guixeres, J. J. (2009). The intelligent e-therapy system: A new paradigm for telepsychology and cybertherapy. British Journal of Guidance \& Counselling, 37(3), 287-296. doi: $10.1080 / 03069880902957015$

American Counseling Association. (2005). ACA Code of Ethics. Retrieved from http://www.counseling.org/Resources/CodeOfEthics/TP/Home/CT2.aspx American Psychological Association "Guidelines for the Practice of Telepsychology” for public comment in February of 2014. Retrieved from: http://www.apapracticecentral.org/ce/guidelines/telepsychology-guidelines.pdf American Psychological Association. (2002). Ethical principles of psychologists and code of conduct. Washington, DC: Author.

Anderson, A. G., Hodge, K. P., Lavallee, D., \& Martin, S. (2004). New Zealand athletes' attitudes towards seeking sport psychology consultation. New Zealand Journal of Psychology, 33, 129-136.

Anderson, A., Miles, A., \& Robinson, P. (2004). Evaluating the athlete's perception of the sport psychologist's effectiveness: What should we be assessing? Psychology of Sport and Exercise, 9, 255-277. 
Association for Applied Sport Psychology. (2012). Ethical principles and standards. Retrieved from http://appliedsportpsych.org/about/ethics.

Astarita, V., Festa, D. C., Mongelli, D. W., Mongelli, N., Ruffolo, O., \& Servino, A. (2014). EcoSmart: A survey and sector analysis of mobile phone application market for fuel consumption reduction. Applied Mechanics and Materials, 519, 1546-1555.

An, Y. \& Reigeluth, C. (2012). Creating technology-enhanced, learner-centered classrooms: K-12 teachers' beliefs, perceptions, barriers, and support needs. Journal of Digital Learning In Teacher Education, 28(2), 54-62.

Anthes, G. (2011). Invasion of the mobile apps. Communications of The ACM, 54(9), 16-18. doi: $10.1145 / 1995376.1995383$

Aoyagi, M. \& Portenga, S. (2010). The role of positive ethics and virtues in the context of sport and performance psychology services delivery. Professional Psychology: Research and Practice, 41(2), 253-259. doi: 10.1037/a0019483

Association of Applied Sport Psychology (2012). About applied sport psychology. Retrieved from https://www.appliedsportpsych.org/about/about-applied-sport-psych

Backinger, C. L., Pilsner, A. M., Augustson, E. M., Frydl, A., Phillips, T., \& Rowden, J. (2011). YouTube as a source of quitting smoking information. Tobacco Control, 20(2), 119-122.

Bailie, J. L. (2012). The criticality of verbal immediacy in online instruction: A modified delphi study. Journal of Educators Online, 9(2). Online publication only.

Barnett, J. (2005). Online counseling: New entity, new challenges. The Counseling Psychologist, 33, 872-880. doi: 10.1177/0011000005279961

Behnke, S. (2008, July/August). Ethics in the age of the Internet. Retrieved from http://www.apa.org/monitor/2008/07-08/ethics.html 
Bellman, S., Potter, R. F., Treleaven-Hassard, S., Robinson, J. A., \& Varan, D. (2011). The effectiveness of branded mobile phone apps. Journal of Interactive Marketing (Mergent, Inc.), 25(4), 191-200.

Bemiller, J. H. \& Wrisberg, C. A. (2011). An overview and critique of NCAA policy regarding the use of sport psychology consultants at the Division I level. Journal of Intercollegiate Sport, 4(2), 227-242.

Bennett, G. (2007). The role of a clinical psychologist in a Division I athletics program. Journal of Clinical Sport Psychology, 1, 261-269.

Cameron, D., Gregory Y. C., \& Battagilia, D. (2012). Nielsen personalizes the mobile shopping app. Journal of Advertising Research, 52(3), 333-338.

Carr, C. M. (2007). A psychologist in the world of intercollegiate sports: Professional development issues. Journal of Clinical Sport Psychology, 1, 293-303.

Chamberlain, R. B. (2007). Sport psychology in a collegiate athletic department setting. Journal of Clinical Sport Psychology, 1, 281-292.

Chapman, M., Ridpath, B., \& Denhart, M. (2014). An examination of increased NCAA Division I athletic department budgets: A case study of student perceptions of fee allocation for athletes. International Journal Of Sport Management, 15(1), 25-48.

Chappuis, B., Gaffey, B., \& Parvizi, P. (2011). Are your customers becoming digital junkies? Mckinsey Quarterly, 3, 20-23.

Christensen, C. \& Prax, P. (2012). Assemblage, adaptation and apps: Smartphones and mobile gaming. Continuum: Journal of Media \& Cultural Studies, 26(5), 731-739. doi: 10.1080/10304312.2012.706461

Coakley, J. (2008). Sports in society: Issues and controversies (10th ed.). New York, NY: McGraw-Hill. 
Connole, I. (2013). Athletic administrators' preferred characteristics of sport psychology positions in NCAA athletics: A consumer market analysis. ETD Dissertation Submission.

Coyle, C. L., \& Vaughn, H. (2008). Social networking: Communication revolution or evolution? Bell Labs Technical Journal, 13(2), 13-17.

Danish, S. J., Petitpas, A. J., \& Hale, B. D. (1992). A developmental-educational intervention model of sport psychology. Sport Psychologist, 6, 403-415.

DeAngelis, T. (2012). Practicing distance therapy, legally and ethically. Monitor on Psychology, 43, 53. doi: 10.1037/0735-7028.21.2.107

DeFreese, J. D. \& Smith, A. L. (2013). Teammate social support, burnout, and selfdetermined motivation in collegiate athletes. Psychology of Sport \& Exercise, 14(2), 258-265.

Dellaert, B., \& Häubl, G. (2012). Searching in choice mode: consumer decision processes in product search with recommendations. Journal Of Marketing Research (JMR), 49(2), 277-288. doi:10.1509/jmr.09.0481

Dewiggins, S., Hite, B., \& Alston, V. (2010). Personal performance plan: Application of mental skills training to real-world military tasks. Journal of Applied Sport Psychology, 22, 458- 473.

Dieffenbach, K., Gould, D., \& Moffett, A. (2002). The coach's role in developing champions. International Journal of Volleyball Research, 5, 30-32.

Dillman, D. A. (2011). Mail and internet surveys: The tailored design method-2007 Update with new Internet, visual, and mixed-mode guide. New York, NY: Wiley.

Eddy, N. (2011). Mobile devices to boost online ad spending in 2012: Berg. Channel Insider, 1, 3-9. 
Etzel, E. F. \& Watson II, J. C. (2007). Ethical challenges for psychological consultations in intercollegiate athletics. Journal of Clinical Sport Psychology, 1, 304-317.

Ferrante, A. P., \& Etzel, E. F. (2009). College student-athletes and counseling services in the new millennium. In E. Etzel (Ed.), Counseling and Psychological Services for College Student-Athletes (pp. 67-94). Morgantown, WV: Fit Information Technologies.

Filipowski, T., Kazienko, P., Brodka, P., \& Kajdanowicz, T. (2012). Web-based knowledge exchange through social links in the workplace. Behaviour \& Information Technology, 31(8), 779-790. doi: 10.1080/0144929X.2011.642895

Finn, J. \& Barak, A. (2010). A descriptive study of e-counselor attitudes, ethics, and practice. Counseling and Psychotherapy Research, 10(4), 268-277. doi:

$10.1080 / 15228835.2011 .595262$

Fjeldsoe, B. S., Marshall, A. L., \& Miller, Y. D. (2009). Behavior change interventions delivered by mobile telephone short-message service. American Journal of Preventive Medicine, 36(2), 165-173.

Flowers, R. (2007). Psychologist-sport psychologist liaison between counseling and psychological services and intercollegiate athletics. Journal of Clinical Sport Psychology, 1, 223-246.

Fraser-Thomas, J. L., Côté, J., \& Deakin, J. (2005). Youth sport programs: An avenue to foster positive youth development. Physical Education \& Sport Pedagogy, 10(1), 1940.

Furber, G., Segal, L., Leach, M., \& Cocks, J. (2014). Mapping scores from the Strengths and Difficulties Questionnaire (SDQ) to preference-based utility values. Quality Of Life Research, 23(2), 403-411. doi:10.1007/s11136-013-0494-6

Garg, R., \& Telang, R. (2013). Inferring app demand from publicly available data. MIS Quarterly, 37(4), 1253-1264. 
Good, G. E. \& Wood, P. K. (1995). Male gender role conflict, depression, and help seeking: Do college men face double jeopardy? Journal of Counseling Development, 74, 70-75. doi: 10.1002/j.1556-6676.1995.tb01825.x

Goodwin-Jones, R. (2005). Emerging technologies: Messaging, gaming, peer-to-peer sharing: Language learning strategies \& tools for the millennial generation. Language Learning \& Technology, 9(1), 17-22.

Gould, D., Medberry, R., Damarjian, N., \& Lauer, L. (1999). A survey of mental skills training knowledge, opinion, and practices of junior tennis coaches. Journal of Applied Sport Psychology, 11, 28-50. doi: 10.1080/10413209908402949

Gould, D., Murphy, S., Tammen, V., \& May, J. (1991). An evaluation of U.S. Olympic sport psychology consultant effectiveness. The Sport Psychologist, 5, 111-127.

Green, P., Krieger, A. M., \& Wind, Y. J. (2001). Thirty years of conjoint analysis: Reflections and prospects. Interfaces, 31, S56-S73.

Green, P., \& Srinivasan, V. (1978). Conjoint analysis in consumer research: Issues and outlook. Journal of Consumer Research, 5, 103-123.

Gucciardi, D. F., Gordon, S., Dimmock, J. A., \& Mallett, C. J. (2009). Understanding the coach's role in the development of mental toughness: Perspective of elite Australian football coaches. Journal of Sports Sciences, 27(13), 1483-1496. doi:

$10.1080 / 02640410903150475$

Gupta, S. (2013). For mobile devices, think apps, not ads. Harvard Business Review, 91(3), $70-75$.

Hack, B. (2007). The development and delivery of sport psychology services within a university sports medicine department. Journal of Clinical Sport Psychology, 1, 247260. 
Hamilton, K. (2005). Putting the "student" back into the student-athlete: In an Effort to improve retention and graduation rates, the NCAA rolls out new rules and regulations. Black Issues in Higher Education, 22(4), 28.

Hash, R. B., Munna, R. K., Vogel, R. L., \& Bason, J. J. (2003). Does physician weight affect perception of health advice? Journal of Preventive Medicine, 36, 41-44.

Haslam, I. R. (2004). Psychological skills training: A qualitative study of Singapore coaches. Hong Kong Journal of Physical Education, 10, 37-47.

Hays, K. F. (Ed.). (2009). Performance psychology in action. Washington, DC: American Psychological Association.

Holt, L. \& Brockett, R. G. (2012). Self-direction and factors influencing technology use: Examining the relationships for the 21st century workplace. Computers in Human Behavior, 28(6), 2075-2082.

Jae Ko, Y., Durrant, S. M., \& Mangiantini, J. (2008). Assessment of services provided to NCAA Division I athletes: Development of a model and instrument. Sport Management Review (Sport Management Association Of Australia \& New Zealand), $11,193-214$.

Johnson, N. (2012). Strategy encourages more data sharing, mobile apps. Federal Times, $48(11), 18$.

Jowett, S., \& Chaundy, V. (2004). An Investigation into the impact of coach leadership and coach-athlete relationship on group cohesion. Group Dynamics: Theory, Research, and Practice, 8(4), 302.

Jowett, S. \& Cockerill, I. M. (2003). Olympic medalists' perceptive of the athlete-coach relationship. Psychology of Sport and Exercise, 4, 313-331. 
Kaifi, B. A., Nafei, W. A., Khanfar, N. M., \& Kaifi, M. M. (2012). A multi-generational workforce: Managing and understanding millennials. International Journal of Business \& Management, 7(24), 88-93. doi: 10.5539/ijbm.v7n24p88

Kanani, K. \& Regehr, C. (2003). Clinical, ethical, and legal issues in e-therapy. Families in Society: The Journal of Contemporary Human Services, 84, 155-162. doi: $10.1606 / 1044-3894.98$

Kaplan, A. M. (2012). If you love something, let it go mobile: Mobile marketing and mobile social media 4x4. Business Horizons, 55(2), 129-139.

Kelley, B., \& Carchina, C. (2013). "Hey, data data - swing!”: The hidden demographics of youth sport. ESPN the Magazine. Retrieved from: http://espn.go.com/espn/story/_id/9469252/hidden-demographics-youth-sports-espnmagazine

Kolmes, K. (2012). Social media in the future of professional psychology. Professional Psychology: Research and Practice, 43(6), 606-612. doi: 10.1037/a0028678

Kornspan, A. \& Duve, M. (2006). A niche in need: A summary of the need for sport psychology consultants in college sports. Annals of the American Psychotherapy Association, 9, 19-25.

Kourouthanassis, P. E. \& Giaglis, G. M. (2012). Introduction to the special issue mobile commerce: The past, present, and future of mobile commerce research. International Journal of Electronic Commerce, 16(4), 5-18. doi: 10.2753/JEC1086-4415160401

Kremer, P. J., \& Marchant, D. B. (2002). Reflections and considerations of providing sport psychology services with professional football players. In W. Spinks (Ed.), Science and Football IV (pp.294-299). London: Routledge. 
Landers, D. M., \& Arent, S. M. (2001). Physical activity and mental health. In C. B. Corbin \& R.P. Pangrazi (Eds.), Toward a better understanding of physical fitness and activity (pp. 137-143). Scottsdale, AZ: Holcomb Hathaway.

Lee, Y., Iyengar, S., Min, C., Ju, Y., Kang, S., Park, T., Lee, J., Rhee, Y., \& Song, J. (2012). MobiCon: A mobile context-monitoring platform. Communications of the ACM, 55(3), 54-65. doi: 10.1145/2093548.2093567

Liqiong, D. \& Poole, M. (2010). Affecting in web interfaces: A study of the impacts of web page visual complexity and order. MIS Quarterly, 34(4), 711-A10.

Livingstone, S. (2008). Taking risky opportunities in youthful content creation: teenagers' use of social networking sites for intimacy, privacy and self-expression. New media \& society, 10(3), 393-411.

Lubker, J. R., Visek, A. J., Geer, J. R., \& Watson, J. C. (2008). Characteristics of an effective sport psychology consultant: Perspectives from athletes and consultants. Journal of Sport Behavior, 31, 147-165.

Lubker, J. R., Visek, A. J., Watson, J. C., \& Singpurwalla, D. (2012). Athletes’ preferred characteristics and qualifications of sport psychology practitioners: A consumer market analysis. Journal of Applied Sport Psychology, 24, 465-480.

Maheu, M. M., Pulier, M. L., McMenamin, J. P., \& Posen, L. (2012). Future of telepsychology, telehealth, and various technologies in psychological research and practice. Professional Psychology: Research And Practice, 43(6), 613-621. doi: $10.1037 / \mathrm{a} 0029458$

Martin, S. B. (2005). High school and college athletes' attitudes toward sport psychology consulting. Journal of Applied Sport Psychology, 17, 127-139. doi: $10.1080 / 10413200590932434$ 
Martin, S. B., Lavallee, D., Kellmann, M., \& Page, S. J. (2004). Attitudes toward sport psychology consulting of adult athletes from the United States, United Kingdom, and Germany. International Journal of Sport and Exercise Psychology, 2(2), 146-160. doi: 10.1080/1612197X.2004.9671738

Martin, S. B., Wrisberg, C. A., Beitel, P. A., \& Lounsbury, J. (1997). NCAA Division I athletes' attitudes toward seeking sport psychology consultation: The development of an objective instrument. The Sport Psychologist, 11, 201-218.

McMahon, M., \& Pospisil, R. (2005). Laptops for a digital lifestyle: Millennial students and wireless mobile technologies. Proceedings of the Australasian Society for Computers in Learning in Tertiary Education, 17, 421-431.

Meyers, A. W., Coleman, J. K., Whelan, J. P., \& Mehlenbeck, R. S. (2001). Examining careers in sport psychology: Who is working and who is making money? Professional Psychology: Research And Practice, 32, 5-11.

Moore, M. (2012). Interactive media usage among millennial consumers. Journal of Consumer Marketing, 29(6), 436-444. doi: 10.1108/07363761211259241

NCAA (2012a). About the NCAA. Retrieved from http://www.ncaa.org/wps/wcm/connect/public/ncaa/about+the+ncaa

NCAA (2012b). 2012-2013 NCAA Division I Manual. Text prepared by: NCAA Academic and Membership Affairs Staff. Indianapolis, IN: SO\&SO Co., LLC.

Nielson. (2012). The digital revolution: A look through the marketer's lens. MEDIA: U.S. Digital Consumer Report, Q3-Q4.

Nelson, E., Bui, T. N., \& Velasquez, S. E. (2011). Telepsychology: Research and practice overview. Child and Adolescent Psychiatric Clinics of North America, 20(1), 67-79.

Nikirk, M. (2009). Today's millennial generation: A look ahead to the future they create. Techniques: Connecting Education and Careers, 84(5), 20-23. 
Ohio Psychological Association. (2010). Telepsychology Guidelines. Retrieved from: http://www.ohpsych.org/mce/requirements-and-ethic-requirements/

Orme, B. (2006). Getting started with conjoint analysis: Strategies for product design and pricing research. Madison, WI: Research Publishers, LLC.

Orne, M. T. (1962). On the social psychology of the psychological experiment: With particular reference to demand characteristics and their implications. American Psychologist, 17, 776-783.

Pain, M. A., \& Harwood, C. G. (2004). Knowledge and perceptions of sport psychology within English soccer. Journal of Sports Sciences, 22, 813-826.

Patel, R. (2011). How to build apps business. Siliconindia, 14(10), 40-41.

Perry, F. D. (2012). Review of 'Biofeedback and neurofeedback applications in sport psychology.' The Sport Psychologist, 26(2), 313-314.

Perry, F., Shaw, L., \& Zaichkowsky, L. (2011). Biofeedback and neurofeedback in sports. Biofeedback, 39(3), 95-100. doi: http://dx.doi.org/10.5298/1081-5937-39.3.10

Pew Internet: Mobile (2012). Global digital communication: Texting, social networking popular worldwide. Retrieved from http://www.pewglobal.org/2011/12/20/globaldigital-communication-texting-social-networking-popular-worldwide/

Pew Internet: Mobile (2013). Cell phone and smartphone ownership and use. Retrieved from http://pewinternet.org/Commentary/2013/February/Pew-Internet-Mobile.aspx

Portenga, S. (2012). iPerformance psychology releases new sports psychology app. Retrieved from http://www.prweb.com/releases/2012/7/prweb9701120.htm

Ritzhaupt, A. D., Dawson, K., \& Cavanaugh, C. (2012). An investigation of factors influencing student use of technology in K-12 classrooms using path analysis. Journal of Educational Computing Research, 46(3), 229-254. doi: 10.2190/EC.46.3.b 
Sabo, D., \& Veliz, P. (2008). Go out and play: Youth sports in America. Women's Sports Foundation, 5, 12-19.

Sahu, A. (2012). Betting on a bigger piece of the mobile app market. Siliconindia, 15(10), $18-21$.

Sawtooth (2014). Sawtooth discovery conjoint analysis software. Choice-based Conjoint Analysis Version 8.0. Retrieved from: https://sawtoothsoftware.com/download/techpap/cbctech.pdf

Scully, D., \& Hume. A. (1995). Sport psychology: Status, knowledge and use among elite level coaches and performers in Ireland. The Irish Journal of Psychology, 16, 52-66.

Sexton, P. (2012). Adventures in Facebook interpretation. Legacy (National Association For Interpretation), 23(2), 18-23.

Shandley, K., Klein, B., Kyrios, M., Austin, D., Ciechomski, L., \& Murray, G. (2011). Training postgraduate psychology students to deliver psychological services online. Australian Psychologist, 46(2), 120-125. doi: 10.1111/j.1742-9544.2011.00034.x

Sheard, M. \& Golby, J. (2006). Effect of a psychological skills training program on swimming performance and positive psychological development. International Journal of Sport \& Exercise Psychology, 4(2), 149-169. doi:

10.1080/1612197X.2006.9671790

Subramanya, S. R. \& Farahani, A. (2012). Point-of-view article on: Design of a smartphone app for learning concepts in mathematics and engineering. International Journal of Innovation Science, 4(3), 173-184. doi: 10.1260/1757-2223.4.3.173

Schwartz, C. J. \& Lamphere, B. (2012). Ethics in sport and performance psychology: The use of e-therapy in athletics. Psychotherapy Bulletin, 47(4), 30-33. 
Steinfeldt, J. A., Foltz, B. D., Mungro, J., Speight, Q. L., Wong, Y. J., \& Blumberg, J. (2011). Masculinity socialization in sport: The influence of college football coaches. Psychology of Men and Masculinity, 12, 247-259. doi: 10.1037/a0020170

Steinfeldt, J. A., Steinfeldt, C. M., Speight, Q., \& England, B. (2009). Gender role conflict and help-seeking stigma among college football players. Psychology of Men and Masculinity, 10, 260-270. doi: 10.1037/a0017223

Subramanya, S. R. \& Farahani, A. (2012). Point-of-view article on: Design of a smartphone app for learning concepts in mathematics and engineering. International Journal of Innovation Science, 4(3), 173-184. doi: 10.1260/1757-2223.4.3.173

Sullivan, S. E., \& Arthur, M. B. (2006). The evolution of the boundaryless career concept: Examining physical and psychological mobility. Journal of Vocational Behavior, 69(1), 19-29.

Taylor, A. (2012). A study of the information search behaviour of the millennial generation. Information Research: An International Electronic Journal, 17(1), 67-81.

Taylor, D. G., Voelker, T. A., \& Pentina, I. (2011). Mobile application adoption by young adults: A social network perspective. International Journal of Mobile Marketing, 6(2), $60-70$.

Tunks, K. W. (2012). An introduction and guide to enhancing online instruction with web 2.0 tools. Journal of Educators Online, 9(2).

Turban, E., Lee, J. K., King, D., Liang, T. P., \& Turban, D. (2009). Electronic commerce 2010. New York: Prentice Hall Press. 
Turner-McGrievy, G. M., Beets, M. W., Moore, J. B., Kaczynski, A. T., Barr-Anderson, D. J., \& Tate, D. F. (2013). Comparison of traditional versus mobile app self-monitoring of physical activity and dietary intake among overweight adults participating in a mobile health weight loss program. Journal of the American Medical Informatics Association, 20(3), 513-518.

Turner-McGrievy, G., \& Tate, D. (2011). Tweets, apps, and pods: Results of the 6-month mobile pounds off digitally (Mobile POD) randomized weight-loss intervention among adults. Journal of medical Internet research, 13(4).

Varnhagen, C. K., Gushta, M., Daniels, J., Peters, T. C., Parmar, N., Law, D., \& ... Johnson, T. (2005). How informed is online informed consent? Ethics \& Behavior, 15(1), 37 48. doi: 10.1207/s15327019eb1501_3

Vayena, E., Mastroianni, A., \& Kahn, J. (2012). Ethical issues in health research with novel online sources. American Journal of Public Health, 102(12), 2225-2230. doi: 10.2105/AJPH.2012.300813

Venkatesh, V. L., Thong, J. Y., \& Xu, X. (2012). Consumer acceptance and use of information technology: Extending the unified theory of acceptance and use of technology. MIS Quarterly, 36(1), 157-178.

Veretilo, P. \& Billick, S. (2012). Psychiatric illness and facebook: A case report. The Psychiatric Quarterly, 83(3), 385-389. doi: 10.1007/s11126-012-9207-5

Voight, M. \& Callaghan, J. (2001). The use of sport psychology services at NCAA Division I universities from 1998 - 1999. The Sport Psychologist, 15, 91-102.

Wang, J. (2012). Lessons in app building. Entrepreneur, 40(8), 80-87.

Watson II, J. C. \& Etzel, E. F. (2000). Considering ethics: Using the Internet in sport psychology. AAASP Newsletter, 15(3). 13-16. 
Watson II, J. C. \& Halbrook, M. (2014). Incorporating technology into practice: A service delivery approach. Becoming a Performance Psychologist: International Perspectives on Service Delivery and Supervision. Routledge: Psychology Press.

Watson, J., Lubker, J. R., Zakrajsek, R. A., \& Quartiroli, A. A. (2012). Internet usage patterns and ethical concerns in sport and exercise psychology. Athletic Insight: The Online Journal of Sport Psychology, 14(1).

Watson II, J. C., Tenenbaum, G., Lidor, R., \& Alfermann, D. (2001). Ethical uses of the Internet in sport psychology: A position stand. International Journal of Sport Psychology, 32, 207-222.

Weidner, T. G. \& Henning, J. M. (2002). Historical perspective of athletic training clinical education. Journal of Athletic Training, 37(4), 222S-228S.

Weinberg, R. S., \& Williams, J. M. (2010). Integrating and implementing a psychological skills training program. In J. M. Williams (Ed.), Applied sport psychology: Personal growth to peak performance (6th ed., pp. 361-391). New York: McGraw-Hill.

Williams, J. M., \& Scherzer, C. B. (2003). Tracking the training and careers of graduates of advanced degree programs in sport psychology, 1994 to 1999. Journal of Applied Sport Psychology, 15, 335-353.

Wilson, K. A., Gilbert, J. N., Gilbert, W. D., \& Sailor, S. R. (2009). College athletic directors' perceptions of sport psychology consulting. The Sport Psychologist, 23, 405-424.

Wright, V. H. \& Wilson, E. K. (2011). Teachers' use of technology: Lessons learned from the teacher education program to the classroom. SRATE Journal, 20(2), 48-60.

Wrisberg, C., Withycombe, J., Simpson, D., Loberg, L. A., \& Reed, A. (2012a). NCAA Division-I administrators' perceptions of the benefits of sport psychology services and possible roles for a consultant. The Sport Psychologist, 26(1), 16-28. 
Wrisberg, C., Withycombe, J., Simpson, D., Loberg, L. A., \& Reed, A. (2012b). An exploratory investigation of NCAA Division-I coaches' support of sport psychology consultants and willingness to seek mental training services. The Sport Psychologist, $24,489-503$.

Wrisberg, C. A., Simpson, D., Loberg, L. A., Withycombe, J. L., \& Reed, A. (2009). NCAA Division-I student-athletes' receptivity to mental skills training by sport psychology consultants. The Sport Psychologist, 23(4), 470-486.

Wrisberg, C. A., Loberg, L. A., Simpson, D., Withycombe, J. L., \& Reed, A. (2010). An exploratory investigation of NCAA division-I coaches' support of sport psychology consultants and willingness to seek mental training services. Sport Psychologist, 24(4), 489-503.

Yang, S. \& Jowett, S. (2013). The psychometric properties of the short and long versions of the coach-athlete relationship questionnaire. Measurement in Physical Education \& Exercise Science, 17(4), 281-294. doi: 10.1080/1091367X.2013.831763

Zakrajsek, R. A., Martin, S. B., \& Zizzi, S. J. (2011). American high school football coaches' attitudes toward sport psychology consultation and intentions to use sport psychology services. International Journal of Sports Science \& Coaching, 6(3), 461-478. doi: $10.1260 / 1747-9541.6 .3 .461$

Zakrajsek, R. A., Steinfeldt, J. A., Bodey, K. J., Martin, S. B., \& Zizzi, S. J. (2013). NCAA Division I coaches' perceptions and preferred use of sport psychology services: A qualitative perspective. Sport Psychologist, 27(3).

Zakrajsek, R. A. \& Zizzi, S. J. (2007). Factors influencing track and swimming coaches intentions to use sport psychology services. The Online Journal of Sport Psychology, 9(2), Retrieved from http://www.athleticinsight.com/Vol9Iss2/ CoachingIntentions.htm 
Zakrajsek, R. A., \& Zizzi, S. J. (2008). How do coaches' attitudes change when exposed to a sport psychology workshop? Journal of Coaching Education, 1(1). Retrieved from http://www.aahperd.org/naspe/jce/pdf_files/Zakrajsek_Zizzi_JCE_2008.pdf.

Zeithammer, R., \& Lenk, P. (2009). Statistical benefits of choices from subsets. Journal of Marketing Research, 46, 816-831.

Zillmer, E. A., \& Gigli, R. (2007). Clinical sport psychology in intercollegiate athletics. Journal of Clinical Sport Psychology, 1, 210-222.

Zizzi, S. J. \& Perna, F. M. (2002). Integrating web pages and e-mail into sport psychology consultations. Sport Psychologist, 16(4), 416.

Zizzi, S. \& Schmid, O. (2012). Reach out and text someone: The creative and effective use of text messaging in sport performance consultations. Athletic Insight's Writings in Sport Psychology, 317-327.

Zur, O., Williams, M. H., Lehavot, K., \& Knapp, S. (2009). Psychotherapist self-disclosure and transparency in the Internet age. Professional Psychology: Research And Practice, 40(1), 22-30. doi: 10.1037/a0014745 